\title{
ITERATIVE DAMAGE INDEX METHOD FOR STRUCTURAL HEALTH MONITORING
}

\author{
A Thesis \\ by \\ TAESUN YOU
}

\begin{abstract}
Submitted to the Office of Graduate Studies of
Texas A\&M University

in partial fulfillment of the requirements for the degree of

MASTER OF SCIENCE
\end{abstract}

December 2009

Major Subject: Civil Engineering 


\title{
ITERATIVE DAMAGE INDEX METHOD FOR STRUCTURAL HEALTH MONITORING
}

\author{
A Thesis \\ by \\ TAESUN YOU \\ Submitted to the Office of Graduate Studies of \\ Texas A\&M University \\ in partial fulfillment of the requirements for the degree of \\ MASTER OF SCIENCE
}

Approved by:

Co-Chairs of Committee, Paolo Gardoni

Stefan Hurlebaus

Member of Committee, Anastasia Muliana

Head of Department, John Niedzwecki

December 2009

Major Subject: Civil Engineering 


\author{
ABSTRACT \\ Iterative Damage Index Method for Structural Health Monitoring. (December 2009) \\ Taesun You, B.S., Hanyang University, Seoul, South Korea \\ Co-Chairs of Advisory Committee: Dr. Paolo Gardoni, \\ Dr. Stefan Hurlebaus
}

Structural Health Monitoring (SHM) is an effective alternative to conventional inspections which are time-consuming and subjective. SHM can detect damage early and reduce maintenance cost and thereby help reduce the likelihood of catastrophic structural events to infrastructure such as bridges. After reviewing the Damage Index Method, an Iterative Damage Index Method (IDIM) is proposed to improve the accuracy of damage detection. These two damage detection techniques are compared numerically and experimentally using measurements from two structures, a simply supported beam and a pedestrian bridge. The dynamic properties for the numerical comparison are extracted by modal analysis in ABAQUS, while the dynamic characteristics for the experimental comparison are obtained with the Wireless Sensor Network and the Time Domain Decomposition. In both the numerical and experimental phases, the accuracy of damage predictions from each method is quantified. Compared to the traditional damage detection algorithm, the proposed IDIM is shown to be less arbitrary and more accurate when applied to both structures. The proposed IDIM has the potential to improve SHM. 


\section{ACKNOWLEDGMENTS}

I would like to thank Dr. Paolo Gardoni and Dr. Stefan Hurlebaus for technical guidance and financial assistance during the research period. I also thank a committee member, Dr. Anastasia Muliana. In addition I would like to thank the funding provided by the Association of American Railroads (AAR). Finally, I appreciate my family and friends for their continuous supports. 


\section{TABLE OF CONTENTS}

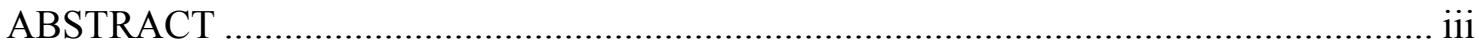

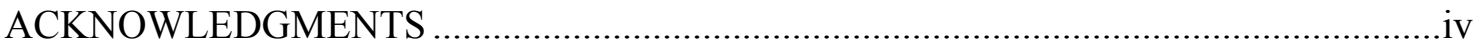

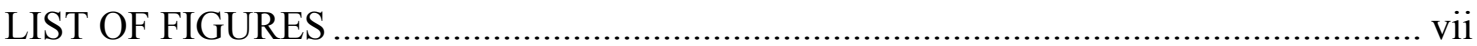

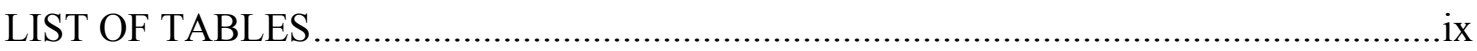

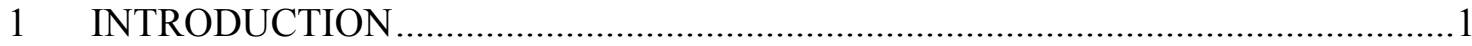

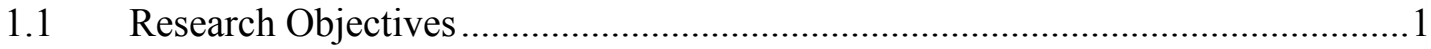

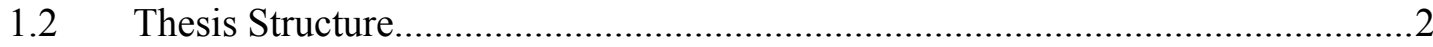

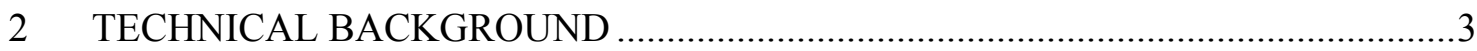

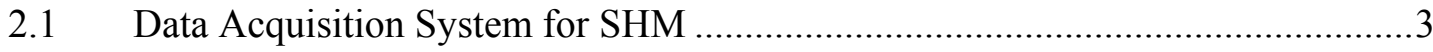

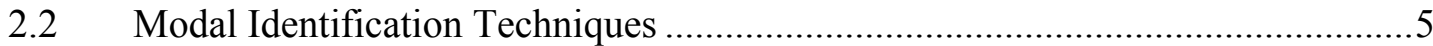

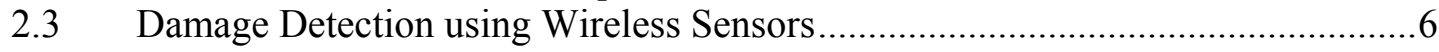

2.4 Damage Identification Algorithms................................................................

3 DAMAGE DETECTION ALGORITHMS .......................................................

3.1 Damage Index Method with a Fixed Threshold................................................

3.2 Proposed Iterative Damage Index Method............................................................ 13

3.3 Determination of the Correlation between Modeshapes ....................................16

3.4 Quantification of the Accuracy of Predicted Damage ...................................... 18

4 VALIDATION USING NUMERICAL DATA .........................................................20

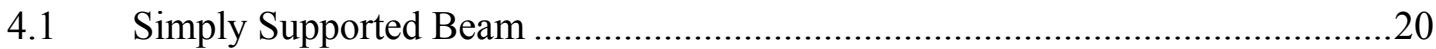

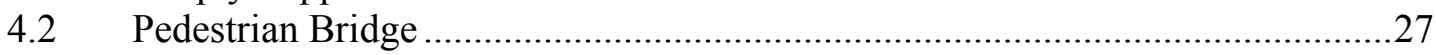

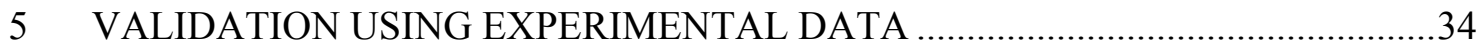

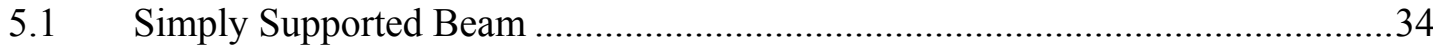

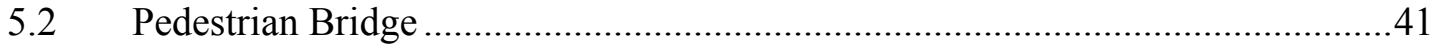

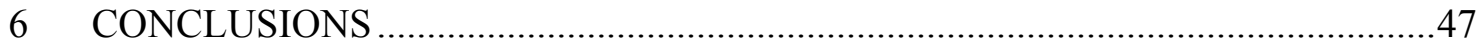

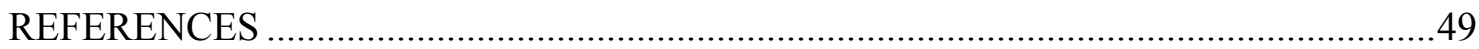




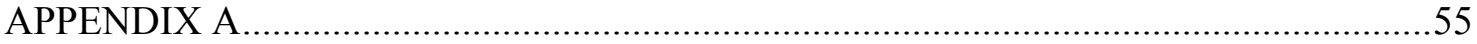

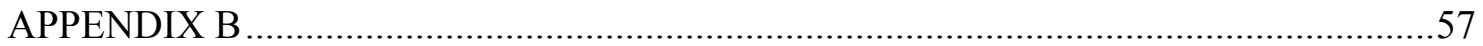

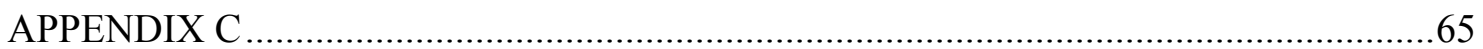

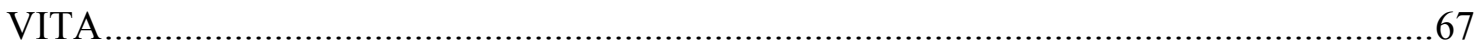




\section{LIST OF FIGURES}

Page

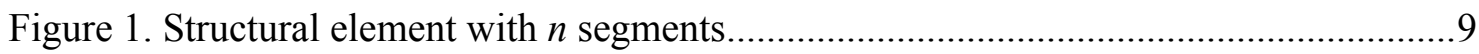

Figure 2. Flow chart of the Damage Index Method........................................................... 11

Figure 3. Damage detection with (a) appropriate threshold, (b) smaller threshold, and (c) larger threshold.

Figure 4. Damage detection results with (a) $N_{r}$ recording points and $N_{s-1}$ spline points and (b) $N_{r}$ recording points and $N_{s-2}$ spline points $\left(N_{s-1}<N_{s-2}\right)$.

Figure 5. Flow chart of the proposed Iterative Damage Index Method. 17

Figure 6. (a) Numerical modeshapes and (b) Curvature of the modeshapes (solid lines indicate the undamaged and dashed lines indicate the damaged)..... .23

Figure 7. Pedestrian bridge in Texas A\&M Golf Course at Texas A\&M University, College Station, TX

Figure 8. Pedestrian bridge generated in ABAQUS (2004) .28

Figure 9. The first three bending modeshapes of the pedestrian bridge: (a) $1^{\text {st }}$ bending modeshapes, (b) $2^{\text {nd }}$ bending modeshapes, and (c) $3^{\text {rd }}$ bending modeshapes.........30

Figure 10. The first three modeshapes for the simply supported beam (solid lines indicate the undamaged and dashed lines indicate the damaged).....

Figure 11. Three measuring sets and a reference point for the simply supported beam.......36

Figure 12. (a) Test set-up for a simply supported beam for including MICA 2 motes, base station, and lap-top computer, (b) MICA 2 mote, and (c) base station.......37

Figure 13. Damage prediction with 29 spline points in a simply supported beam using (a) the current DIM and (b) the proposed IDIM (solid lines indicate actual damage and dashed lines indicate predicted damage) 
Figure 14. Damage prediction with 141 spline points in a simply supported beam using (a) the current DIM and (b) the proposed IDIM (solid lines indicate actual damage and dashed lines indicate predicted damage)

Figure 15. Added concrete blocks on the pedestrian bridge ..............................................43

Figure 16. The first three modeshapes for the pedestrian bridge (solid lines indicate the undamaged and dashed lines indicate the damaged)

Figure 17. Two measuring sets and one reference point for the pedestrian bridge

Figure 18. Damage prediction with 29 spline points in a pedestrian bridge using (a) the current DIM and (b) the proposed IDIM (solid lines indicate actual damage and dashed lines indicate predicted damage)

Figure 19. Damage prediction with 141 spline points in a pedestrian bridge using (a) the current DIM and (b) the proposed IDIM (solid lines indicate actual damage and dashed lines indicate predicted damage) 


\section{LIST OF TABLES}

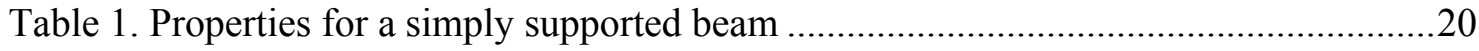

Table 2. Damage scenarios for a simply supported beam ..............................................21

Table 3. MAC, TMAC, CAC, and TCAC for the simply supported beam ........................22

Table 4. The minimum number of recording points $\left(N_{r}\right)$ and the minimum number of spline points $\left(N_{s}\right)$ to detect damage accurately $(\Delta=0$ and $\mathrm{e}=0) \ldots \ldots \ldots \ldots \ldots \ldots \ldots . . . .25$

Table 5. Damage detection percentage Case 1 (unit is \%) ...............................................25

Table 6. Damage detection percentage Case 2 (unit is \%) ...............................................25

Table 7. Damage detection percentage Case 5 (unit is \%) .............................................26

Table 8. Damage detection percentage Case 9 (unit is \%) ............................................26

Table 9. Damage detection percentage Case 11 (unit is \%) ............................................26

Table 10. Damage detection percentage Case 13 (unit is \%) ...........................................27

Table 11. Properties for a pedestrian bridge ........................................................... 27

Table 12. Damage scenarios for a pedestrian bridge ................................................. 31

Table 13. MAC, TMAC, CAC, and TCAC for the pedestrian bridge .................................

Table 14. The minimum number of recording points $\left(N_{r}\right)$ and the minimum number of spline points $\left(N_{s}\right)$ to detect damage with $\Delta=0.006$ and $\mathrm{e}=0.1 \ldots \ldots \ldots \ldots \ldots \ldots \ldots . . . . . . . . . . .32$

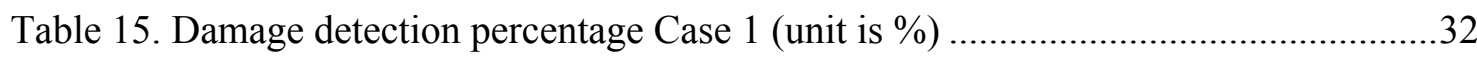

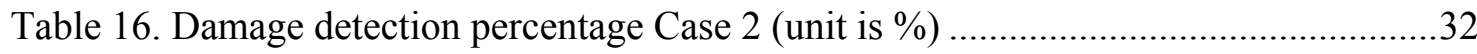

Table 17. Damage detection percentage Case 5 (unit is \%) .............................................33

Table 18. Damage detection percentage Case 8 (unit is \%) .................................................33

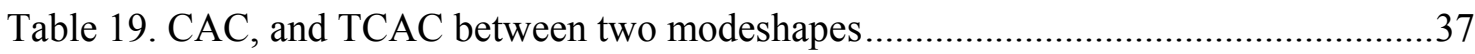


Table 20. Average of e and $\Delta$ for a simply supported beam ............................................38

Table 21. MAC, TMAC, CAC, and TCAC between two modeshapes ...............................42

Table 22. Average of e and $\Delta$ for a pedestrian bridge ............................................42 


\section{INTRODUCTION}

On August $1^{\text {st }}, 2007$, the I-35W Mississippi River Bridge in Minneapolis collapsed. The failure of the bridge was primarily due to an error in the design of the gusset plates that was not detected by conventional inspections (Rosenker, 2008). This event dramatized the importance of the Bureau of Transportation Statistics (2008) report that nearly 26 percent of the bridges in the U.S. were found to be substandard. Traditional inspection procedures for bridges generally rely on subjective and irregular visual examination. As such, there are variations in the inspection results even for the same structure because of the differences in inspectors' experience and judgment. Visual checking is also apt to be a schedule-based practice that delivers a discrete inspection process. Discrete inspection processes can fail to detect hidden effects of poor design or maintenance which can be the source of sudden and dangerous events such as a bridge collapse. Between 1989 and 2000, out of 65 bridge failures (caused by design, detailing, construction, maintenance, or material problems), 43 failures were attributed to poor maintenance (Wardhana and Hadipriono, 2003). As an alternative to periodic inspections, structural health monitoring (SHM) is a continuous process (Hurlebaus and Gaul, 2006) that can detect damage early, reduce the cost of repair and rehabilitation, and help reduce the chance of catastrophic events with the structures.

\subsection{Research Objectives}

The purpose of the work described in this thesis is to develop a less arbitrary and more accurate vibration-based damage detection method for SHM. A modified DIM, referred

This thesis follows the style of the Journal of Structural Engineering. 
to as the Iterative Damage Index Method (IDIM), is proposed here. The proposed IDIM does not require applying an arbitrary threshold to indicate damage and it is independent of the number of spline points. Thus, the proposed method promises an improved capability to detect damage.

This thesis refers to the measured points on a structure as recording points. Interpolation between selected recording points is then used to make the modeshapes a smooth line. In this thesis, the points used in interpolating the modeshapes are called spline points. Note the number of spline points is always equal to or greater than the number of recording points.

\subsection{Thesis Structure}

The remaining of this thesis consists of four sections. The technical background is described in the following section. After a brief review of the algorithms used by the current DIM, the proposed IDIM is described. Then, the accuracy of damage prediction using the DIM and the IDIM for a simply supported beam and a pedestrian bridge are compared using numerical data and experimental data. Finally, the last section summarizes the findings of this thesis and suggests some future work. 


\section{TECHNICAL BACKGROUND}

In this study, the damage detection method using the modal properties obtained by ambient vibration tests is used. The following literature review interprets the state of the art on the data acquisition system of SHM, modal identification techniques, damage detection using wireless sensors, and damage detection algorithms.

\subsection{Data Acquisition System for SHM}

SHM implementation often relies on wired data acquisition systems to collect the vibration response data on bridges (Peak et al., 2004). However, wired sensor systems are costly and dangerous to install. Wiring sensors on a bridge requires long cables running to various locations. Also, installation of cable networks risks incomplete connection or separation of cables between sensors and a central computer due to strong wind, heavy rain, earthquake, etc. Moreover, connecting the wired sensors requires a substantial amount of labor and time ${ }^{1}$ (Hurlebaus and Gaul, 2006), which means it is difficult to change locations of the wired sensors and to add or remove the sensors. Protecting cables from severe environmental conditions also increases the installation cost of the wired sensors. Finally, costly traffic disruptions and public inconvenience result when the wired sensors are installed on in-service bridges, since shutting down the bridges is usually required.

A wireless sensor network (WSN) has three main advantages: (1) lower maintenance and installation cost; (2) flexibility in changing locations, adding or removing sensors; and (3) faster installation time. These benefits enable the deployment of denser network systems (Whelan et al., 2007). The wireless sensor network is more flexible, so that more reliable

\footnotetext{
${ }^{1}$ The installation of the SHM system on the Tsing Ma suspension bridge cost almost $\$ 27,000$ per sensing channel (Farrar, 2001).
} 
results can be achieved. It takes less time not only to install a WSN than traditional sensors and cables in infrastructure such as bridges or buildings, but also to test the system because individual cables in a wired system must be checked for loss of data. ${ }^{2}$ These advantages enable a WSN to obtain vibration data even for old or damaged bridges where deploying traditional sensor networks is not practical due to cost and safety issues (Paek et al., 2004). Finally, a wireless sensor system can also be applied to bridges in service without any need to close the bridges.

The interest in wireless sensors has increased since their introduction in the 1990s with the growth of Information Technology (IT). Although the initial purpose of wireless sensors was to remove numerous lengths of cables (Lynch et al., 2006a), its worthwhile features soon attracted the attention of many researchers studying SHM. The first low-cost wireless sensor for ambient excitation was suggested by Straser and Kiremidjian (1998). Since then Lynch et al. (2001), Lynch (2002), Casciati et al. (2003), Shinozuka (2003), Wang et al. (2005), and Kim et al. (2007b) have proposed additional prototypes.

Following Pei et al. (2006), an ideal wireless sensor is: (1) inexpensive; (2) low in power consumption; (3) small (so that its installation does not interfere with the functionality and aesthetics of the bridge); (4) easily positioned and maintained; and (5) durable. Because a wireless platform, the MICA 2, developed at University of California, Berkeley and made by Crossbow (Lynch and Loh, 2006), offers these features, it is used in this study. The MICA 2 was introduced in early 2002 and the reliability of the communication channel was improved in 2003 by using a new radio to reduce data loss as well as interference (Lynch and Loh, 2006). Since then, the MICA 2 has been adopted and refined by many researchers to

\footnotetext{
${ }^{2}$ The conventional SHM system reportedly needs twice as much installation time as a wireless system (Lynch and Loh, 2006).
} 
measure the dynamic responses of various laboratory structures. Xu et al. (2004) designed and evaluated a wireless network system using the MICA 2 motes. The wireless network system was evaluated by monitoring the dynamic responses from a ceiling structure. The performance of the MICA 2 was verified by Kurata et al. (2005). They installed a reference accelerometer and the MICA 2 on a shaking table, and found that the accelerations measured by both systems were in strong agreement.

Other issues with WSN are the range in communication and the power consumption of wireless sensors (Lynch and Loh, 2006). Wireless sensors without power cables require an independent power generator or portable power supplies like a battery. Moreover, communication over a long range entails more power consumption. A wireless sensor with low-power can reduce reliability of the data collection and/or the process of sending the data to a central computer.

\subsection{Modal Identification Techniques}

Modal identification (MI) is a method to extract vibration characteristics such as frequencies, modeshapes, and damping of a structure. Since SHM depends on reliable modal properties, selecting an MI method is intimately linked with SHM. Traditionally, forced vibration tests (FVTs) have been used to obtain the modal properties for an uncomplicated process. Arici and Mosalam (2000) performed FVTs to determine the modeshapes and damping ratios of seven bridges in California. Four different highway bridges were monitored by Brownjohn et al. (2005). However, because the FVTs need instruments to record excitation sources, an ambient vibration tests (AVTs), also called an output-only modal test, have gained acceptance in last three decades because it offers two major benefits: simplicity and

efficiency. Consequently, many researchers (e.g., Arici and Mosalam, 2005; Omenzetter and 
Brownjohn, 2006; Arici and Mosalam, 2007; Siringoringo and Fujino, 2007) have performed the AVTs for bridge monitoring.

The Basic Frequency Domain technique (Peak Picking technique) proposed by Bendat and Mikulcik (1980) is one generally applied output-only test for the modal analysis of large civil structures. Another approach is the Ibrahim time domain (ITD) method with a random decrement technique (Kim et al., 2005). However, those methods require a great deal of skills and heavy computations. Brinker et al. (2000b) suggested Frequency domain decomposition (FDD) to overcome the challenges of existing output-only approaches. They applied singular value decomposition (SVD) to the output spectral density matrix. The FDD was evaluated in real bridges (Brinker et al., 2000a; Brinker et al., 2001). To improve the quality of identified modal parameters, Rodrigues et al. (2004) applied the random decrement technique to the FDD. They compared the new method with the basic frequency domain decomposition and the FDD. Unfortunately, enormous computation time is necessary to apply the SVD process in a frequency domain (Kim et al., 2005). In order to reduce computation time for the SVD process, Kim et al. (2005) developed Time Domain Decomposition (TDD) to extract modal characteristics such as modeshapes and frequencies using acceleration signals. In this study, the TDD is used to obtain the modeshapes. Note that the modeshapes are natural properties of a structure and do not be affected by the excitation source (McHargue and Richardson, 1993).

\subsection{Damage Detection using Wireless Sensors}

Although many researchers have investigated a wireless monitoring system with various types of structures, few studies of damage detection using the wireless monitoring system have been reported. Kurata et al. (2005) applied wireless sensor motes, MICA and the MICA 2 , to risk monitoring on a building. A method where the irregular change of accelerations 
was a risk indicator was tested with a two-story structure, but the method was only able to identify severe damage conditions like a collapse. In an effort to improve on those results by monitoring damages such as stiffness reduction, the ratio of frequency change was obtained with the MICA 2 by Clayton et al. (2005). They tried a laboratory test with a cantilever beam, but the method is not useful for real structures such as bridges because the frequency change between an intact structure and a damaged structure is too small to give a clear signal. As an alternative, Lynch et al. (2006b) operated wireless sensor prototypes, proposed by Wang et al. (2005), to measure accelerations in a three-story test structure. Time series analysis proposed by Sohn and Farrar (2001) was selected to detect damage, but the method could not localize and quantify the damage. Finally, the approaches proposed in these three studies have not been verified through a field test.

\subsection{Damage Identification Algorithms}

A number of studies have sought to improve the accuracy of damage detection using SHM. Several researchers (e.g., Lenzen, 2005; Kim and Kawatani, 2007; Mizuno et al., 2008) have developed damage identification methods using the analysis of dynamic responses of a structure. However, the damage can be estimated where the dynamic responses are recorded. On the other hand, many studies took advantages of the development of instrumentation using sensors that facilitates observation of the dynamic characteristics of a structure, such as frequencies and modeshapes. For example, Pandey et al. (1991) proposed to track the changes in modeshapes curvature while Pandey and Biswas (1994) used flexibility changes. Zhang and Aktan (1995) combined the two methods proposed by Pandey et al. (1991) and Pandey and Biswas (1994), and developed a method using the changes in flexibility curvature. Shi et al. (2000) introduced the correlation between the measured modeshapes change for the undamaged and damaged and the analytical modeshapes change for the undamaged and 
damaged. If the correlation is unity, the damage is estimated correctly. Despite those efforts, the methods are not practical in infrastructures such as bridges and buildings. This is often the case because small changes in physical properties do not alter frequencies and modeshapes enough to allow the detection. In other case, it is difficult to obtain as many modes as these methods need from these complicated structures. To overcome the limitations, Stubbs and Kim (1996) suggested a Damage Index Method (DIM) using modal strain energy to detect damage.

Several researchers (e.g., Stubbs and Kim, 1996; Stubbs and Park, 1996; Kim and Stubbs, 2002; Kim et al., 2003) verified the method's accuracy with numerical simulation models, while others confirmed its usefulness with experimental evaluation techniques (e.g., Park et al., 2001; Kim and Stubbs, 2003; Kim et al., 2007a; Choi et al., 2008). Compared with commonly used vibration-based damage detection methods, the DIM is the most accurate by far (Alvandi and Cremona, 2006; Humar et al., 2006).

The DIM relies on calculation of the modal strain energy by measurement of the modeshapes of a structure to detect damage. However, the current DIM has two major limitations with regard to this calculation. First, selection of a fixed threshold to determine whether there is enough change in measurable physical properties to indicate damage in a structure has been arbitrary. Second, damage detection with any fixed threshold can be affected by the number of spline points selected. 


\section{DAMAGE DETECTION ALGORITHMS}

\subsection{Damage Index Method with a Fixed Threshold}

This section reviews the Damage Index Method (DIM) referred by Stubbs and Kim (1996). Assuming a structural element can be considered as a Euler-Bernoulli beam (see Figure 1), the $i^{\text {th }}$ modal strain energy of this undamaged element, $K_{i}$, can be calculated by

$$
K_{i}=\int_{0}^{L} E I(x)\left[\phi_{i}^{\prime \prime}(x)\right]^{2} d x
$$

where $L$ is the length of the element, $E I$ is the flexural rigidity, and $\phi_{i}^{\prime \prime}$ is the $i^{\text {th }}$ modal curvature. If the element can be divided into $n$ segments, the modal strain energy contribution from the $j^{\text {th }}$ segment to the $i^{\text {th }}$ mode, $k_{i j}$, is given by

$$
k_{i j}=\int_{a}^{b} E I_{j}\left[\phi_{i}^{\prime \prime}(x)\right]^{2} d x
$$

where the $j^{\text {th }}$ segment is between $x=a$ and $b$. As such, the fraction of the $j^{\text {th }}$ segment's contribution to the total modal strain energy, $F_{i j}$, can be expressed as

$$
F_{i j}=\frac{k_{i j}}{K_{i}}
$$

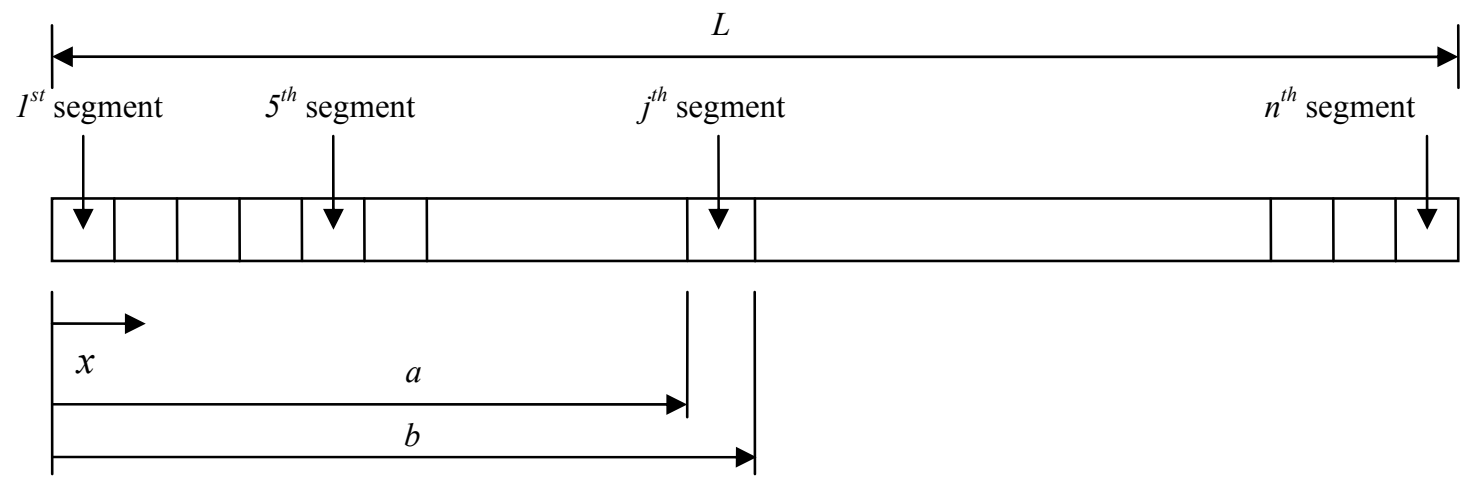

Figure 1. Structural element with $n$ segments

Similarly, for the corresponding damaged element, we have 


$$
\begin{gathered}
K_{i}^{d}=\int_{0}^{L} E I^{d}(x)\left[\phi_{i}^{d^{\prime \prime}}(x)\right]^{2} d x \\
k_{i j}{ }^{d}=\int_{a}^{b} E I^{d}{ }_{j}(x)\left[\phi_{i}^{d{ }^{\prime \prime}}(x)\right]^{2} d x \\
F_{i j}{ }^{d}=\frac{k_{i j}{ }^{d}}{K_{i}{ }^{d}}
\end{gathered}
$$

where the superscript ' $d$ ' denotes 'damaged'. Assuming that the fraction of the $j^{\text {th }}$ element's contribution to the $i^{\text {th }}$ modal strain energy in the undamaged and damaged structure remains constant (i.e., $F_{i j}=F_{i j}{ }^{d}$ ), the ratio of the $j^{\text {th }}$ segment flexural rigidity in the undamaged and damaged structure is given by

$$
\beta_{j}=\frac{E I_{j}}{E I_{j}^{d}}=\frac{\int_{0}^{L} E I(x)\left[\phi_{i}^{\prime \prime}(x)\right]^{2} d x}{\int_{a}^{b}\left[\phi_{i}^{\prime \prime}(x)\right]^{2} d x} \frac{\int_{a}^{b}\left[\phi_{i}^{d^{\prime \prime}}(x)\right]^{2} d x}{\int_{0}^{L} E I^{d}(x)\left[\phi_{i}^{d \prime \prime}(x)\right]^{2} d x}
$$

where $\beta_{j}$ is the damage index for the $j^{\text {th }}$ segment. For multiple modes, $\beta_{j}$ is expressed as

$$
\beta_{j}=\sum_{i=1}^{n m}\left\{\frac{\int_{0}^{L} E I(x)\left[\phi_{i}^{\prime \prime}(x)\right]^{2} d x}{\int_{a}^{b}\left[\phi_{i}^{\prime \prime}(x)\right]^{2} d x} \frac{\int_{a}^{b}\left[\phi_{i}^{d \prime \prime}(x)\right]^{2} d x}{\int_{0}^{L} E I^{d}(x)\left[\phi_{i}^{d \prime \prime}(x)\right]^{2} d x}\right\}
$$

where $n m$ is the number of modes. Accordingly, the normalized damage index, $Z_{j}$, is obtained as

$$
Z_{j}=\frac{\beta_{j}-\bar{\beta}}{\sigma_{\beta}}
$$

where $\bar{\beta}$ and $\sigma_{\beta}$ are the mean and the standard deviation of the damage index, respectively. For a chosen threshold, $Z_{\text {threshold }}$, if $Z_{j} \geq Z_{\text {threshold }}$, it indicates the $j^{\text {th }}$ segment is damaged. In this thesis, $Z_{\text {threshold }}$ is chosen to be 1.0 , meaning that the confidence level for damage 
detection is $84.1 \%$. A flowchart shown in Figure 2 depicts the entire procedure of the current DIM.

STEP

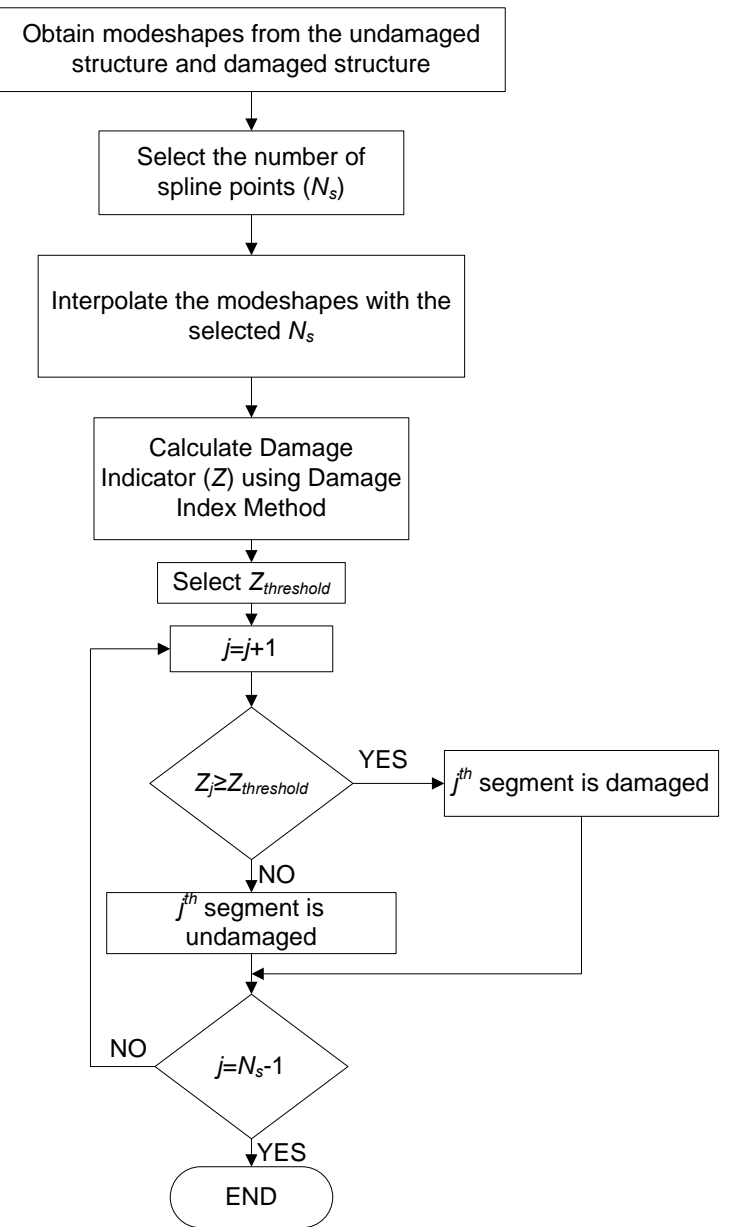

Figure 2. Flow chart of the Damage Index Method

As mentioned in the previous section, there are two crucial restrictions in the use of the DIM. First, the choice of a fixed threshold is arbitrary. Because the particular fixed threshold chosen drives the damage detection results, selection of the threshold is critical in the DIM. If the selected threshold is smaller than the limit at which actual damage occurs, damage would be overestimated. In contrast, damage would be underestimated if the 
selected threshold is set too high. As an illustration, in Figure 3, (a) is an appropriate threshold, (b) is a smaller threshold, and (c) is a larger threshold. In spite of this problem with use of a fixed threshold to detect damage, various thresholds have been selected. For instance, the threshold was chosen to be 1 by some researchers (e.g., Park et al., 2001; Alvandi and Cremona, 2006) while other researchers selected thresholds of 2 (e.g., Stubbs and Kim, 1996; Kim and Stubbs, 2002) and 3 (e.g., Kim and Stubbs, 2003; Kim et al., 2007a).

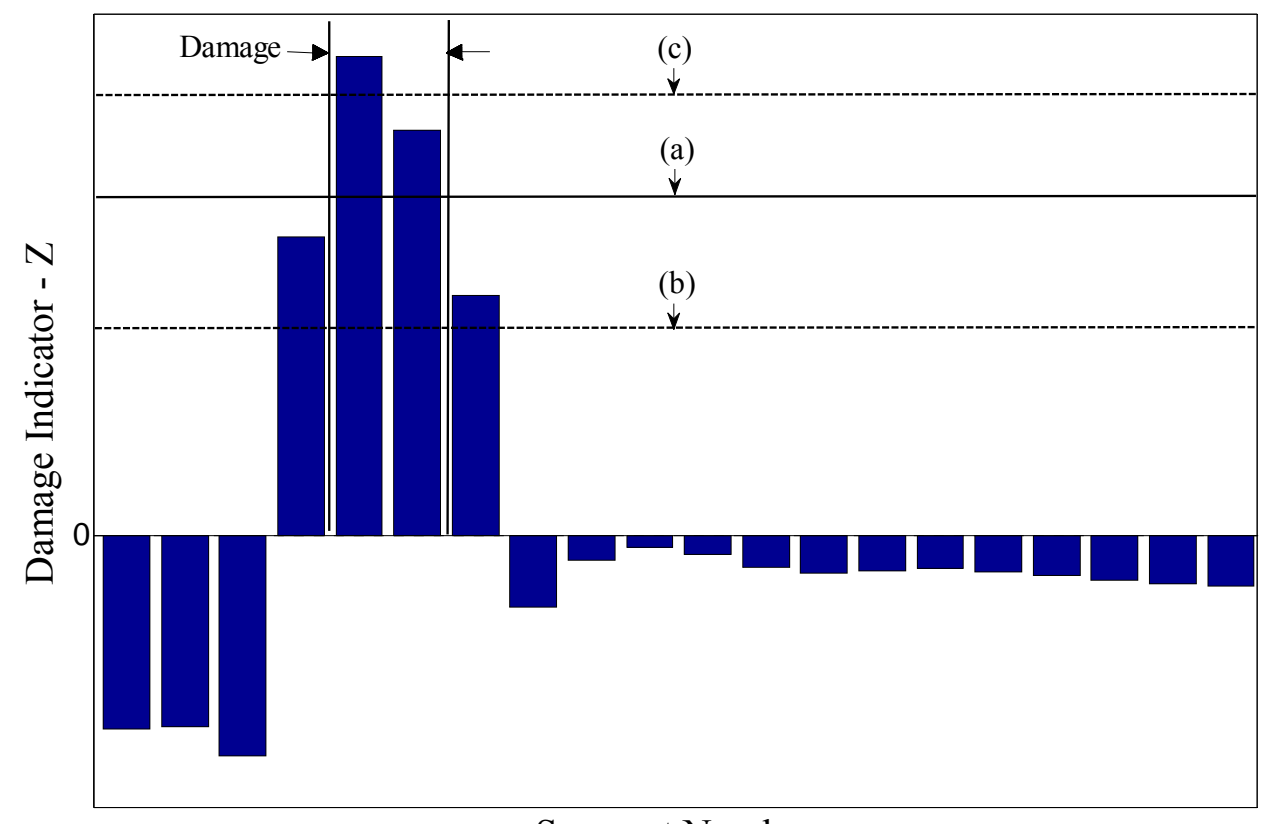

Segment Number

Figure 3. Damage detection with (a) appropriate threshold, (b) smaller threshold, and (c) larger threshold

Second, the number of spline points selected in the DIM can influence the damage detection results. For example, Figure 4 illustrates the problem by showing two predicted damage cases with the same recording points but different spline points. Although the damage in the two cases is identical, the damage detection results by the same fixed threshold 
are different. The extent of damage is detected correctly in Figure 4 (a) while the damage is overestimated in Figure 4 (b).

\subsection{Proposed Iterative Damage Index Method}

The Iterative Damage Index Method (IDIM) proposed in this thesis overcomes these limitations by relying on the idea that the $Z_{\text {ratio }}$ for the same recording points remains constant when different numbers of spline points are used. The $Z_{\text {ratio }}$ is given by

$$
Z_{\text {ratio }}=\frac{\sum_{i=1}^{n a} Z_{A_{i}}}{\sum_{j=1}^{n p} Z_{p_{j}}}
$$

where $n a$ is the number of damage indicators in an actual damage location, $\mathrm{Z}_{A_{i}}$ is the $i^{\text {th }}$ damage indicator in an actual damage location, $n p$ is the number of the positive damage indicators, and $\mathrm{Z}_{p_{j}}$ is the $j^{\text {th }}$ positive damage indicator. By plotting of the number of recording points and the $Z_{\text {ratio }}$, a fitting function, $u_{c}$, is formulated by

$$
u_{c}=1-\exp \left(\frac{-N_{r}}{\tau}\right)
$$

where $N_{r}$ is the number of recording points and $\tau$ is a parameter that needs to be estimated. Unfortunately, $\tau$ varies with different damage sizes. To solve the problem, we introduce a new parameter, $C$, that remains constant over different damage sizes and 


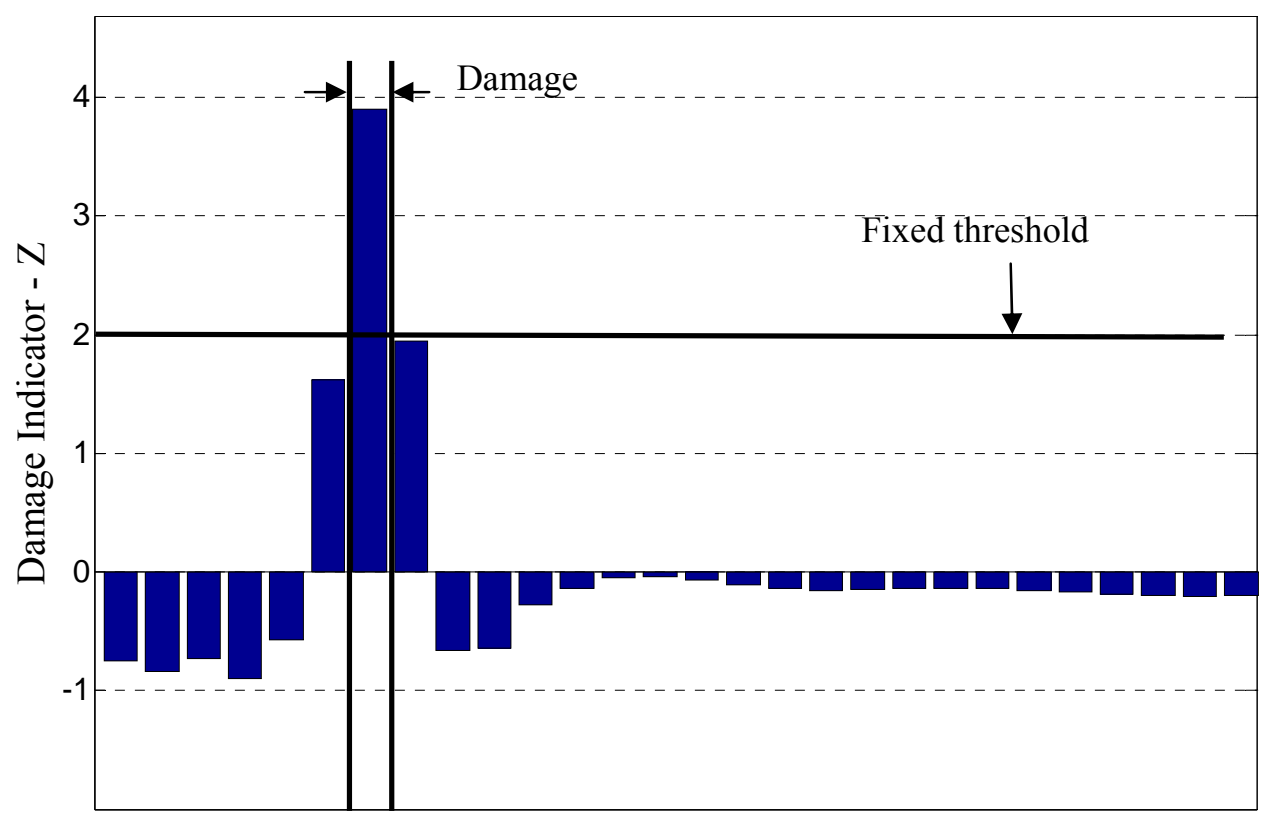

Segment Number

(a)

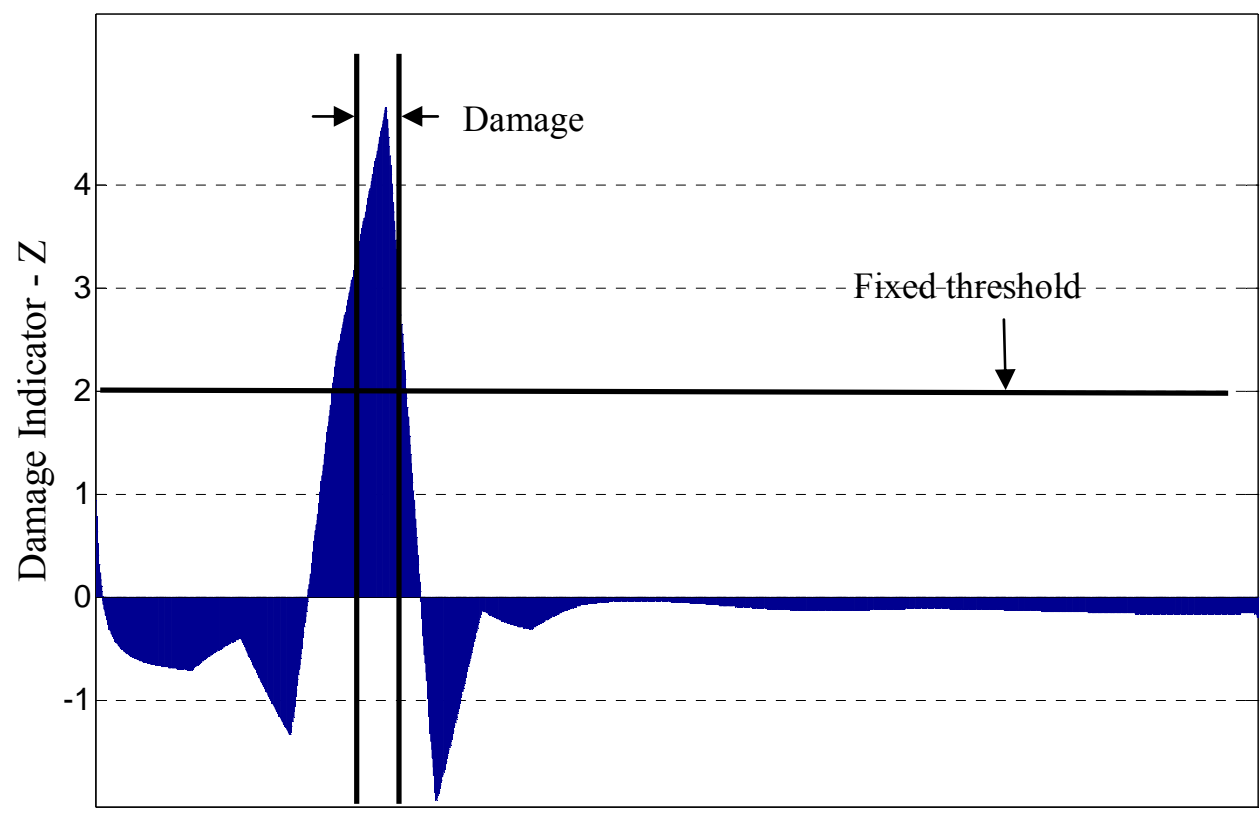

Segment Number

(b)

Figure 4. Damage detection results with (a) $N_{r}$ recording points and $N_{s-1}$ spline points and (b) $N_{r}$ recording points and $N_{s-2}$ spline points $\left(N_{s-1}<N_{s-2}\right)$ 
is defined as

$$
C=\ell \times \tau
$$

where $\ell$ is the length of damage. In this thesis, it is assumed that $C$ is unchanged corresponding to the change of damage length. Based on parameter study, the engineering practical rule to decide the $C$ is that the effective length of a structure for a specific boundary condition can be used as the $C$. For example, the effective length for a simply supported beam is the same as the total length of a beam, while the effective length of a fixed-free beam is half of the total length of a beam (For the detail, see Appendix A and B).

The IDIM is based on the current DIM. Figure 5 gives a flowchart for the IDIM. The first four steps of the proposed method are the same as those of the current DIM (see Figures 2 and 5). The sum of the positive damage indicators, $Z_{\text {sum }}$, is given by

$$
Z_{\text {sum }}=\sum_{j=1}^{n p} Z_{p_{j}}
$$

After numbering the positive damage indicators in descending order (i.e. $Z_{p 1}=$ maximum of $Z_{p}$ ), the sum of the first $k$ positive damage indicator(s), $Z_{\text {sum }}^{\prime}$, can be calculated by

$$
Z_{\text {sum }}^{\prime}=\sum_{i=1}^{k} Z_{p i}
$$

where $k$ is the iteration number. Thus, the ratio of the sum of the positive damage indicators to the sum of the first $k$ positive damage indicator(s), $Z_{\text {ratio }}$, is expressed as

$$
Z_{\text {ratio }}=\frac{Z_{\text {sum }}^{\prime}}{Z_{\text {sum }}}
$$

For a structural element with a total length of $L$, the predicted damage size, $\ell_{p}$, is given by

$$
\ell_{p}=\frac{L}{N_{s}-1} k
$$


where $N_{s}$ is the number of spline points. Next, the fitting function for the predicted damage size, $u_{c_{p}}$, is given by

$$
u_{c_{p}}=1-\exp \left(\frac{-N_{r}}{\tau_{p}}\right) \text { where } \tau_{p}=\frac{C}{\ell_{p}}
$$

The ratio, $\alpha$, is given by

$$
\alpha=\frac{u_{c_{p}}}{Z_{\text {ratio }}}
$$

If $|1-\alpha| \leq \varepsilon$, the iteration will be stopped, where $\varepsilon$ is the tolerance.

\subsection{Determination of the Correlation between Modeshapes}

The Modal Assurance Criteria (MAC) and Total Modal Assurance Criteria (TMAC), suggested by Ewins (1985), were used to determine the correlation between two modeshapes. These criteria are specified as

$$
\begin{gathered}
\operatorname{MAC}\left(\phi_{i}^{A}, \phi_{i}^{B}\right)=\frac{\left[\left(\phi_{i}^{A}\right)^{T} \phi_{i}^{B}\right]^{2}}{\left[\left(\phi_{i}^{A}\right)^{T} \phi_{i}^{A}\right]\left[\left(\phi_{i}^{B}\right)^{T} \phi_{i}^{B}\right]} \quad i=1,2, \ldots, n \\
T M A C=\prod_{i=1}^{n} \operatorname{MAC}\left(\phi_{i}^{A}, \phi_{i}^{B}\right)
\end{gathered}
$$

where $\phi_{i}^{A}$ and $\phi_{i}^{B}$ are the $i^{\text {th }}$ modeshape of a structure. The closer to one the MAC and TMAC are, the greater the correlation between two modeshapes is. Since the two methods rely on strain energy, the curvature of modeshapes can be used to determine the 
STEP

(3)

Interpolate the modeshapes with the selected $N_{s}$

(4)

Calculate Damage Indicator $(Z)$ using Damage Index Method

(5)

$$
Z_{\text {sum }}=\sum_{j=1}^{n p} Z_{p_{j}}
$$

where $Z_{p_{j}} \geq 0$ and $n p$ is the number of positive indicators

(6) Number $Z_{p}$ in descending order (i.e. $Z_{p 1}=$ maximum of $Z_{p}$ )

(7)

(8)

(11)

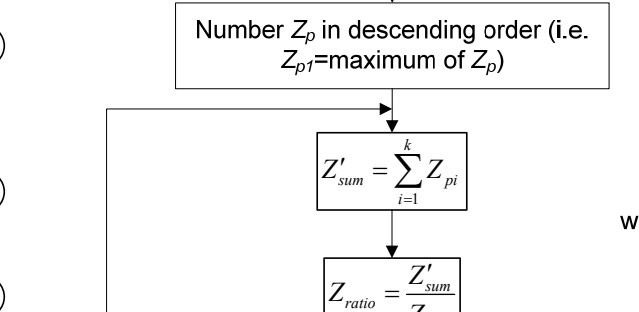

where $k=$ iteration number $Z_{\text {ratio }}=\frac{Z_{\text {sum }}^{\prime}}{Z_{\text {sum }}}$

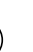

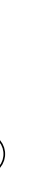
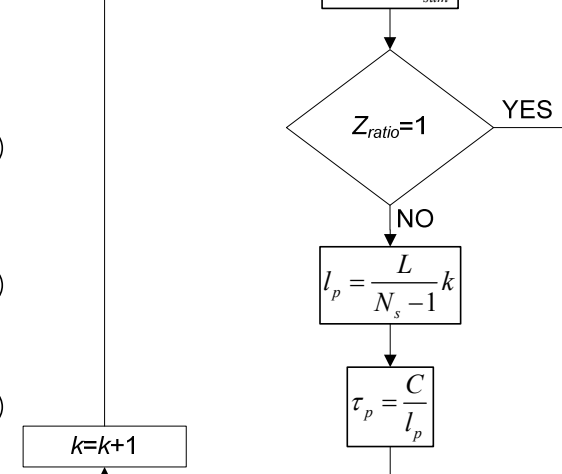

(12)

(13)

(14)

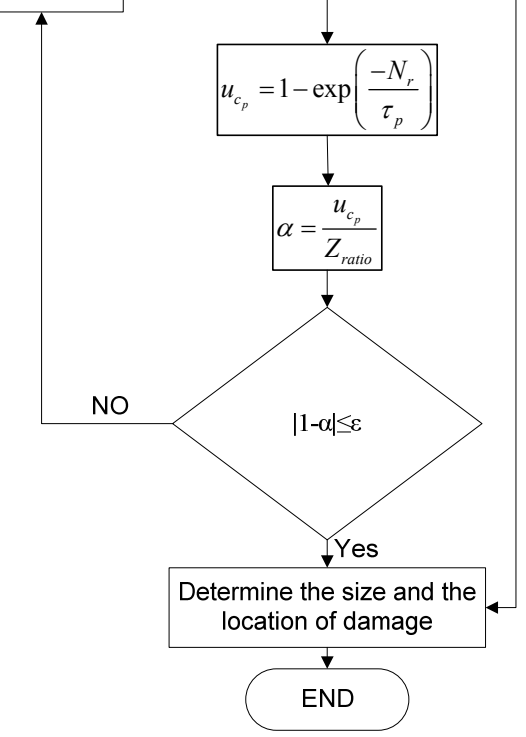

where $I_{p}=$ predicted damage size, $L=$ total length of a structure, and $k=$ iteration number

where $C=$ constant

where $\varepsilon$ is tolerance

Figure 5. Flow chart of the proposed Iterative Damage Index Method 
correlation between two modeshapes. Therefore, we apply the Curvature Assurance Criteria (CAC) and Total Curvature Assurance Criteria (TCAC) as expressed by

$$
\begin{gathered}
C A C\left(\phi_{i}^{A^{\prime \prime}}, \phi_{i}^{B^{\prime \prime}}\right)=\frac{\left[\left(\phi_{i}^{A^{\prime \prime}}\right)^{T} \phi_{i}^{B^{\prime \prime}}\right]^{2}}{\left[\left(\phi_{i}^{A^{\prime \prime}}\right)^{T} \phi_{i}^{A^{\prime \prime}}\right]\left[\left(\phi_{i}^{B^{\prime \prime}}\right)^{T} \phi_{i}^{B^{\prime \prime}}\right]} \quad i=1,2, \ldots, n \\
T C A C=\prod_{i=1}^{n} C A C\left(\phi_{i}^{A^{\prime \prime}}, \phi_{i}^{B^{\prime \prime}}\right)
\end{gathered}
$$

If the CAC and TCAC are close to one, the curvatures of the modeshapes are highly correlated. In this thesis, the MAC, TMAC, CAC, and TCAC are calculated between the modeshapes from the undamaged structure and the modeshapes from the damaged structure. Because the MAC can be used for structural damage detection (Allemang, 2003), it is investigated whether the four criteria are able to indicate the presence of damage prior to the damage detection process by the DIM and the IDIM in this thesis. In this study, if that the criteria, expressed as four significant digits, are less than one, the criteria can show the existence of damage.

\subsection{Quantification of the Accuracy of Predicted Damage}

To quantify the accuracy of predicted damage, two factors are introduced: e and $\Delta$. The e refers to the ratio between the actual damage size and the predicted damage size and it can be formulated as

$$
\mathrm{e}=\frac{s-\hat{s}}{s}
$$

where $s$ is an actual damage size and $\hat{s}$ is the predicted damage size. The $\Delta$ refers to the difference between the center of the actual damage and the center of the predicted damage and is written as 


$$
\Delta=\frac{c-\hat{c}}{L}
$$

where $L$ is the total length of a structure, $c$ is the center of the actual damage, and $\hat{c}$ is the center of the predicted damage. If the e and $\Delta$ are zero, then the damage is exactly detected. Moreover, the smaller the absolute values of both the e and the $\Delta$ are, the more accurate the damage detection is. Note that e and $\Delta$ can be calculated for each damage detection model, where the damage detection model is an imaginary structure used for the damage detection. The damage detection model is composed of selected $N_{r}$ and $N_{s}$.

To generalize and compare the accuracy of predicted damage in the DIM and the IDIM, the damage detection percentage is calculated. Assuming there are damage detection models composed of various $N_{r}$ and $N_{s}$, the damage detection percentage, $\gamma$, is

$$
\gamma=\frac{n_{c}}{n_{t}} \times 100(\%)
$$

where $n_{t}$ is the number of total damage detection models and $n_{c}$ is the number of correct damage predictions (i.e., $\mathrm{e}=0$ and $\Delta=0$ ) among $n_{t}$ cases. In addition, $\gamma$ also can be calculated by applying various e and $\Delta$ to consider the error of predicted damage. Because various numbers of recording points $\left(N_{r}\right)$ cannot be used in experimental tests, the average of the e and $\Delta$ are calculated for the damage detection models with the only change of $N_{s}$. The average of the e and $\Delta$ will be used to compare how the two methods perform in the experimental tests. 


\section{VALIDATION USING NUMERICAL DATA}

In this section, two numerical examples validate the proposed IDIM. A simply supported beam with cross section HSS $2 \times 2 \times 1 / 2$ and a pedestrian bridge on the Texas A\&M Golf Course at Texas A\&M University, College Station, TX are modeled in ABAQUS (2004).

\subsection{Simply Supported Beam}

The material and geometric properties for the simply supported beam can be found in Table 1 . For numerical simulation, the simply supported beam is constructed in ABAQUS (2004), including 280 beam elements $\left(\mathrm{B} 31^{3}\right)$ with an equivalent width of $0.013 \mathrm{~m}(0.5 \mathrm{in})$. From the modal analysis, the first three modeshapes are extracted and used in the DIM and IDIM. The first three eigenfrequencies are $11.205,44.760$, and $100.490 \mathrm{~Hz}$. The numerical modeshapes can be obtained with 281 nodes.

Table 1. Properties for a simply supported beam

\begin{tabular}{cc}
\hline Properties & Values \\
\hline Length, L & $3.56 \mathrm{~m}(140 \mathrm{in})$ \\
Young's modulus, E & $2.0 \times 10^{5} \mathrm{MPa}\left(2.9 \times 10^{4} \mathrm{ksi}\right)$ \\
Second moment of cross-sectional inertia, I & $3.11 \times 10^{5} \mathrm{~mm}^{4}\left(0.747 \mathrm{in}^{4}\right)$ \\
Cross section area, A & $974.19 \mathrm{~mm}^{2}\left(1.51 \mathrm{in}^{2}\right)$ \\
Density, $\rho$ & $7.85 \times 10^{3} \mathrm{~kg} / \mathrm{m}^{3}\left(0.28 \mathrm{lb} / \mathrm{in}^{3}\right)$ \\
\hline
\end{tabular}

Fourteen damage cases are studied, as summarized in Table 2, to investigate the effect of various sizes, severities, and locations of damage. Cases 1, 2, and 3 are chosen to simulate three different sizes of damage, while Cases 1, 4, 5, 6, and 7 are selected to simulate various

\footnotetext{
${ }^{3}$ A 2-node linear beam in space (ABAQUS 2004)
} 
damage severities. Moreover, Cases 8, 9, and 10 investigate the influence of different damage locations. The last four damage cases are decided to simulate multiple locations of damage. Damage is simulated by reducing the modulus of elasticity of the appropriate elements.

Table 2. Damage scenarios for a simply supported beam

\begin{tabular}{|c|c|c|c|c|c|c|c|c|}
\hline \multirow{2}{*}{$\begin{array}{c}\text { Damage } \\
\text { Case }\end{array}$} & \multirow{2}{*}{$\begin{array}{l}\text { Damage } \\
\text { size }\end{array}$} & \multicolumn{2}{|c|}{ Location } & \multirow{2}{*}{ Severity ${ }^{\dagger}$} & \multirow{2}{*}{$\begin{array}{c}\text { Damage } \\
\text { size }\end{array}$} & \multicolumn{2}{|c|}{ Location } & \multirow{2}{*}{ Severity ${ }^{\dagger}$} \\
\hline & & From & To & & & From & To & \\
\hline Undamaged & $0.00 \mathrm{~m}$ & 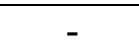 & & 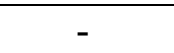 & - & - & - & - \\
\hline 1 & $0.13 \mathrm{~m}$ & $0.76 \mathrm{~m}$ & $\begin{array}{c}0.89 \\
\mathrm{~m}\end{array}$ & -20 & - & - & - & - \\
\hline 2 & $0.25 \mathrm{~m}$ & $0.76 \mathrm{~m}$ & $\begin{array}{c}1.02 \\
\mathrm{~m}\end{array}$ & -20 & - & - & - & - \\
\hline 3 & $0.51 \mathrm{~m}$ & $0.51 \mathrm{~m}$ & $\begin{array}{c}1.02 \\
\mathrm{~m}\end{array}$ & -20 & - & - & - & - \\
\hline 4 & $0.13 \mathrm{~m}$ & $0.76 \mathrm{~m}$ & $\begin{array}{c}0.89 \\
\mathrm{~m}\end{array}$ & -1 & - & - & - & - \\
\hline 5 & $0.13 \mathrm{~m}$ & $0.76 \mathrm{~m}$ & $\begin{array}{c}0.89 \\
\mathrm{~m}\end{array}$ & -10 & - & - & - & - \\
\hline 6 & $0.13 \mathrm{~m}$ & $0.76 \mathrm{~m}$ & $\begin{array}{c}0.89 \\
\mathrm{~m}\end{array}$ & -40 & - & - & - & - \\
\hline 7 & $0.13 \mathrm{~m}$ & $0.76 \mathrm{~m}$ & $\begin{array}{c}0.89 \\
\mathrm{~m}\end{array}$ & -60 & - & - & - & - \\
\hline 8 & $0.13 \mathrm{~m}$ & $0.00 \mathrm{~m}$ & $\begin{array}{c}0.13 \\
\mathrm{~m}\end{array}$ & -20 & - & - & - & - \\
\hline 9 & $0.13 \mathrm{~m}$ & $0.51 \mathrm{~m}$ & $\begin{array}{c}0.64 \\
\mathrm{~m}\end{array}$ & -20 & - & - & - & - \\
\hline 10 & $0.13 \mathrm{~m}$ & $1.65 \mathrm{~m}$ & $\begin{array}{l}1.78 \\
\mathrm{~m}\end{array}$ & -20 & - & - & - & - \\
\hline 11 & $0.13 \mathrm{~m}$ & $0.76 \mathrm{~m}$ & $\begin{array}{c}0.89 \\
\mathrm{~m}\end{array}$ & -20 & $0.13 \mathrm{~m}$ & $\begin{array}{c}2.54 \\
\mathrm{~m}\end{array}$ & $\begin{array}{c}2.67 \\
\mathrm{~m}\end{array}$ & -20 \\
\hline 12 & $0.13 \mathrm{~m}$ & $0.76 \mathrm{~m}$ & $\begin{array}{c}0.89 \\
\mathrm{~m}\end{array}$ & -20 & $0.13 \mathrm{~m}$ & $\begin{array}{c}2.54 \\
\mathrm{~m}\end{array}$ & $\begin{array}{c}2.67 \\
\mathrm{~m}\end{array}$ & -50 \\
\hline 13 & $0.13 \mathrm{~m}$ & $0.76 \mathrm{~m}$ & $\begin{array}{c}0.89 \\
\mathrm{~m}\end{array}$ & -50 & $0.13 \mathrm{~m}$ & $\begin{array}{c}2.54 \\
\mathrm{~m}\end{array}$ & $\begin{array}{c}2.67 \\
\mathrm{~m}\end{array}$ & -20 \\
\hline 14 & $0.13 \mathrm{~m}$ & $0.76 \mathrm{~m}$ & $\begin{array}{c}0.89 \\
\mathrm{~m}\end{array}$ & -50 & $0.13 \mathrm{~m}$ & $\begin{array}{c}2.54 \\
\mathrm{~m}\end{array}$ & $\begin{array}{c}2.67 \\
\mathrm{~m}\end{array}$ & -50 \\
\hline
\end{tabular}

${ }^{\dagger}$ Severity $(\%)=\left(E^{d}-E\right) / E \times 100$ where $E$ and $E^{d}$ are the modulus of elasticity for the undamaged and damaged element, respectively. 
Figure 6 shows the first numerical modeshapes and the curvatures for an undamaged and a damaged (Case 1) beam. There are obvious differences in the curvature seen in Figure 6 (b) while the two modeshapes seen Figure 6 (a) are similar. The MAC, TMAC, CAC, and TCAC are calculated for the fourteen damage cases and expressed as four significant digits, as shown in Table 3. Note that the MAC and TMAC are calculated using modeshapes while the CAC and TCAC are based on the curvature. The MAC and TMAC are not sensitive enough to demonstrate the presence of damage because the MAC and TMAC are equal to one in eight out of the fourteen damage cases. However, the CAC and TCAC can be useful to indicate the state of damage as pre-processing of the DIM and the IDIM as the CAC and TCAC are equal to one in only one of the fourteen damage cases. Because the CAC and TCAC for the ten damage cases are able to show the presence of damage, the modeshapes obtained from the undamaged and the damaged beam can be applied to detect damage by the DIM and the IDIM.

Table 3. MAC, TMAC, CAC, and TCAC for the simply supported beam

\begin{tabular}{|c|c|c|c|c|c|c|c|c|}
\hline \multirow[b]{2}{*}{$\begin{array}{c}\text { Damage } \\
\text { Case }\end{array}$} & \multicolumn{3}{|c|}{ MAC } & \multirow[b]{2}{*}{ TMAC } & \multicolumn{3}{|c|}{$\mathrm{CAC}$} & \multirow[b]{2}{*}{ TCAC } \\
\hline & $1^{\text {st }}$ mode & $\begin{array}{l}2^{\text {nd }} \\
\text { mode }\end{array}$ & $3^{\text {rd }}$ mode & & $1^{\text {st }}$ mode & $\begin{array}{c}2^{\text {nd }} \\
\text { mode }\end{array}$ & $\begin{array}{c}3^{\text {rd }} \\
\text { mode }\end{array}$ & \\
\hline 1 & 1.000 & 1.000 & 1.000 & 1.000 & 0.998 & 0.996 & 0.998 & 0.992 \\
\hline 2 & 1.000 & 1.000 & 1.000 & 1.000 & 0.996 & 0.994 & 0.997 & 0.987 \\
\hline 3 & 1.000 & 0.999 & 0.999 & 0.998 & 0.994 & 0.990 & 0.995 & 0.979 \\
\hline 4 & 1.000 & 1.000 & 1.000 & 1.000 & 1.000 & 1.000 & 1.000 & 1.000 \\
\hline 5 & 1.000 & 1.000 & 1.000 & 1.000 & 1.000 & 0.999 & 1.000 & 0.998 \\
\hline 6 & 1.000 & 1.000 & 0.999 & 0.999 & 0.987 & 0.976 & 0.986 & 0.950 \\
\hline 7 & 1.000 & 0.998 & 0.997 & 0.995 & 0.942 & 0.904 & 0.946 & 0.805 \\
\hline 8 & 1.000 & 1.000 & 1.000 & 1.000 & 0.999 & 1.000 & 1.000 & 0.999 \\
\hline 9 & 1.000 & 1.000 & 1.000 & 1.000 & 0.999 & 0.997 & 0.996 & 0.992 \\
\hline 10 & 1.000 & 1.000 & 1.000 & 1.000 & 0.996 & 1.000 & 0.997 & 0.993 \\
\hline 11 & 1.000 & 1.000 & 1.000 & 1.000 & 0.996 & 0.993 & 0.997 & 0.986 \\
\hline 12 & 1.000 & 1.000 & 0.999 & 0.999 & 0.967 & 0.952 & 0.982 & 0.904 \\
\hline 13 & 1.000 & 0.999 & 0.999 & 0.998 & 0.972 & 0.950 & 0.970 & 0.896 \\
\hline 14 & 1.000 & 1.000 & 0.999 & 0.999 & 0.947 & 0.919 & 0.955 & 0.832 \\
\hline
\end{tabular}




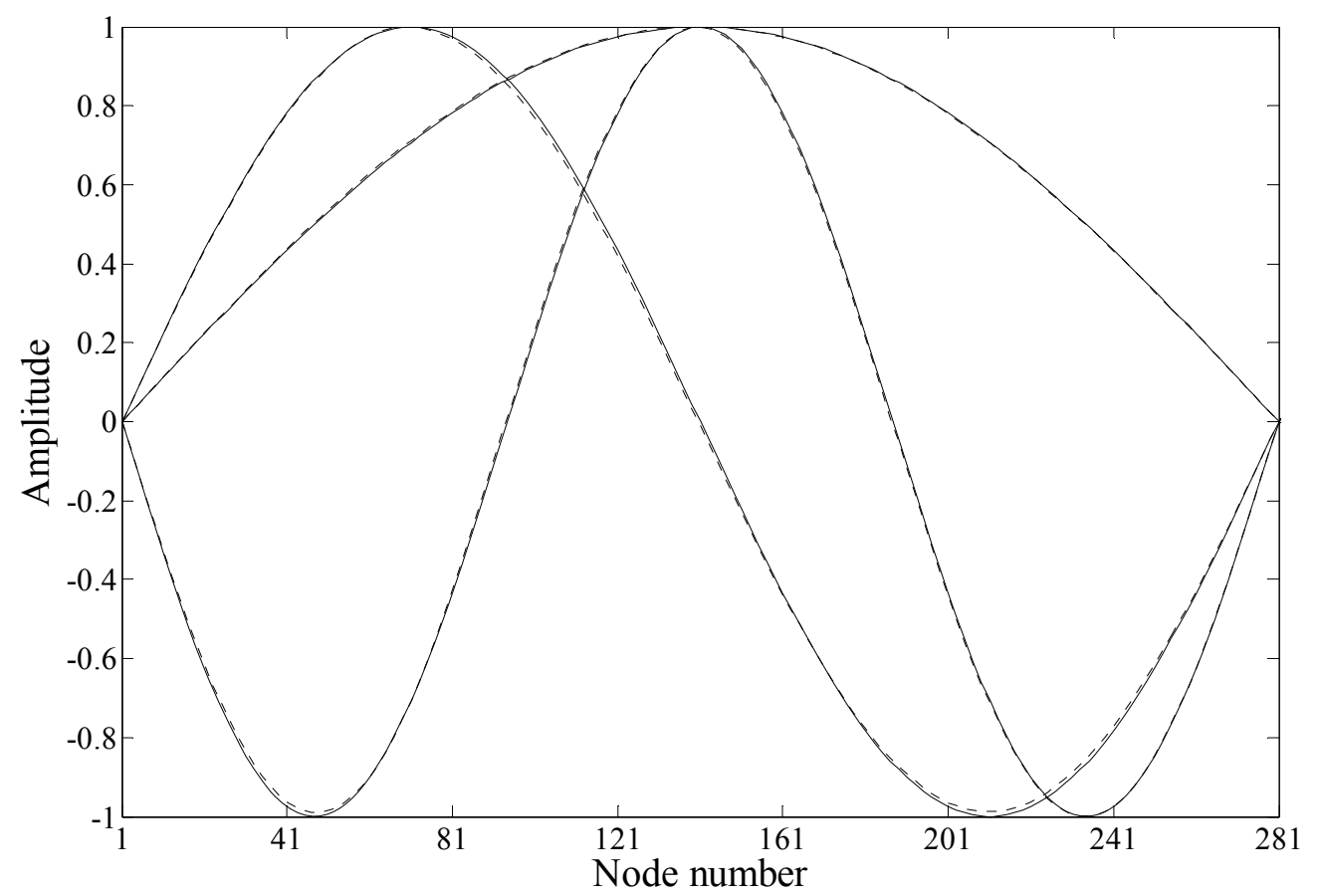

(a)

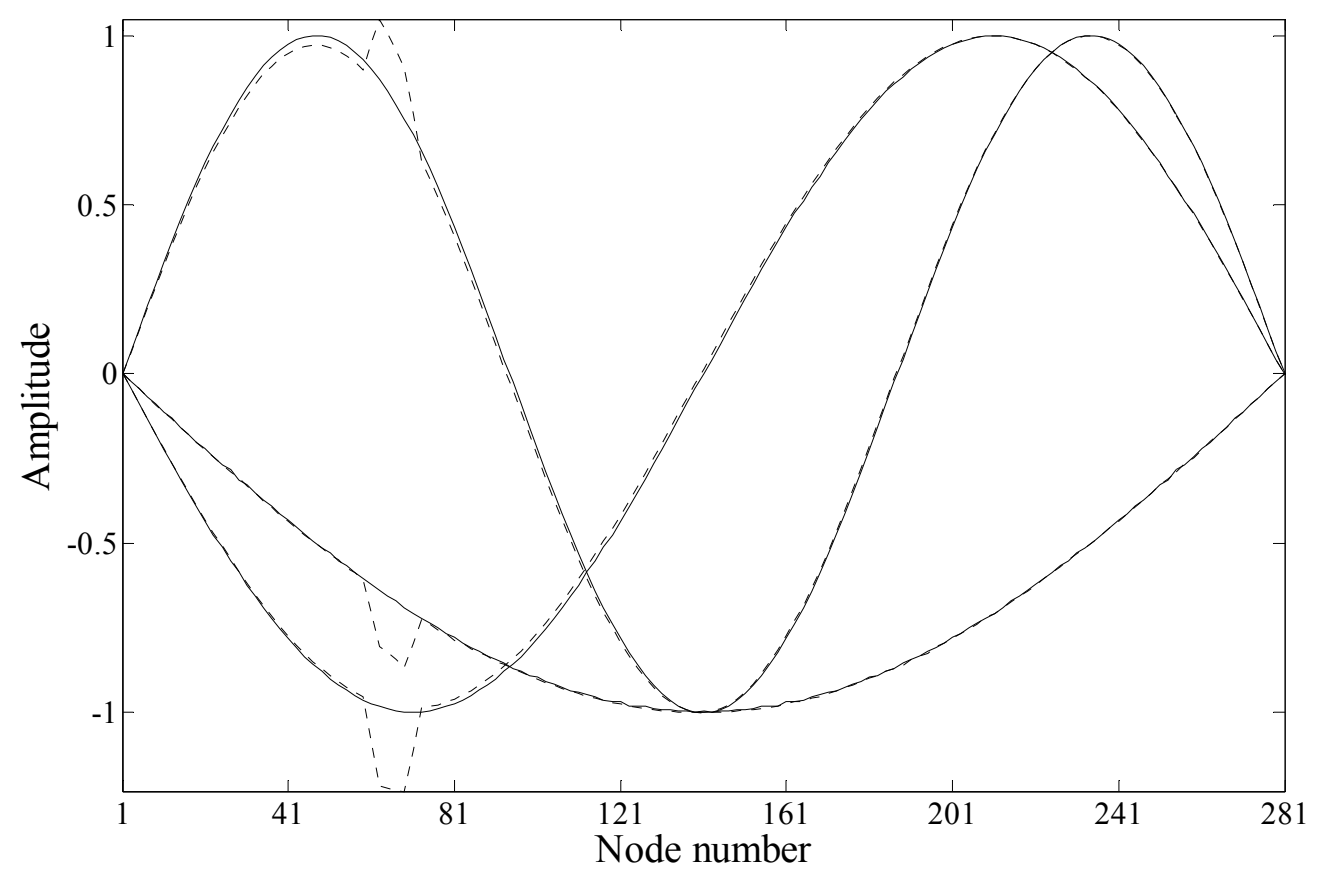

(b)

Figure 6. (a) Numerical modeshapes and (b) Curvature of the modeshapes (solid lines indicate the undamaged and dashed lines indicate the damaged) 
The modeshapes can be obtained more accurately by increasing $N_{r}$ which promises more reliable damage detection. However, it is necessary to decide on the minimum $N_{r}$ for correct damage detection because one can not use an unlimited $N_{r}$. Table 4 shows the minimum $N_{r}$ to detect damage correctly (i.e., $\Delta=0$ and $\mathrm{e}=0$ ) for all damage cases. It is apparent that a smaller $N_{r}$ is needed in the IDIM for most of damage cases. Therefore, the IDIM is generally more economical than the DIM in the simply supported beam.

The damage detection percentages for the simply supported beam are calculated by considering ten thousand damage detection models (i.e., $\left.n_{t}=10,000\right)$ with various $N_{r}$ and $N_{s}$. Those percentages for only six of the fourteen damage cases are summarized in Tables 5-10 since the results for the rest of the cases are similar. Five main implications can be drawn from these tables. First, the IDIM is more accurate than the DIM in the simply supported beam because the damage detection percentages of the IDIM are higher in most of the damage cases. Second, comparison of the Tables 5 and 6 shows that the IDIM is more efficient in estimating minor damage associated with Table 5. Third, as shown in Tables 5 and 7, the more severe damage associated with Table 7 is estimated more accurately by the IDIM. Fourth, the similarity between Tables 5 and 8 imply the location of damage does not affect the relative accuracy of damage predictions. Finally, Tables 9 and 10 show that the IDIM is much more accurate than the DIM in identifying the multiple locations of damage. 
Table 4. The minimum number of recording points $\left(N_{r}\right)$ and the minimum number of spline points $\left(N_{s}\right)$ to detect damage accurately $(\Delta=0$ and $\mathrm{e}=0)$

\begin{tabular}{|c|c|c|}
\hline \multirow{2}{*}{ Damage Case } & \multicolumn{2}{|c|}{$\operatorname{Minimum} N_{r}\left(N_{s}\right)$} \\
\hline & DIM & IDIM \\
\hline 1 & $59(113)$ & $21(29)$ \\
\hline 2 & $13(29)$ & $12(15)$ \\
\hline 3 & $9(15)$ & $12(15)$ \\
\hline 4 & $64(85)$ & $17(29)$ \\
\hline 5 & $64(113)$ & $17(29)$ \\
\hline 6 & $40(85)$ & $10(29)$ \\
\hline 7 & $40(57)$ & $14(29)$ \\
\hline 8 & $22(113)$ & $74(85)$ \\
\hline 9 & N/A & $12(29)$ \\
\hline 10 & $58(85)$ & $5(29)$ \\
\hline 11 & $78(99)$ & $29(50)$ \\
\hline 12 & N/A & $5099)$ \\
\hline 13 & $\mathrm{~N} / \mathrm{A}$ & $50(99)$ \\
\hline 14 & $71(99)$ & $29(50)$ \\
\hline
\end{tabular}

N/A: Damage can not be detected.

Table 5. Damage detection percentage Case 1 (unit is \%)

\begin{tabular}{|c|c|c|c|c|c|c|c|c|c|c|c|c|}
\hline \multirow{2}{*}{$\Delta$} & & \multicolumn{11}{|c|}{$\mathrm{e}$} \\
\hline & & 0 & 0.1 & 0.2 & 0.3 & 0.4 & 0.5 & 1.0 & 1.5 & 2.0 & 2.5 & 3.0 \\
\hline \multirow{2}{*}{0} & DIM & 0.8 & 15.3 & 51.6 & 69.1 & 77.5 & 80.4 & 86.5 & 92.0 & 94.4 & 94.6 & 96.4 \\
\hline & IDIM & 5.3 & 67.5 & 79.4 & 82.9 & 84.6 & 86.7 & 95.5 & 95.6 & 95.7 & 96.4 & 99.6 \\
\hline \multirow{2}{*}{0.01} & DIM & 0.8 & 15.3 & 51.6 & 69.1 & 77.5 & 80.4 & 86.5 & 92.0 & 94.4 & 94.6 & 96.4 \\
\hline & IDIM & 5.3 & 67.5 & 79.4 & 82.9 & 84.6 & 86.7 & 95.5 & 95.6 & 95.7 & 96.4 & 99.6 \\
\hline \multirow{2}{*}{0.02} & DIM & 0.8 & 15.3 & 51.6 & 69.1 & 77.5 & 80.4 & 86.5 & 92.0 & 94.4 & 94.6 & 96.4 \\
\hline & IDIM & 5.3 & 67.5 & 79.4 & 82.9 & 84.6 & 86.7 & 95.5 & 95.6 & 95.7 & 96.4 & 99.6 \\
\hline
\end{tabular}

Table 6. Damage detection percentage Case 2 (unit is \%)

\begin{tabular}{ccccccccccccc}
\hline \multirow{2}{*}{$\Delta$} & & \multicolumn{10}{c}{$\mathrm{e}$} \\
\cline { 3 - 12 } & & 0 & 0.1 & 0.2 & 0.3 & 0.4 & 0.5 & 1.0 & 1.5 & 2.0 & 2.5 & 3.0 \\
\hline \multirow{2}{*}{0} & DIM & 11.1 & 81.5 & 92.1 & 93.6 & 95.6 & 95.7 & 97.8 & 97.9 & 97.9 & 98.0 & 98.1 \\
& IDIM & 5.4 & 80.5 & 85.9 & 87.3 & 89.4 & 91.1 & 99.6 & 99.9 & 99.9 & 100.0 & 100.0 \\
\hline \multirow{2}{*}{0.01} & DIM & 11.1 & 81.5 & 92.1 & 93.6 & 95.6 & 95.7 & 97.8 & 97.9 & 97.9 & 98.0 & 98.1 \\
& IDIM & 5.4 & 80.5 & 85.9 & 87.3 & 89.4 & 91.1 & 99.6 & 99.9 & 99.9 & 100.0 & 100.0 \\
\hline \multirow{2}{*}{0.02} & DIM & 11.1 & 81.5 & 92.1 & 93.6 & 95.6 & 95.7 & 97.8 & 97.9 & 97.9 & 98.0 & 98.1 \\
& IDIM & 5.4 & 80.5 & 85.9 & 87.3 & 89.4 & 91.1 & 99.6 & 99.9 & 99.9 & 100.0 & 100.0 \\
\hline
\end{tabular}


Table 7. Damage detection percentage Case 5 (unit is \%)

\begin{tabular}{ccccccccccccc}
\hline \multirow{2}{*}{$\Delta$} & & \multicolumn{10}{c}{$\mathrm{e}$} \\
\cline { 3 - 12 } & & 0 & 0.1 & 0.2 & 0.3 & 0.4 & 0.5 & 1.0 & 1.5 & 2.0 & 2.5 & 3.0 \\
\hline \multirow{2}{*}{0} & DIM & 0.2 & 12.1 & 48.2 & 65.3 & 74.3 & 77.7 & 83.7 & 89.4 & 91.7 & 92.0 & 93.8 \\
& IDIM & 1.5 & 25.7 & 72.4 & 83.3 & 85.3 & 87.9 & 95.5 & 95.6 & 95.8 & 96.3 & 99.6 \\
\hline \multirow{2}{*}{0.01} & DIM & 0.2 & 12.1 & 48.2 & 65.3 & 74.3 & 77.7 & 83.7 & 89.4 & 91.7 & 92.0 & 93.8 \\
& IDIM & 1.5 & 25.7 & 72.4 & 83.3 & 85.3 & 87.9 & 95.5 & 95.6 & 95.8 & 96.3 & 99.6 \\
\hline \multirow{2}{*}{0.02} & DIM & 0.2 & 12.1 & 48.2 & 65.3 & 74.3 & 77.7 & 83.7 & 89.4 & 91.7 & 92.0 & 93.8 \\
& IDIM & 1.5 & 25.7 & 72.4 & 83.3 & 85.3 & 87.9 & 95.5 & 95.6 & 95.8 & 96.3 & 99.6 \\
\hline
\end{tabular}

Table 8. Damage detection percentage Case 9 (unit is \%)

\begin{tabular}{ccccccccccccc}
\hline \multirow{2}{*}{$\Delta$} & & \multicolumn{10}{c}{$\mathrm{e}$} \\
\cline { 3 - 13 } & & 0 & 0.1 & 0.2 & 0.3 & 0.4 & 0.5 & 1.0 & 1.5 & 2.0 & 2.5 & 3.0 \\
\hline \multirow{2}{*}{0} & DIM & 0.0 & 21.2 & 60.0 & 73.2 & 80.2 & 82.7 & 87.2 & 88.9 & 92.6 & 92.9 & 94.9 \\
& IDIM & 3.1 & 53.2 & 75.9 & 82.5 & 83.9 & 84.4 & 91.1 & 91.9 & 93.8 & 93.9 & 95.8 \\
\hline \multirow{2}{*}{0.01} & DIM & 0.0 & 21.2 & 60.0 & 73.2 & 80.2 & 82.7 & 87.2 & 88.9 & 92.6 & 92.9 & 94.9 \\
& IDIM & 3.1 & 53.2 & 75.9 & 82.5 & 83.9 & 84.4 & 91.1 & 91.9 & 93.8 & 93.9 & 95.8 \\
\hline \multirow{2}{*}{0.02} & DIM & 0.0 & 21.2 & 60.0 & 73.2 & 80.2 & 82.7 & 87.2 & 88.9 & 92.6 & 92.9 & 94.9 \\
& IDIM & 3.1 & 53.2 & 75.9 & 82.5 & 83.9 & 84.4 & 91.1 & 91.9 & 93.8 & 93.9 & 95.8 \\
\hline
\end{tabular}

Table 9. Damage detection percentage Case 12 (unit is \%)

\begin{tabular}{ccccccccccccc}
\hline \multirow{2}{*}{$\Delta$} & & \multicolumn{10}{c}{$\mathrm{e}$} \\
\cline { 3 - 13 } & & 0 & 0.1 & 0.2 & 0.3 & 0.4 & 0.5 & 1.0 & 1.5 & 2.0 & 2.5 & 3.0 \\
\hline \multirow{2}{*}{0} & DIM & 0.0 & 0.0 & 0.0 & 1.4 & 12.3 & 22.3 & 67.0 & 67.0 & 67.0 & 67.0 & 67.0 \\
& IDIM & 8.4 & 61.4 & 71.2 & 75.9 & 78.5 & 81.6 & 89.6 & 90.2 & 93.7 & 95.7 & 95.8 \\
\hline \multirow{2}{*}{0.01} & DIM & 0.0 & 0.0 & 0.0 & 1.4 & 12.3 & 22.3 & 67.0 & 67.0 & 67.0 & 67.0 & 67.0 \\
& IDIM & 8.4 & 61.4 & 71.2 & 75.9 & 78.5 & 81.6 & 89.6 & 90.2 & 93.7 & 95.7 & 95.8 \\
\hline \multirow{2}{*}{0.02} & DIM & 0.0 & 0.0 & 0.0 & 1.4 & 12.3 & 22.3 & 67.0 & 67.0 & 67.0 & 67.0 & 67.0 \\
& IDIM & 8.4 & 61.4 & 71.2 & 75.9 & 78.5 & 81.6 & 89.6 & 90.2 & 93.7 & 95.7 & 95.8 \\
\hline
\end{tabular}


Table 10. Damage detection percentage Case 14 (unit is \%)

\begin{tabular}{ccccccccccccc}
\hline \multirow{2}{*}{$\Delta$} & & \multicolumn{10}{c}{$\mathrm{e}$} \\
\cline { 3 - 13 } & & 0 & 0.1 & 0.2 & 0.3 & 0.4 & 0.5 & 1.0 & 1.5 & 2.0 & 2.5 & 3.0 \\
\hline \multirow{2}{*}{0} & DIM & 9.0 & 63.8 & 78.3 & 81.3 & 82.4 & 83.7 & 92.5 & 95.6 & 95.8 & 95.9 & 95.9 \\
& IDIM & 9.6 & 64.9 & 74.8 & 78.8 & 81.8 & 84.5 & 93.6 & 93.8 & 95.4 & 97.8 & 97.9 \\
\hline \multirow{2}{*}{0.01} & DIM & 9.0 & 63.8 & 78.3 & 81.3 & 82.4 & 83.7 & 92.5 & 95.6 & 95.8 & 95.9 & 95.9 \\
& IDIM & 9.6 & 64.9 & 74.8 & 78.8 & 81.8 & 84.5 & 93.6 & 93.8 & 95.4 & 97.8 & 97.9 \\
\hline \multirow{2}{*}{0.02} & DIM & 9.0 & 63.8 & 78.3 & 81.3 & 82.4 & 83.7 & 92.5 & 95.6 & 95.8 & 95.9 & 95.9 \\
& IDIM & 9.6 & 64.9 & 74.8 & 78.8 & 81.8 & 84.5 & 93.6 & 93.8 & 95.4 & 97.8 & 97.9 \\
\hline
\end{tabular}

\subsection{Pedestrian Bridge}

The pedestrian bridge, shown in Figure 7, has a length of 9.04 meters (356 in), consists of two arched frames, a deck and bracings and other properties as summarized in Table 11. For numerical validation, this pedestrian bridge is modeled in ABAQUS (2004) (see Figure 8). A total of 2,674 beam elements (B31) are used to model the bridge with eight longitudinal beams. From the modal analysis, the first three bending modeshapes of the fourth longitudinal beam are extracted and used in the DIM and IDIM (see Figure 9). The first three bending eigenfrequencies are 16.936, 24.310, and $33.499 \mathrm{~Hz}$.

Table 11. Properties for a pedestrian bridge

\begin{tabular}{cc}
\hline Properties & Values \\
\hline Length, $\mathrm{L}$ & $9.04 \mathrm{~m}(356 \mathrm{in})$ \\
Young's modulus, E & $2.0 \times 10^{5} \mathrm{MPa}\left(2.9 \times 10^{4} \mathrm{ksi}\right)$ \\
Density, $\rho$ & $10.13 \times 10^{3} \mathrm{~kg} / \mathrm{m}^{3}\left(0.29 \mathrm{lb} / \mathrm{in}^{3}\right)$ \\
Poisson's ratio, $v$ & 0.3 \\
\hline
\end{tabular}




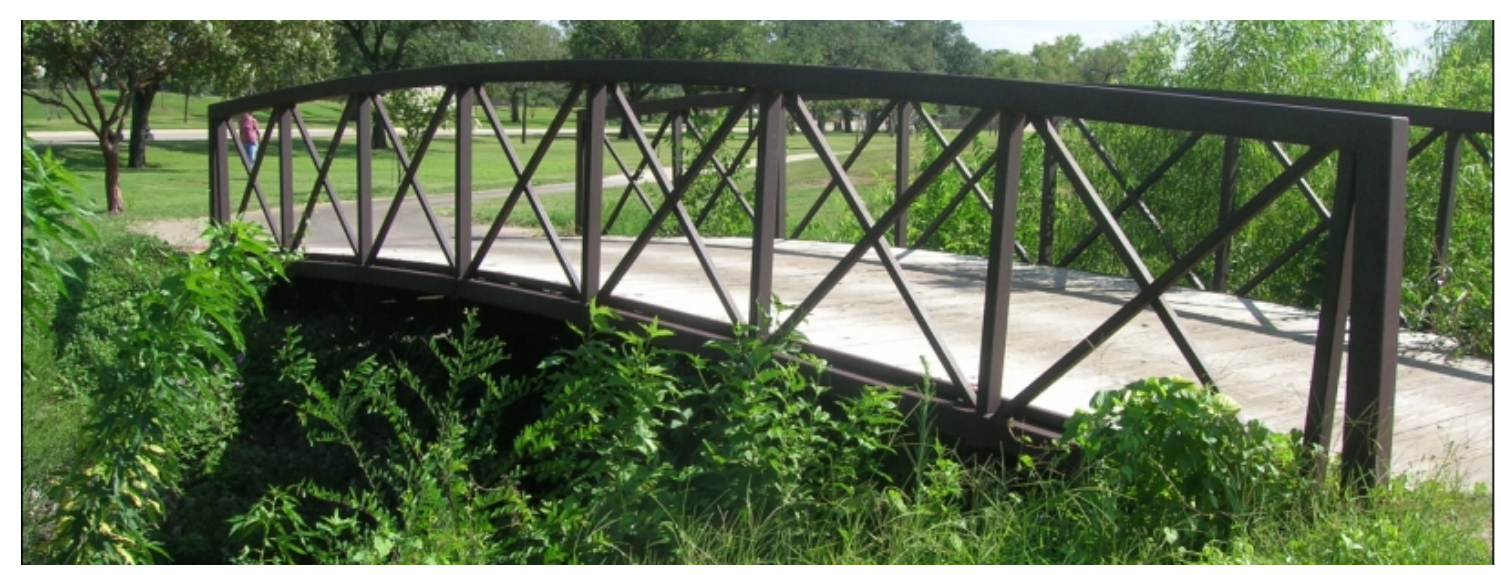

Figure 7. Pedestrian bridge in Texas A\&M Golf Course at Texas A\&M University, College Station, TX

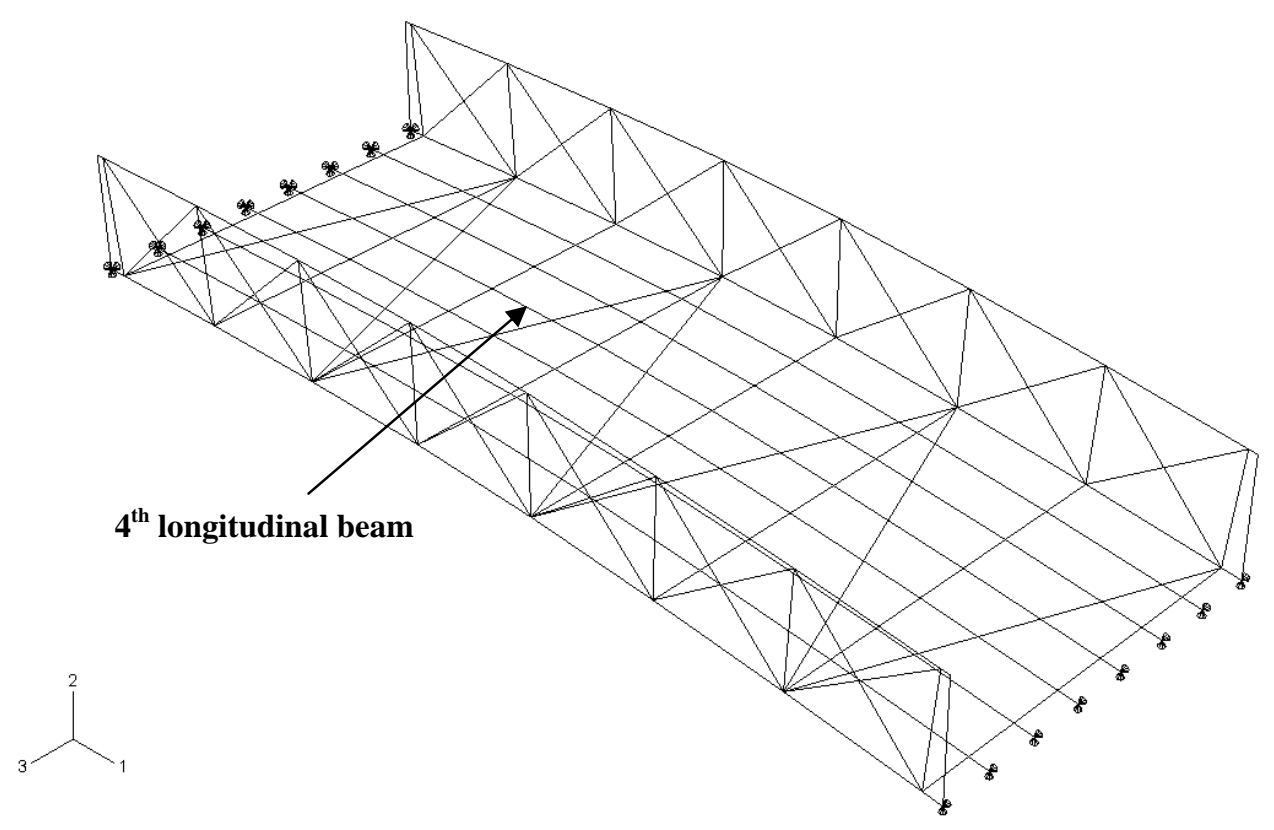

Figure 8. Pedestrian bridge generated in ABAQUS (2004)

We investigate ten damage cases analogous to those used for the previous numerical example. They are summarized in Table 12. The MAC, TMAC, CAC, and TCAC are calculated for the ten damage cases and expressed as four significant digits, as shown in Table 13. The MAC and TMAC of the ten damage cases are equal to one while the CAC and 
TCAC of those are less than one. It is certain that the CAC and TCAC are useful to show the existence of damage. Consequently, the modeshapes obtained from the undamaged and the damaged bridge can be also utilized for the damage detection process performed by the DIM and the IDIM.

Because the damage scenarios can not be detected accurately (i.e., $\Delta=0$ and e $=0$ ) by the two methods, $\Delta=0.006$ and $\mathrm{e}=0.1$ are used to determine the minimum $N_{r}$ for all damage cases (see Table 14). Smaller $N_{r}$ is required in the IDIM for all of the damage cases to achieve equivalent accuracy even with this less precise standard. Consequently, the IDIM also prove to be more economical than the DIM with the pedestrian bridge. The damage detection percentages for the pedestrian bridge are calculated by considering ten thousand damage detection models (i.e., $\left.n_{t}=10,000\right)$ with various $N_{r}$ and $N_{s}$. Those percentages for four damage cases among the ten cases are summarized in Tables 15 to 18 , again because the results for the rest of the cases are not significantly different. The findings from those tables for the bridge are even more compelling than those for the beam. In particular, the damage detection percentages for the IDIM are higher across all damage cases. 


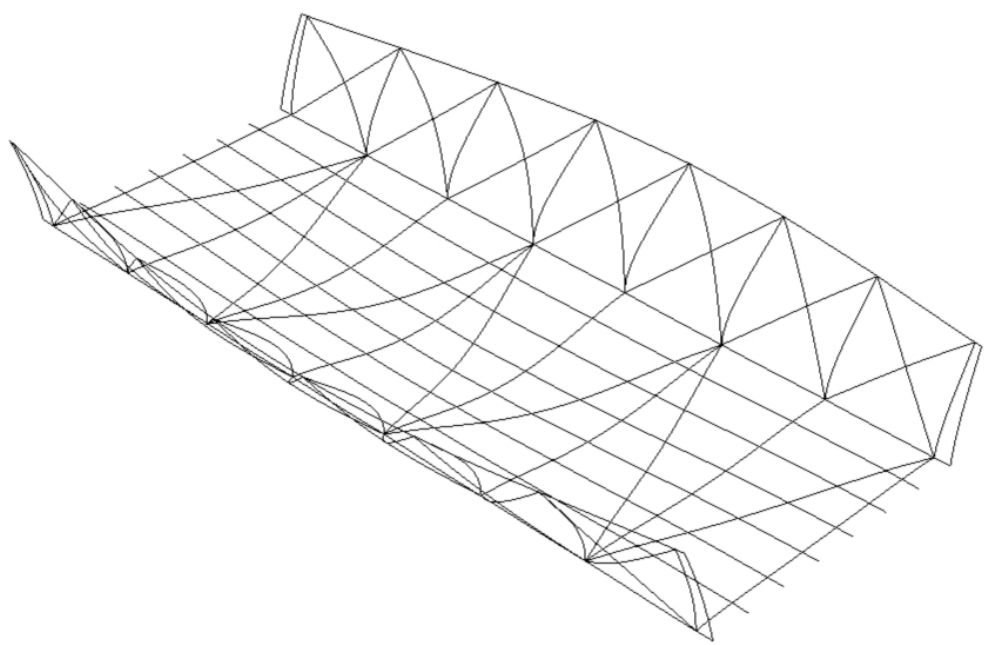

(a)

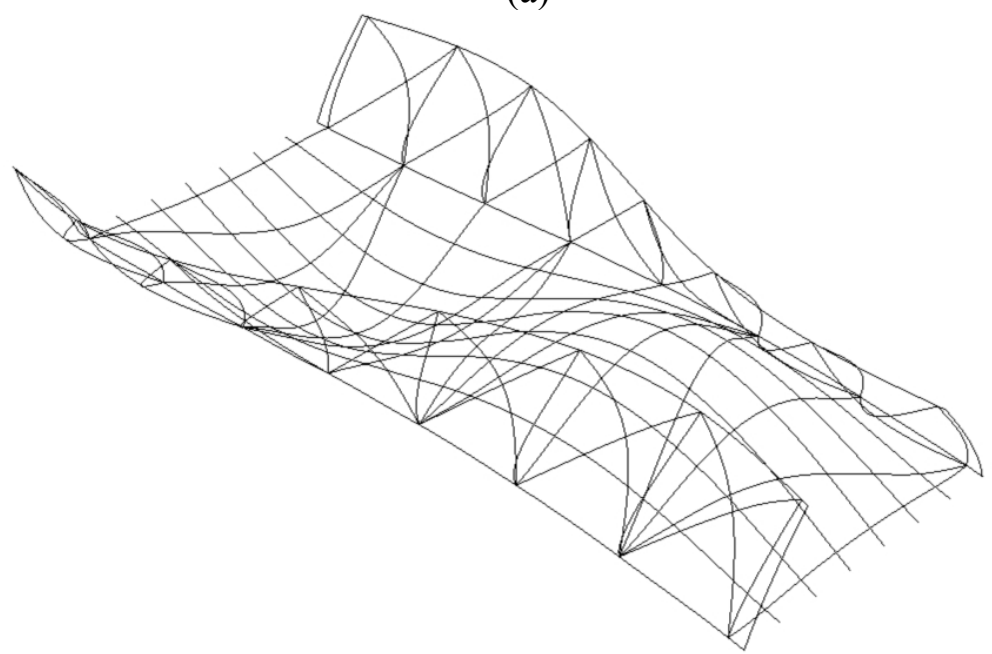

(b)

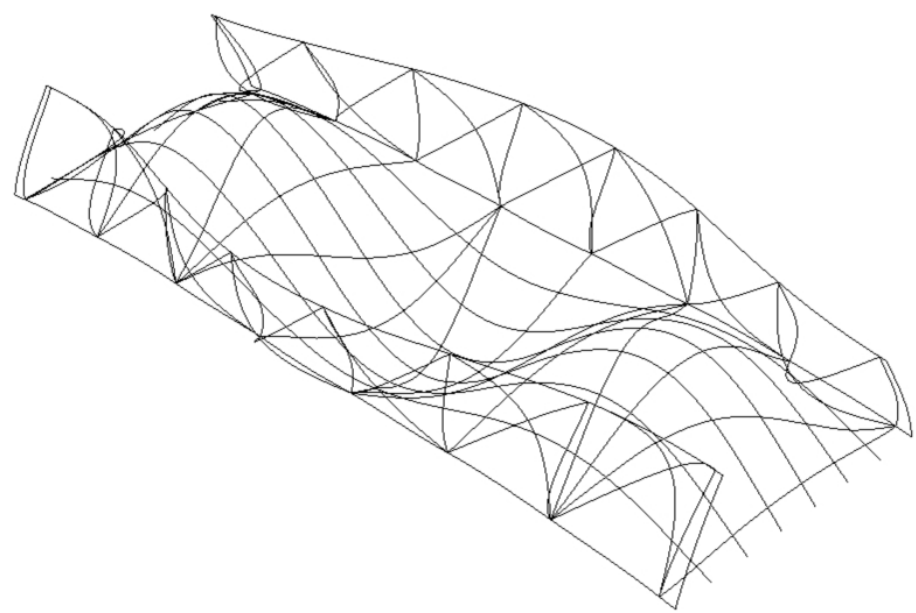

(c)

Figure 9. The first three bending modeshapes of the pedestrian bridge: (a) $1^{\text {st }}$ bending modeshapes, (b) $2^{\text {nd }}$ bending modeshapes, and (c) $3^{\text {rd }}$ bending modeshapes 
Table 12. Damage scenarios for a pedestrian bridge

\begin{tabular}{ccccc}
\hline \multirow{2}{*}{ Damage Case } & \multirow{2}{*}{ Damage size } & \multicolumn{2}{c}{ Location } & \multirow{2}{*}{ Severity $^{\dagger}$} \\
\cline { 3 - 4 } & & From & To & \\
\hline Undamaged & $0.000 \mathrm{~m}$ & - & - & - \\
1 & $0.078 \mathrm{~m}$ & $2.47 \mathrm{~m}$ & $2.55 \mathrm{~m}$ & -50 \\
2 & $0.156 \mathrm{~m}$ & $2.47 \mathrm{~m}$ & $2.63 \mathrm{~m}$ & -50 \\
3 & $0.311 \mathrm{~m}$ & $2.47 \mathrm{~m}$ & $2.78 \mathrm{~m}$ & -50 \\
4 & $0.078 \mathrm{~m}$ & $2.47 \mathrm{~m}$ & $2.55 \mathrm{~m}$ & -10 \\
5 & $0.078 \mathrm{~m}$ & $2.47 \mathrm{~m}$ & $2.55 \mathrm{~m}$ & -20 \\
6 & $0.078 \mathrm{~m}$ & $2.47 \mathrm{~m}$ & $2.55 \mathrm{~m}$ & -70 \\
7 & $0.078 \mathrm{~m}$ & $2.55 \mathrm{~m}$ & $2.63 \mathrm{~m}$ & -50 \\
8 & $0.078 \mathrm{~m}$ & $2.70 \mathrm{~m}$ & $2.78 \mathrm{~m}$ & -50 \\
9 & $0.078 \mathrm{~m}$ & $3.02 \mathrm{~m}$ & $3.09 \mathrm{~m}$ & -50 \\
10 & $0.078 \mathrm{~m}$ & $3.56 \mathrm{~m}$ & $3.64 \mathrm{~m}$ & -50 \\
\hline
\end{tabular}

Severity $(\%)=\left(\mathrm{E}^{\mathrm{d}}-\mathrm{E}\right) / \mathrm{E} \times 100$ where $\mathrm{E}$ and $\mathrm{E}^{\mathrm{d}}$ are the modulus of elasticity for the undamaged and damaged element, respectively.

Table 13. MAC, TMAC, CAC, and TCAC for the pedestrian bridge

\begin{tabular}{|c|c|c|c|c|c|c|c|c|}
\hline \multirow{2}{*}{$\begin{array}{c}\text { Damage } \\
\text { Case }\end{array}$} & \multicolumn{3}{|c|}{ MAC } & \multirow[b]{2}{*}{ TMAC } & \multicolumn{3}{|c|}{ CAC } & \multirow[b]{2}{*}{ TCAC } \\
\hline & $1^{\text {st }}$ mode & $\begin{array}{l}2^{\text {nd }} \\
\text { mode }\end{array}$ & $3^{\text {rd }}$ mode & & $1^{\text {st }}$ mode & $\begin{array}{c}2^{\text {nd }} \\
\text { mode }\end{array}$ & $\begin{array}{l}3^{\text {rd }} \\
\text { mode }\end{array}$ & \\
\hline 1 & 1.000 & 1.000 & 1.000 & 1.000 & 0.997 & 0.994 & 0.998 & 0.989 \\
\hline 2 & 1.000 & 1.000 & 1.000 & 1.000 & 0.995 & 0.988 & 0.996 & 0.979 \\
\hline 3 & 1.000 & 1.000 & 1.000 & 1.000 & 0.990 & 0.985 & 0.996 & 0.970 \\
\hline 4 & 1.000 & 1.000 & 1.000 & 1.000 & 0.842 & 0.881 & 0.933 & 0.692 \\
\hline 5 & 1.000 & 1.000 & 1.000 & 1.000 & 0.964 & 0.953 & 0.976 & 0.897 \\
\hline 6 & 1.000 & 1.000 & 1.000 & 1.000 & 0.999 & 0.999 & 1.000 & 0.998 \\
\hline 7 & 1.000 & 1.000 & 1.000 & 1.000 & 0.997 & 0.994 & 0.998 & 0.990 \\
\hline 8 & 1.000 & 1.000 & 1.000 & 1.000 & 0.996 & 0.994 & 0.999 & 0.988 \\
\hline 9 & 1.000 & 1.000 & 1.000 & 1.000 & 0.992 & 0.995 & 0.999 & 0.986 \\
\hline 10 & 1.000 & 1.000 & 1.000 & 1.000 & 0.994 & 0.999 & 0.996 & 0.988 \\
\hline
\end{tabular}


Table 14. The minimum number of recording points $\left(N_{r}\right)$ and the minimum number of spline points $\left(N_{s}\right)$ to detect damage with $\Delta=0.006$ and $\mathrm{e}=0.1$

\begin{tabular}{|c|c|c|}
\hline \multirow{2}{*}{ Damage Case } & \multicolumn{2}{|c|}{ Minimum $N_{r}\left(N_{s}\right)$} \\
\hline & DIM & IDIM \\
\hline 1 & N/A & $15(107)$ \\
\hline 2 & $65(103)$ & $11(54)$ \\
\hline 3 & $24(54)$ & $11(29)$ \\
\hline 4 & $\mathrm{~N} / \mathrm{A}$ & $31(108)$ \\
\hline 5 & $\mathrm{~N} / \mathrm{A}$ & $42(107)$ \\
\hline 6 & N/A & $15(104)$ \\
\hline 7 & N/A & $11(106)$ \\
\hline 8 & N/A & $30(107)$ \\
\hline 9 & N/A & $18(108)$ \\
\hline 10 & $\mathrm{~N} / \mathrm{A}$ & $8(103)$ \\
\hline
\end{tabular}

N/A: Damage can not be detected.

Table 15. Damage detection percentage Case 1 (unit is \%)

\begin{tabular}{ccccccccccccc}
\hline \multirow{2}{*}{$\Delta$} & & \multicolumn{10}{c}{$\mathrm{e}$} \\
\cline { 3 - 13 } & & 0 & 0.1 & 0.2 & 0.3 & 0.4 & 0.5 & 1.0 & 1.5 & 2.0 & 2.5 & 3.0 \\
\hline \multirow{2}{*}{0} & DIM & 0.0 & 0.0 & 0.0 & 0.0 & 0.0 & 0.0 & 0.0 & 0.0 & 0.0 & 0.0 & 0.0 \\
& IDIM & 0.0 & 0.0 & 0.0 & 0.0 & 0.0 & 0.0 & 0.0 & 0.0 & 0.0 & 0.0 & 0.0 \\
\hline \multirow{2}{*}{0.01} & DIM & 0.0 & 0.0 & 0.0 & 0.0 & 0.0 & 0.0 & 3.4 & 26.3 & 52.2 & 62.2 & 67.3 \\
& IDIM & 0.0 & 4.5 & 7.9 & 13.0 & 17.3 & 21.9 & 37.5 & 49.1 & 59.6 & 68.7 & 76.1 \\
\hline \multirow{2}{*}{0.02} & DIM & 0.0 & 0.0 & 0.0 & 0.0 & 0.0 & 0.0 & 3.4 & 26.3 & 52.2 & 62.2 & 67.3 \\
& IDIM & 0.0 & 4.5 & 7.9 & 13.0 & 17.3 & 21.9 & 37.5 & 49.1 & 59.6 & 68.7 & 76.1 \\
\hline
\end{tabular}

Table 16. Damage detection percentage Case 2 (unit is \%)

\begin{tabular}{ccccccccccccc}
\hline \multirow{2}{*}{$\Delta$} & & \multicolumn{10}{c}{$\mathrm{c}$} \\
\cline { 3 - 14 } & & 0 & 0.1 & 0.2 & 0.3 & 0.4 & 0.5 & 1.0 & 1.5 & 2.0 & 2.5 & 3.0 \\
\hline \multirow{2}{*}{0} & DIM & 0.0 & 0.0 & 0.0 & 0.0 & 0.0 & 0.0 & 0.0 & 0.0 & 0.0 & 0.0 & 0.0 \\
& IDIM & 0.0 & 0.0 & 0.0 & 0.0 & 0.0 & 0.0 & 0.0 & 0.0 & 0.0 & 0.0 & 0.0 \\
\hline \multirow{2}{*}{0.01} & DIM & 0.0 & 0.0 & 1.3 & 11.2 & 23.6 & 36.2 & 64.0 & 77.0 & 83.9 & 85.9 & 87.0 \\
& IDIM & 0.0 & 14.3 & 27.1 & 39.1 & 47.6 & 53.6 & 70.7 & 76.2 & 83.1 & 90.0 & 92.4 \\
\hline \multirow{2}{*}{0.02} & DIM & 0.0 & 0.0 & 1.3 & 11.2 & 23.6 & 36.2 & 64.0 & 77.0 & 83.9 & 85.9 & 87.0 \\
& IDIM & 0.0 & 14.3 & 27.1 & 39.1 & 47.6 & 53.6 & 70.7 & 76.2 & 83.1 & 90.0 & 92.4 \\
\hline
\end{tabular}


Table 17. Damage detection percentage Case 5 (unit is \%)

\begin{tabular}{ccccccccccccc}
\hline \multirow{2}{*}{$\Delta$} & & \multicolumn{10}{c}{$\mathrm{c}$} \\
\cline { 3 - 13 } & & 0 & 0.1 & 0.2 & 0.3 & 0.4 & 0.5 & 1.0 & 1.5 & 2.0 & 2.5 & 3.0 \\
\hline \multirow{2}{*}{0} & DIM & 0.0 & 0.0 & 0.0 & 0.0 & 0.0 & 0.0 & 0.0 & 0.0 & 0.0 & 0.0 & 0.0 \\
& IDIM & 0.0 & 0.0 & 0.0 & 0.0 & 0.0 & 0.0 & 0.0 & 0.0 & 0.0 & 0.0 & 0.0 \\
\hline \multirow{2}{*}{0.01} & DIM & 0.0 & 0.0 & 0.0 & 0.0 & 0.0 & 0.0 & 2.1 & 19.2 & 49.2 & 61.7 & 67.2 \\
& IDIM & 0.0 & 4.0 & 7.2 & 11.5 & 15.5 & 18.9 & 36.2 & 49.7 & 56.6 & 63.8 & 72.3 \\
\hline \multirow{2}{*}{0.02} & DIM & 0.0 & 0.0 & 0.0 & 0.0 & 0.0 & 0.0 & 2.1 & 19.2 & 49.2 & 61.7 & 67.2 \\
& IDIM & 0.0 & 4.0 & 7.2 & 11.5 & 15.5 & 18.9 & 36.2 & 49.7 & 56.6 & 63.8 & 72.3 \\
\hline
\end{tabular}

Table 18. Damage detection percentage Case 8 (unit is \%)

\begin{tabular}{ccccccccccccc}
\hline \multirow{2}{*}{$\Delta$} & & \multicolumn{10}{c}{$\mathrm{c}$} \\
\cline { 3 - 14 } & & 0 & 0.1 & 0.2 & 0.3 & 0.4 & 0.5 & 1.0 & 1.5 & 2.0 & 2.5 & 3.0 \\
\hline \multirow{2}{*}{0} & DIM & 0.0 & 0.0 & 0.0 & 0.0 & 0.0 & 0.0 & 0.0 & 0.0 & 0.0 & 0.0 & 0.0 \\
& IDIM & 0.0 & 0.0 & 0.0 & 0.0 & 0.0 & 0.0 & 0.0 & 0.0 & 0.0 & 0.0 & 0.0 \\
\hline \multirow{2}{*}{0.01} & DIM & 0.0 & 0.0 & 0.0 & 0.0 & 0.0 & 0.0 & 3.9 & 24.8 & 48.7 & 61.3 & 66.7 \\
& IDIM & 0.0 & 3.2 & 5.8 & 9.0 & 11.7 & 14.2 & 29.8 & 42.4 & 52.0 & 61.5 & 68.6 \\
\multirow{2}{*}{0.02} & DIM & 0.0 & 0.0 & 0.0 & 0.0 & 0.0 & 0.0 & 3.9 & 24.8 & 48.7 & 61.3 & 66.7 \\
& IDIM & 0.0 & 3.2 & 5.8 & 9.0 & 11.7 & 14.2 & 29.8 & 42.4 & 52.0 & 61.5 & 68.6 \\
\hline
\end{tabular}




\section{VALIDATION USING EXPERIMENTAL DATA}

The proposed method is validated using experimental data with two real structures: a simply supported beam and a pedestrian bridge on the Texas A\&M golf course, at College Station, TX. The test data are obtained by a wireless monitoring system. Because a structure gradually deteriorates after its construction, the baseline of the beam and bridge (i.e., modeshapes for an undamaged structure) are obtained from the current structure.

\subsection{Simply Supported Beam}

The geometric and material properties used in Section 4.1 are obtained from the simply supported beam operated here. The accelerations of the simply supported beam in a laboratory are measured from ten recording points. The ten recording points are located with equal spacing ( 0.40 meters $(15.6 \mathrm{in}))$ on the beam. To simulate a mass damage instead of a stiffness damage, we add a weight at specific locations: a steel plate with the weight of $0.6 \mathrm{~kg}$ ( $1.326 \mathrm{lb}$ or $2.11 \%$ of the total mass of the beam) between 0.787 meters ( $31 \mathrm{in})$ and 0.889 meters ( 35 in) from the left end of the beam.

The Wireless Sensor Network (WSN) monitoring system developed by Reyer (2007), is used to measure the response. The MICA 2 mote, operated in the WSN, can measure a variety of responses such as strain, acceleration, temperature, and light using sensor boards. For this study, an MTS310 sensor board operated with the MICA 2 measures accelerations. An ADXL202JE, a two axis accelerometer, is installed on the sensor board. Because the ADXL202JE measures a voltage not acceleration, the conversion is necessary. For one axis, the voltage for $-\mathrm{g}$ and the voltage for $+\mathrm{g}$ can be obtained from one position and the opposite position of the former. The acceleration is converted with the voltages for $\pm \mathrm{g}$. The range of accelerations measured by the ADXL202JE is $\pm 2 \mathrm{~g}$. The MIB510 base station collects data from each wireless mote and transmits it to a computer. As shown in Figure 10, the first 
three modeshapes from the measured accelerations are extracted by the Time Domain Decomposition (TDD) method, proposed by Kim et al. (2005). For the limited number of MICA 2 motes, three measuring sets (Set I, II, and III) and one reference point are used (see Figure 11). The modeshapes obtained from the three sets are recalculated to match the reference point of each set. Note that the impact points in the three sets are identical. Figure 12 (a) shows a test set-up for the Set I with five MICA 2 motes, the base station, and a laptop computer.

The obtained modeshapes are then validated by the CAC and TCAC because it is found that the CAC and TCAC are useful to indicate the presence of damage in numerical validation (Section 4). Table 19 shows the two correlation values between (a) analytical modeshapes for the undamaged beam and experimental modeshapes for the undamaged beam; (b) experimental modeshapes for the undamaged beam and experimental modeshapes for the beam with the added mass; (c) analytical modeshapes for the beam with the added mass and experimental modeshapes for the beam with the added mass; and (d) analytical modeshapes for the undamaged beam and experimental modeshapes for the beam with the added mass.

The low CAC and TCAC in (a) and (c) occurs because the boundary condition for the tests cannot be correctly simulated. However, the CAC and TCAC of (b) are similar to those of (d), less than one, and enough to demonstrate the existence of damage. Consequently, it can be concluded that the modeshapes experimentally obtained in the simply supported beam can be applied for the damage detection process. 


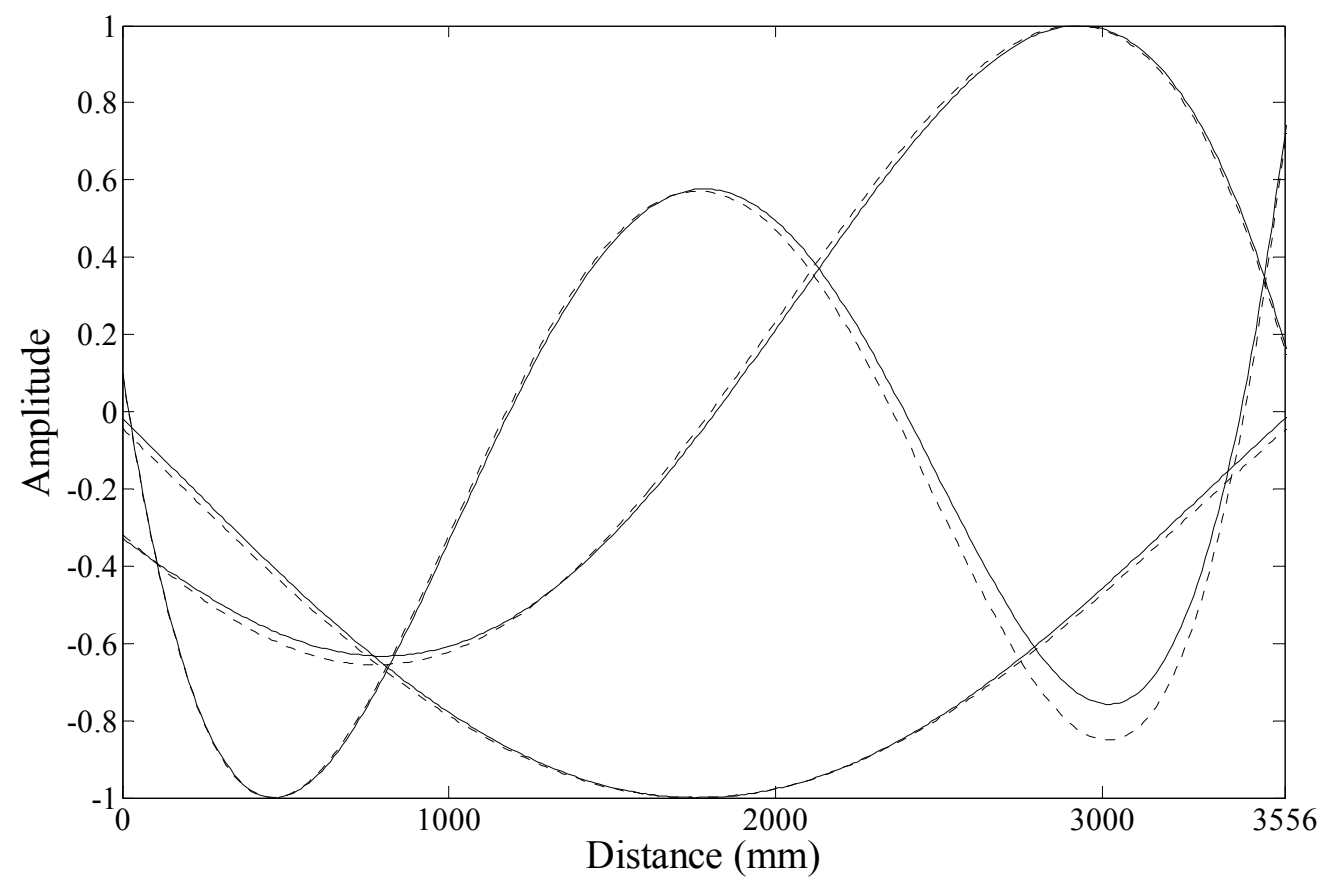

Figure 10. The first three modeshapes for the simply supported beam (solid lines indicate the undamaged and dashed lines indicate the damaged)

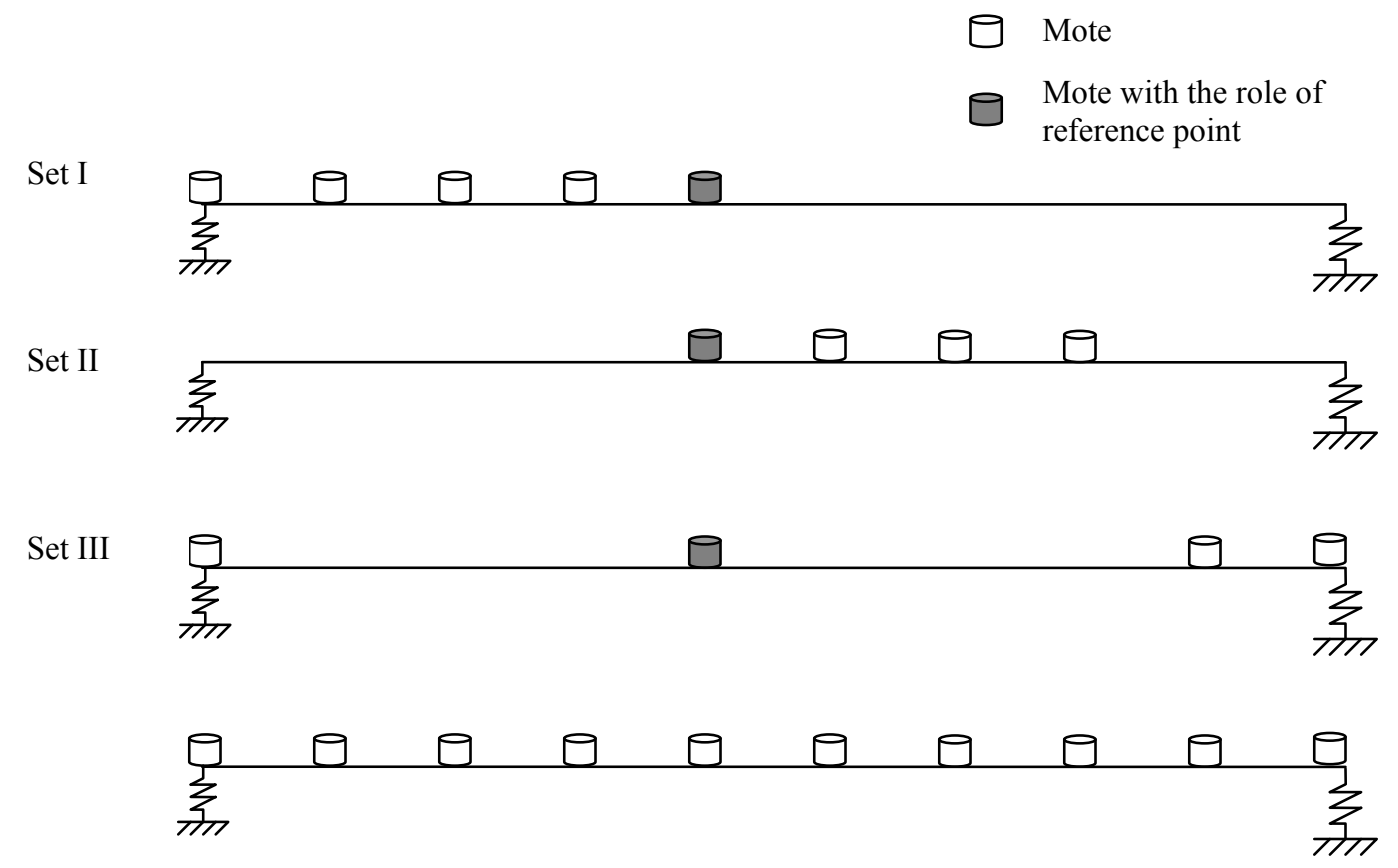

Figure 11. Three measuring sets and a reference point for the simply supported beam 

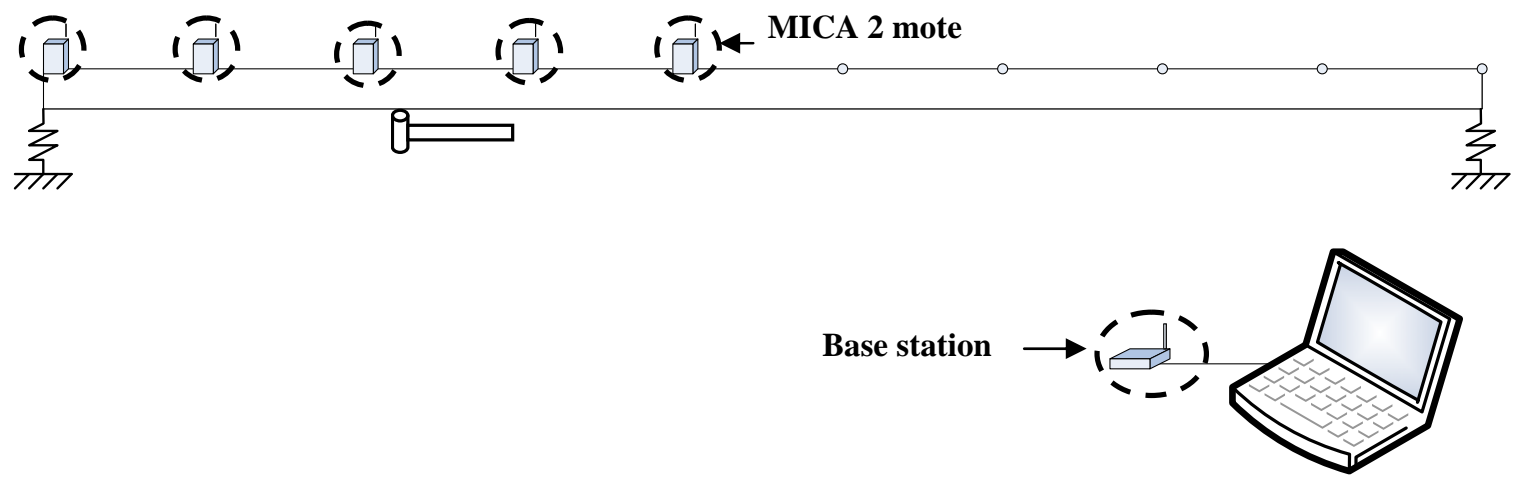

(a)

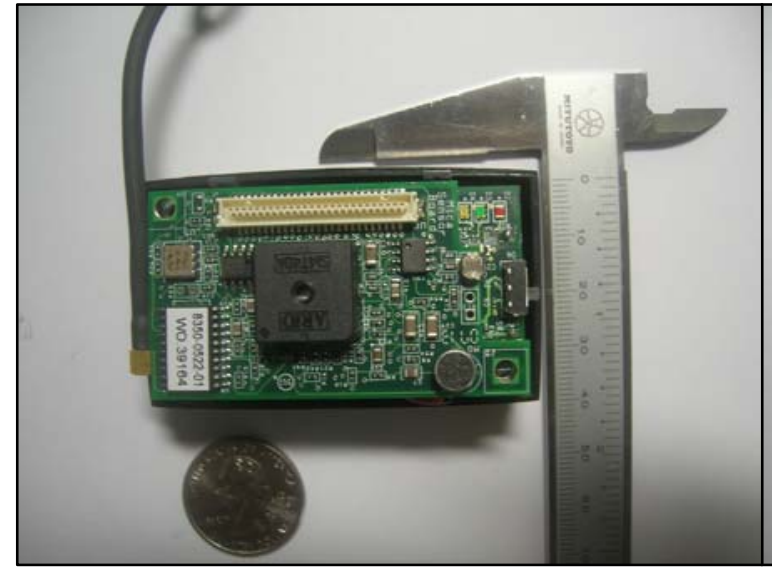

(b)

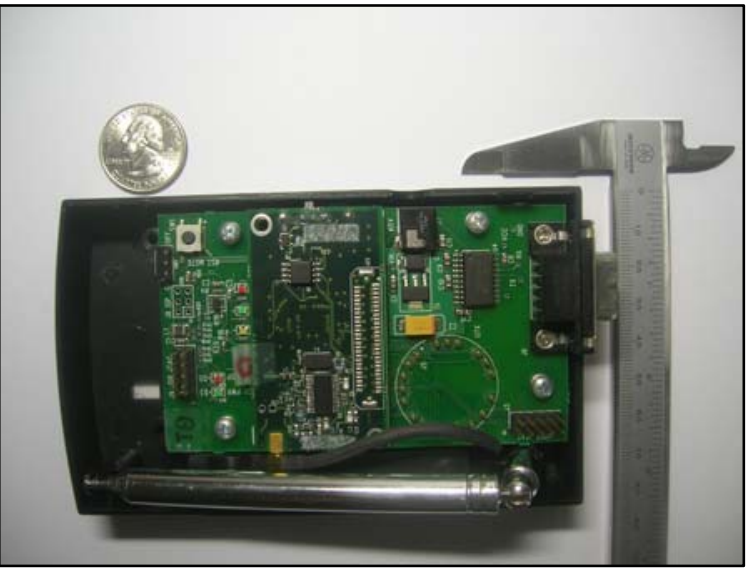

(c)

Figure 12. (a) Test set-up for a simply supported beam for including MICA 2 motes, base station, and lap-top computer, (b) MICA 2 mote, and (c) base station

Table 19. CAC, and TCAC between two modeshapes

\begin{tabular}{ccccc}
\hline & \multicolumn{2}{c}{ CAC } & \multirow{2}{*}{ TCAC } \\
\cline { 2 - 4 } & $1^{\text {st }}$ mode & $2^{\text {nd }}$ mode & $3^{\text {rd }}$ mode & \\
\hline (a) & 0.967 & 0.397 & 0.417 & 0.160 \\
(b) & 1.000 & 0.997 & 1.000 & 0.996 \\
(c) & 0.970 & 0.423 & 0.413 & 0.169 \\
(d) & 1.000 & 1.000 & 1.000 & 0.999 \\
\hline
\end{tabular}

(a) Analytical modeshapes for the undamaged beam and experimental modeshapes for the undamaged beam

(b) Experimental modeshapes for the undamaged beam and experimental modeshapes for the beam with the added mass

(c) Analytical modeshapes for the beam with the added mass and experimental modeshapes for the beam with the added mass

(d) Analytical modeshapes for the undamaged beam and analytical modeshapes for the beam with the added mass 
The average of the e and $\Delta$ are summarized in Table 20 and two representative damage detection results are illustrated in Figures 13 and 14. From Table 20, we find that the averages of $\Delta$ (the accuracy of pinpointing the location of damage) for the current DIM are slightly smaller than those of the proposed IDIM, but the differences of the averages are less than 0.008 (only $0.8 \%$ of the length of the beam), which is negligible. However, the averages of the e for the proposed IDIM are around -3 while those of the current DIM are around -5 . That means that predicted damage size is six times larger than the actual damage size according to DIM but only 4 times larger according to the IDIM. Therefore, the proposed IDIM provides a less extreme over prediction of damage size.

Table 20. Average of e and $\Delta$ for a simply supported beam

\begin{tabular}{cccccccc}
\hline & & \multicolumn{7}{c}{ Range of $N_{s}$} \\
\cline { 3 - 8 } & & $10-100$ & $101-200$ & $201-300$ & $301-400$ & $401-500$ & $501-1000$ \\
\hline \multirow{2}{*}{ Average of $\Delta$} & DIM & 0.037 & 0.037 & 0.037 & 0.037 & 0.037 & 0.037 \\
& IDIM & 0.042 & 0.045 & 0.045 & 0.045 & 0.045 & 0.045 \\
\hline \multirow{2}{*}{ Average of e } & DIM & -4.88 & -4.89 & -4.89 & -4.89 & -4.89 & -4.89 \\
& IDIM & -2.99 & -2.54 & -2.48 & -2.46 & -2.45 & -2.43 \\
\hline
\end{tabular}




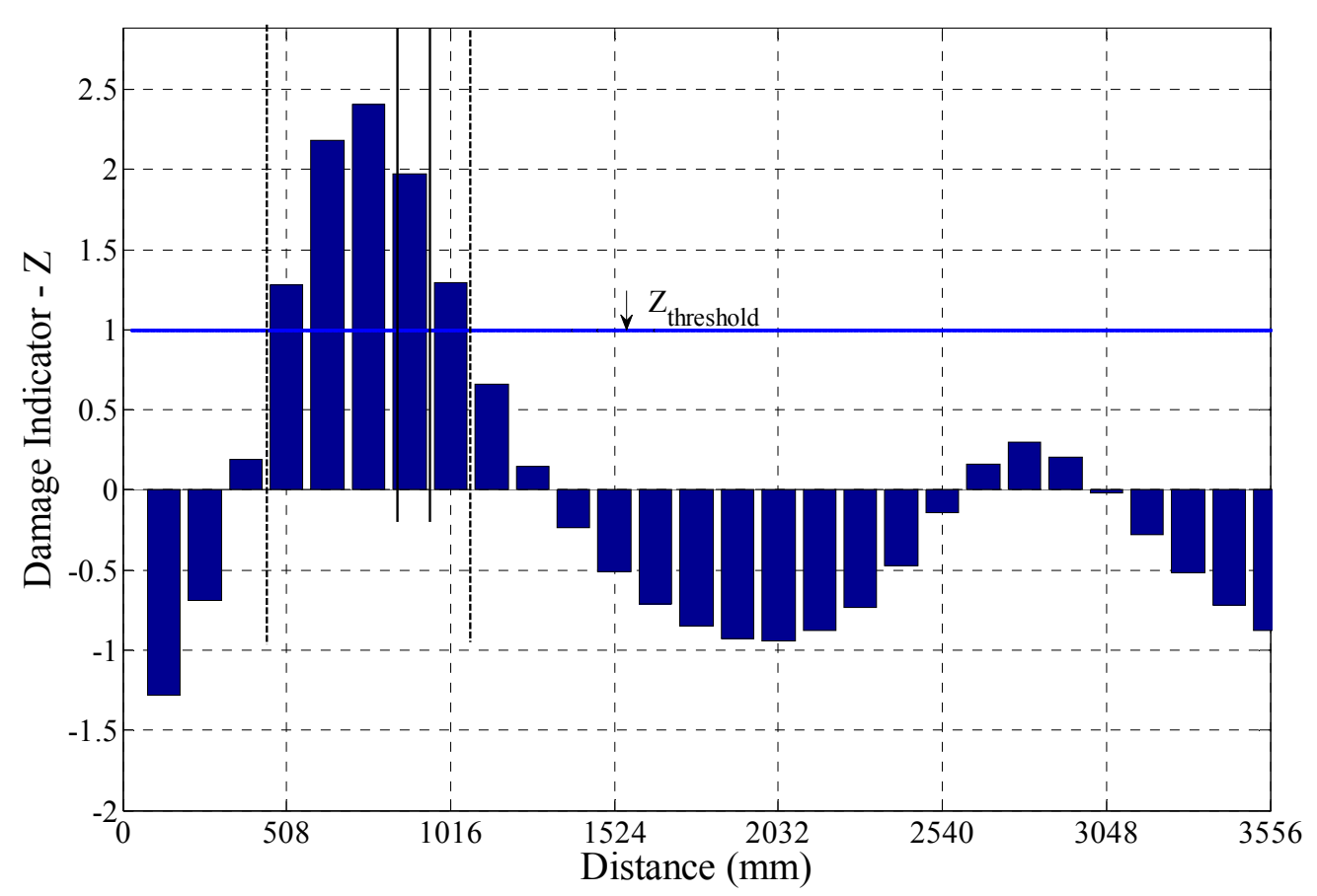

(a)

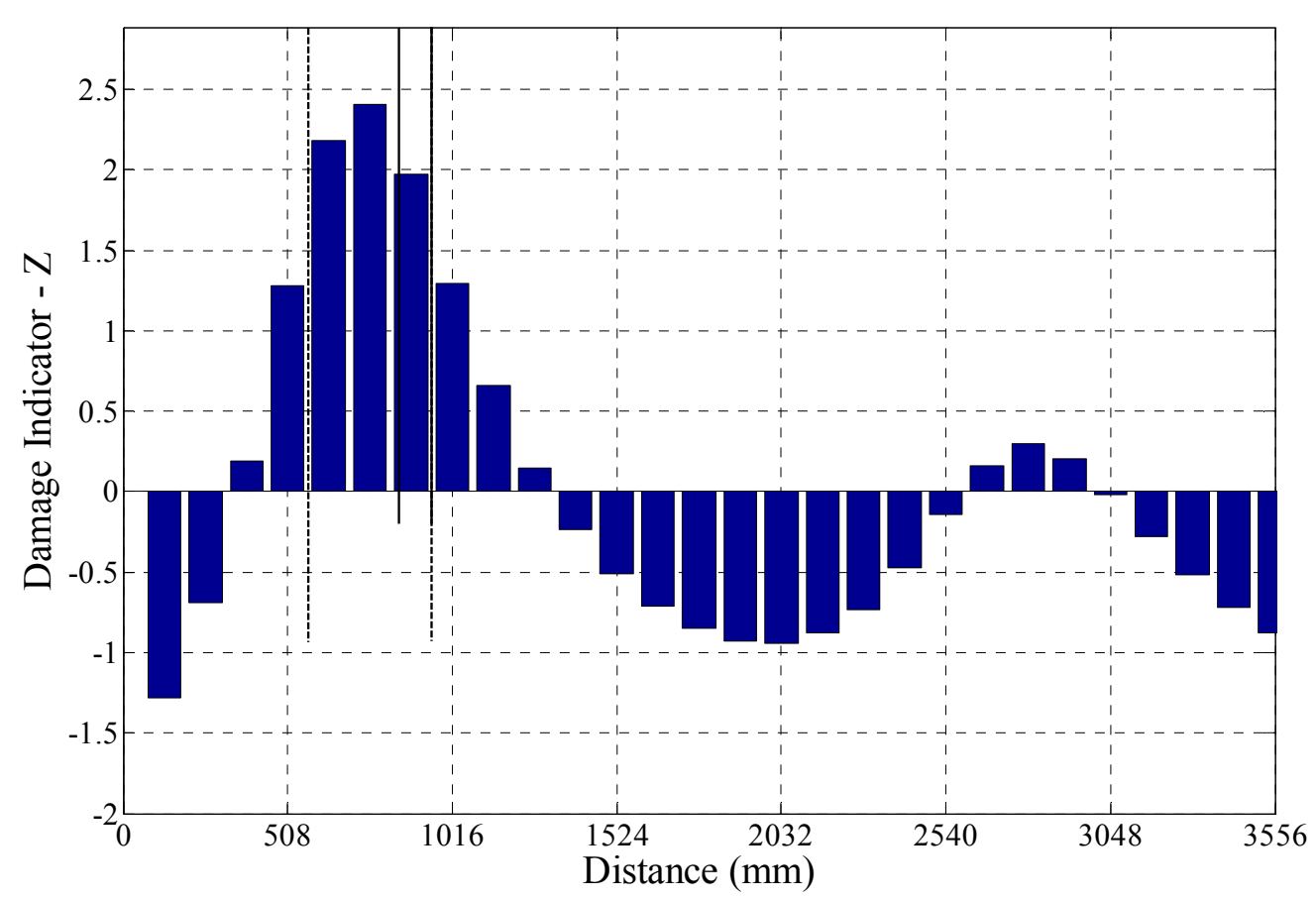

(b)

Figure 13. Damage prediction with 29 spline points in a simply supported beam using (a) the current DIM and (b) the proposed IDIM (solid lines indicate actual damage and dashed lines indicate predicted damage) 


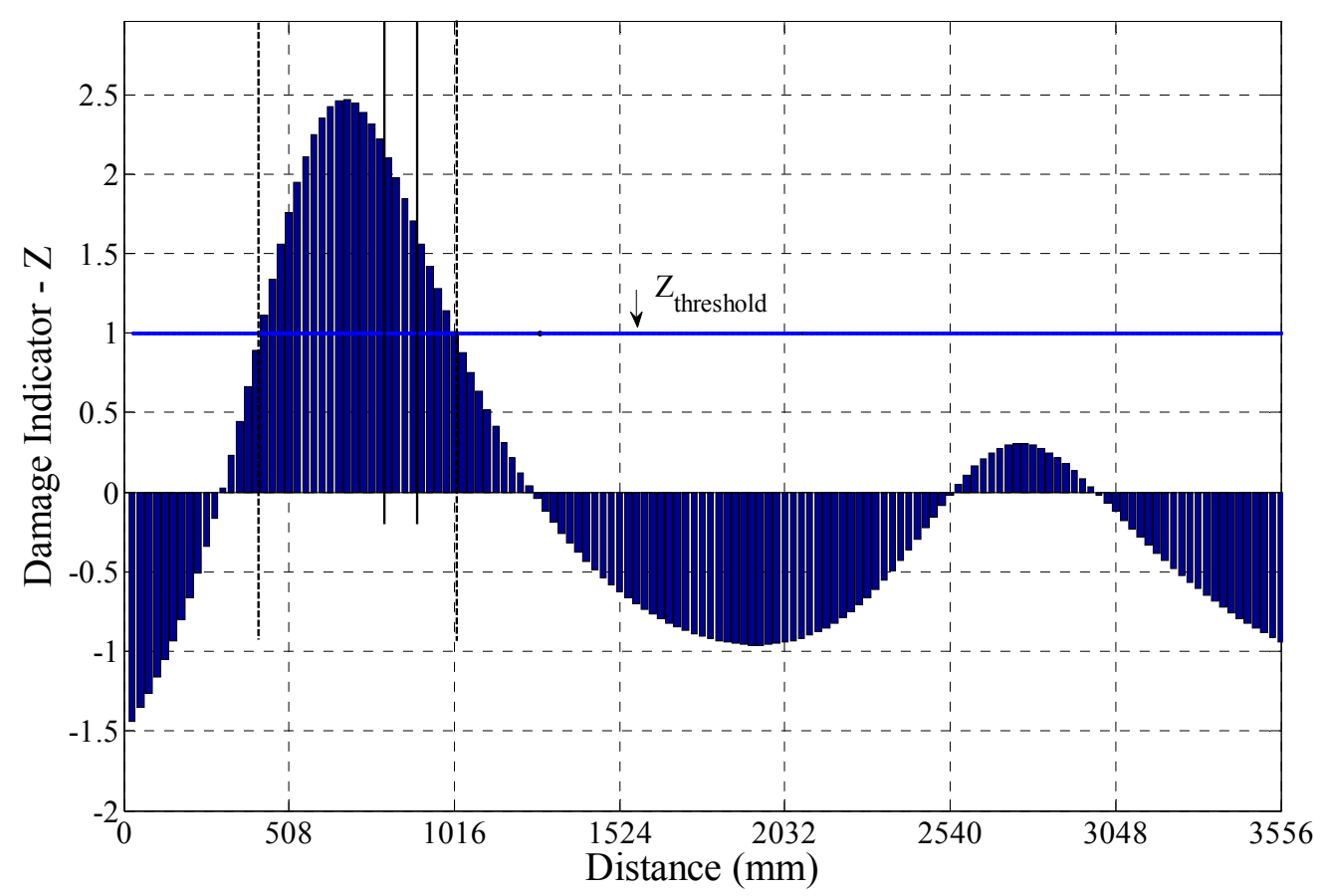

(a)

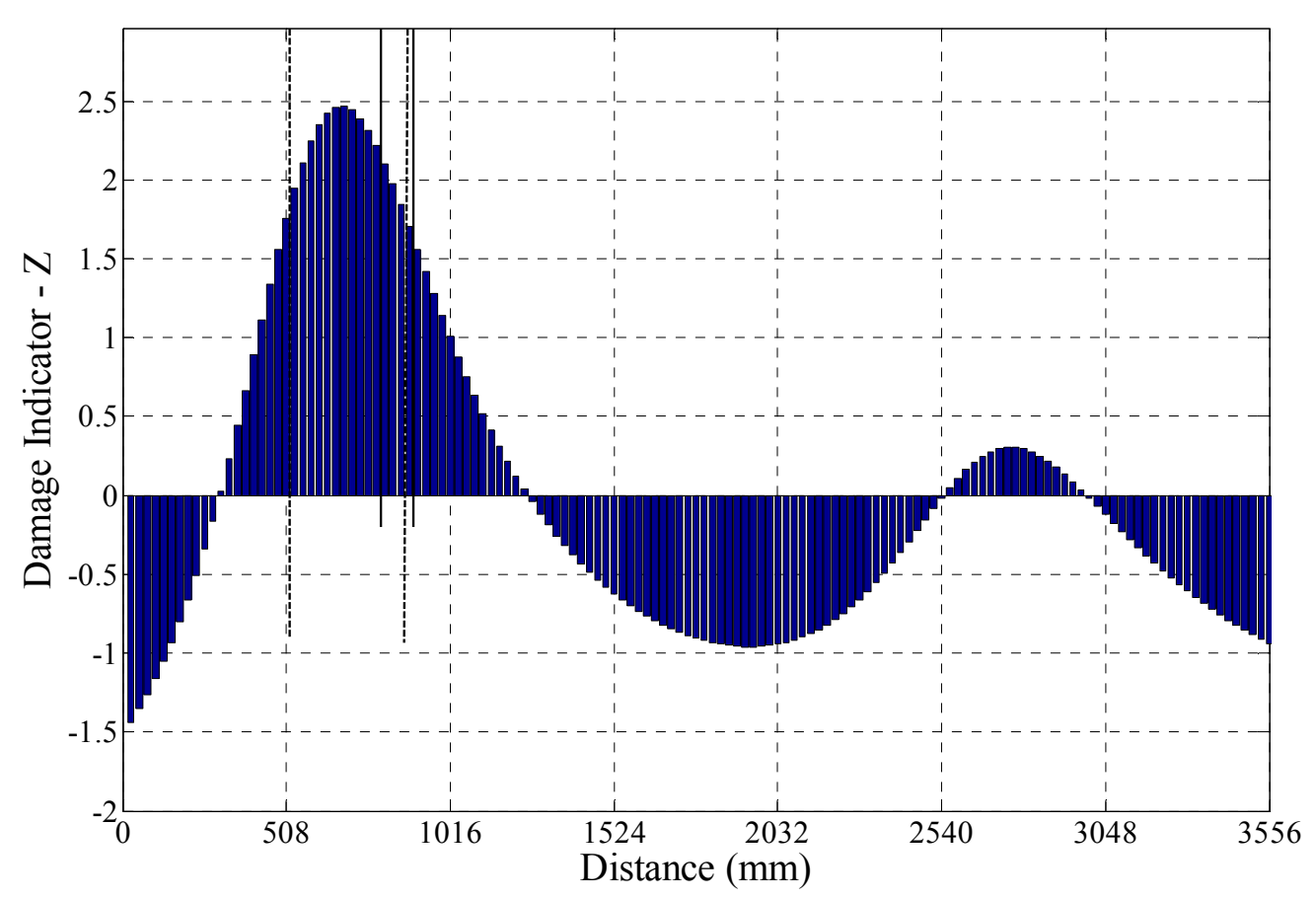

(b)

Figure 14. Damage prediction with 141 spline points in a simply supported beam using (a) the current DIM and (b) the proposed IDIM (solid lines indicate actual damage and dashed lines indicate predicted damage) 


\subsection{Pedestrian Bridge}

The geometric and material properties used in Section 4.2 are obtained from the pedestrian bridge operated here. The accelerations of the pedestrian bridge are measured from nine recording points. One point is located on the center of the $4^{\text {th }}$ longitudinal beam of the bridge and eight other points are equally spaced (1.29 meters $\left(50.79\right.$ in) apart) on the $4^{\text {th }}$ longitudinal beam of the bridge. To simulate a mass damage instead of a stiffness damage, three concrete blocks ( $81.66 \mathrm{~kg}=180 \mathrm{lbs}$ or $2.46 \%$ of the total mass of the bridge) are added between 2.778 meters and 3.277 meters from one end of the bridge. The concrete blocks are located on the flat wood deck, as shown in Figure 15. The first three modeshapes are obtained by the TDD, as shown in Figure 16. Because of the limited number of sensors, two measuring sets (Set A and B) and one reference point are also operated (see Figure 17). The modeshapes are also validated by the CAC and TCAC. Table 21 shows the two correlations values. The CAC and TCAC are far from one in (a) and (c). However, the CAC and TCAC of (b) are similar to those of (d), less than one, and enough to point out that there is damage. Consequently, it can be concluded that the modeshapes experimentally obtained in the pedestrian bridge can be used for the damage detection process.

The average of the e and $\Delta$ for the pedestrian bridge are summarized in Table 22 and two representative damage prediction results are illustrated in Figures 18 and 19. From Table 22, we find that the averages of $\Delta$ for the current DIM are slightly smaller than those of the proposed IDIM, but the differences of the averages are less than 0.017 (only $1.7 \%$ of the bridge length), again negligible. However, the averages of e for the proposed IDIM are about -0.5 with only one being around -1 , while those of the current DIM are all about -2 . The Error value of -2 means that predicted damage size is three times larger than the actual damage size according to the DIM but only one to two times larger according to the IDIM. 
Again, this pedestrian bridge case shows that the proposed IDIM can predict damage size more accurately.

Table 21. MAC, TMAC, CAC, and TCAC between two modeshapes

\begin{tabular}{ccccc}
\hline & \multicolumn{3}{c}{ CAC } & \multirow{2}{*}{ TCAC } \\
\cline { 2 - 3 } & $1^{\text {st }}$ mode & $2^{\text {nd }}$ mode & $3^{\text {rd }}$ mode & \\
\hline (a) & 0.614 & 0.456 & 0.577 & 0.162 \\
(b) & 0.770 & 1.000 & 0.971 & 0.748 \\
(c) & 0.655 & 0.433 & 0.541 & 0.154 \\
(d) & 0.819 & 0.997 & 1.000 & 0.816 \\
\hline
\end{tabular}

(a) Analytical modeshapes for the undamaged beam and experimental modeshapes for the undamaged beam

(b) Experimental modeshapes for the undamaged beam and experimental modeshapes for the beam with the added mass

(c) Analytical modeshapes for the beam with the added mass and experimental modeshapes for the beam with the added mass

(d) Analytical modeshapes for the undamaged beam and analytical modeshapes for the beam with the added mass

Table 22. Average of e and $\Delta$ for a pedestrian bridge

\begin{tabular}{cccccccc}
\hline & & \multicolumn{7}{c}{ Range of $N_{s}$} \\
\cline { 3 - 8 } & & $10-100$ & $101-200$ & $201-300$ & $301-400$ & $401-500$ & $501-1000$ \\
\hline \multirow{2}{*}{ Average of $\Delta$} & DIM & -0.001 & -0.002 & -0.002 & -0.002 & -0.002 & -0.002 \\
& IDIM & 0.012 & 0.015 & 0.015 & 0.015 & 0.015 & 0.015 \\
\hline \multirow{2}{*}{ Average of e } & DIM & -2.27 & -2.25 & -2.25 & -2.25 & -2.25 & -2.25 \\
& IDIM & -0.92 & -0.50 & -0.47 & -0.46 & -0.45 & -0.44 \\
\hline
\end{tabular}




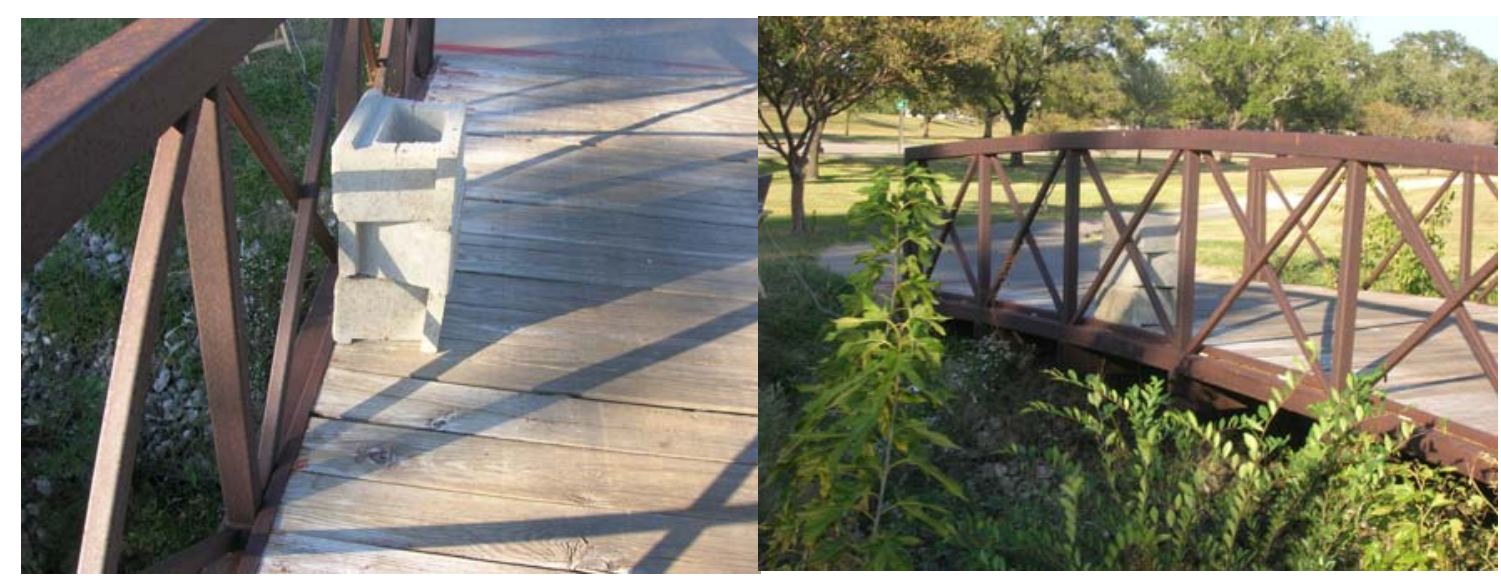

Figure 15. Added concrete blocks on the pedestrian bridge

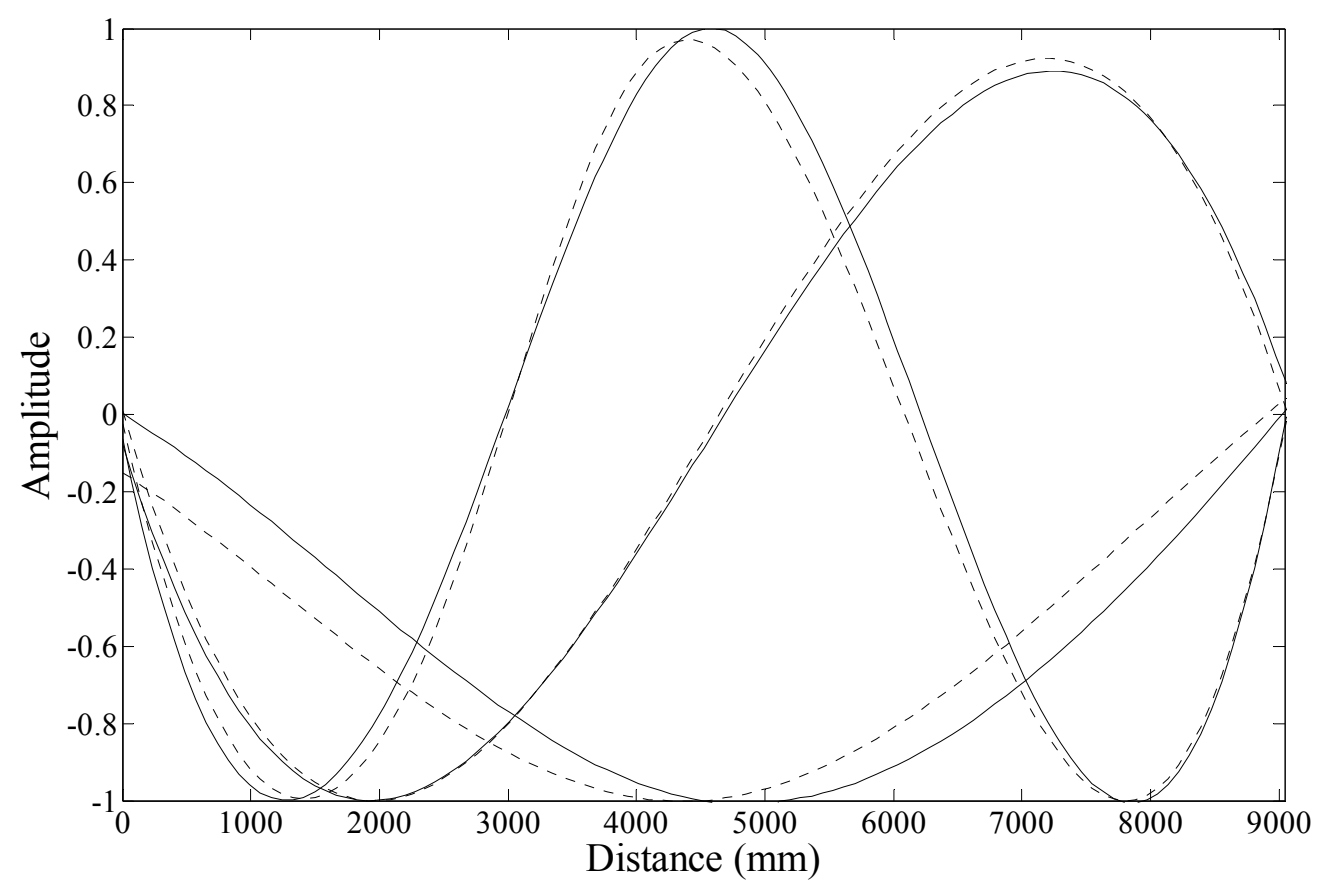

Figure 16. The first three modeshapes for the pedestrian bridge (solid lines indicate the undamaged and dashed lines indicate the damaged) 


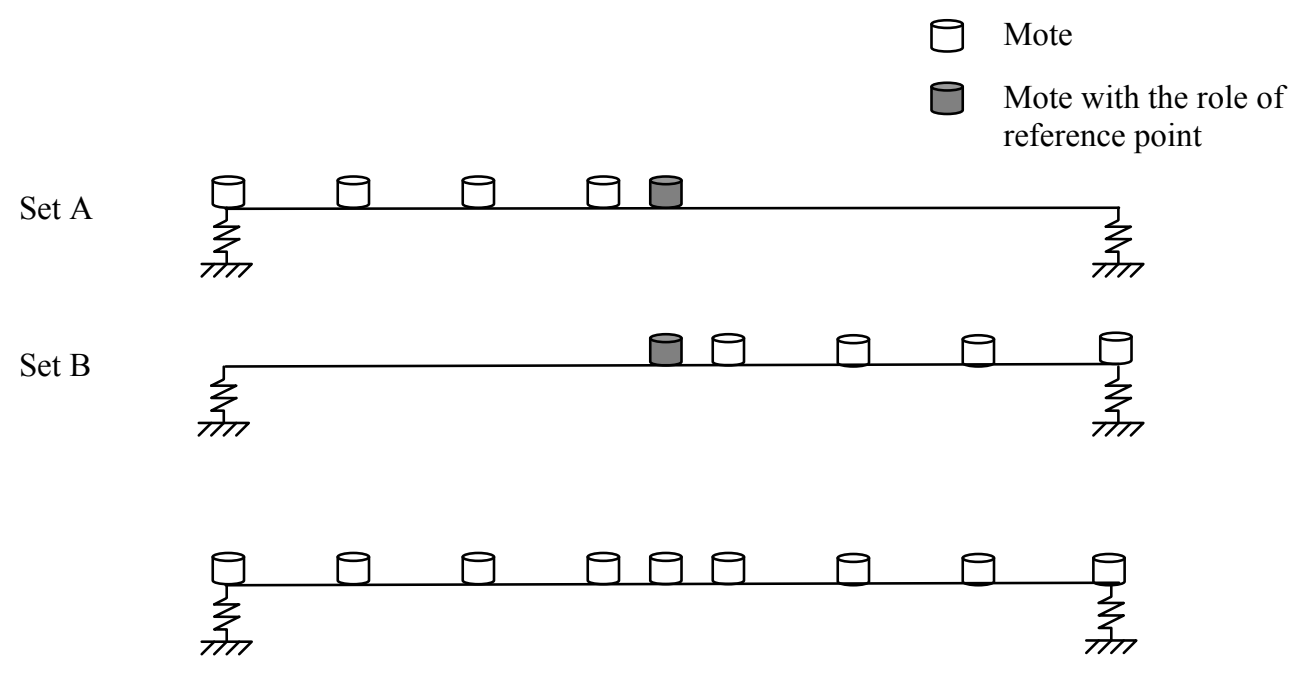

Figure 17. Two measuring sets and one reference point for the pedestrian bridge 


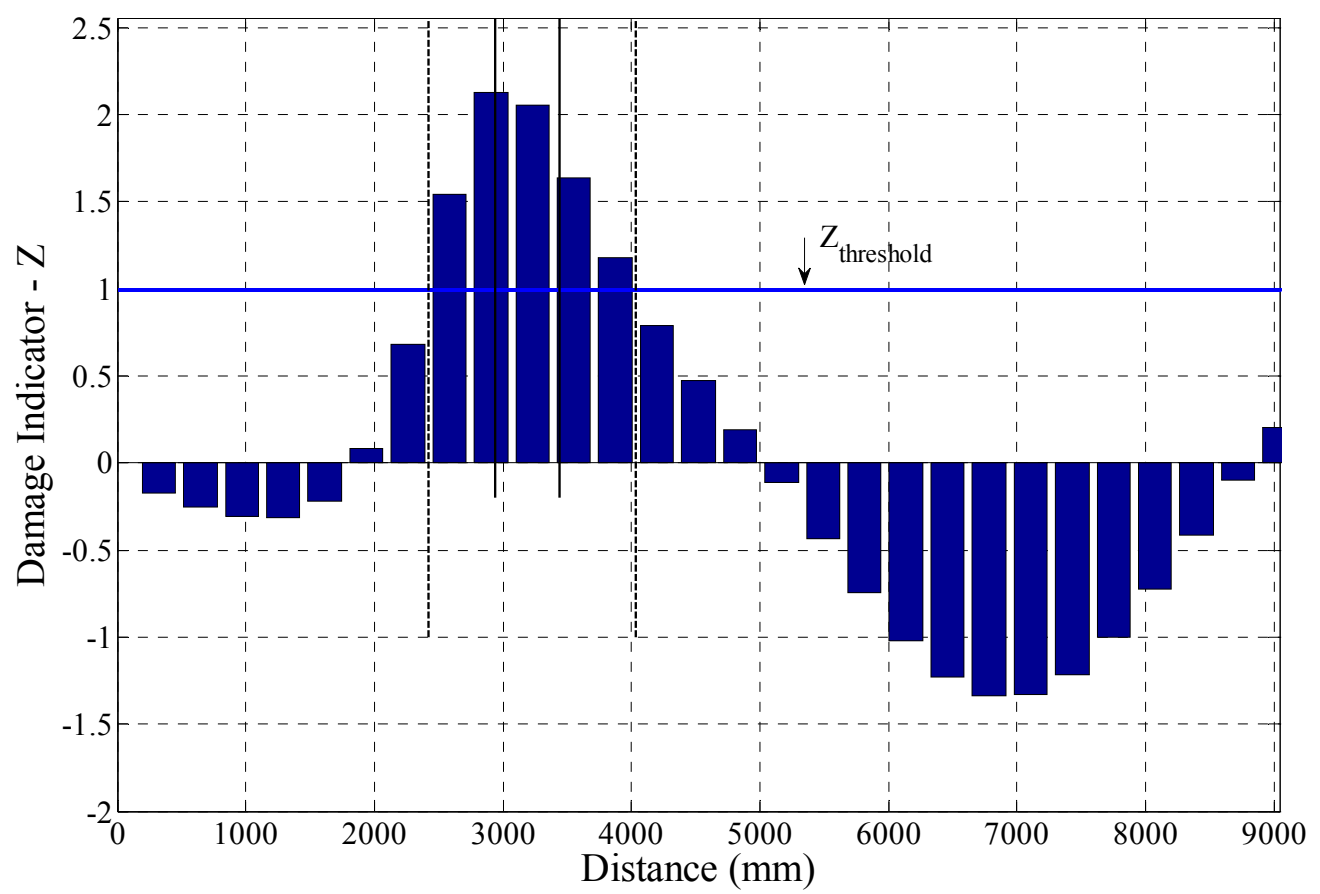

(a)

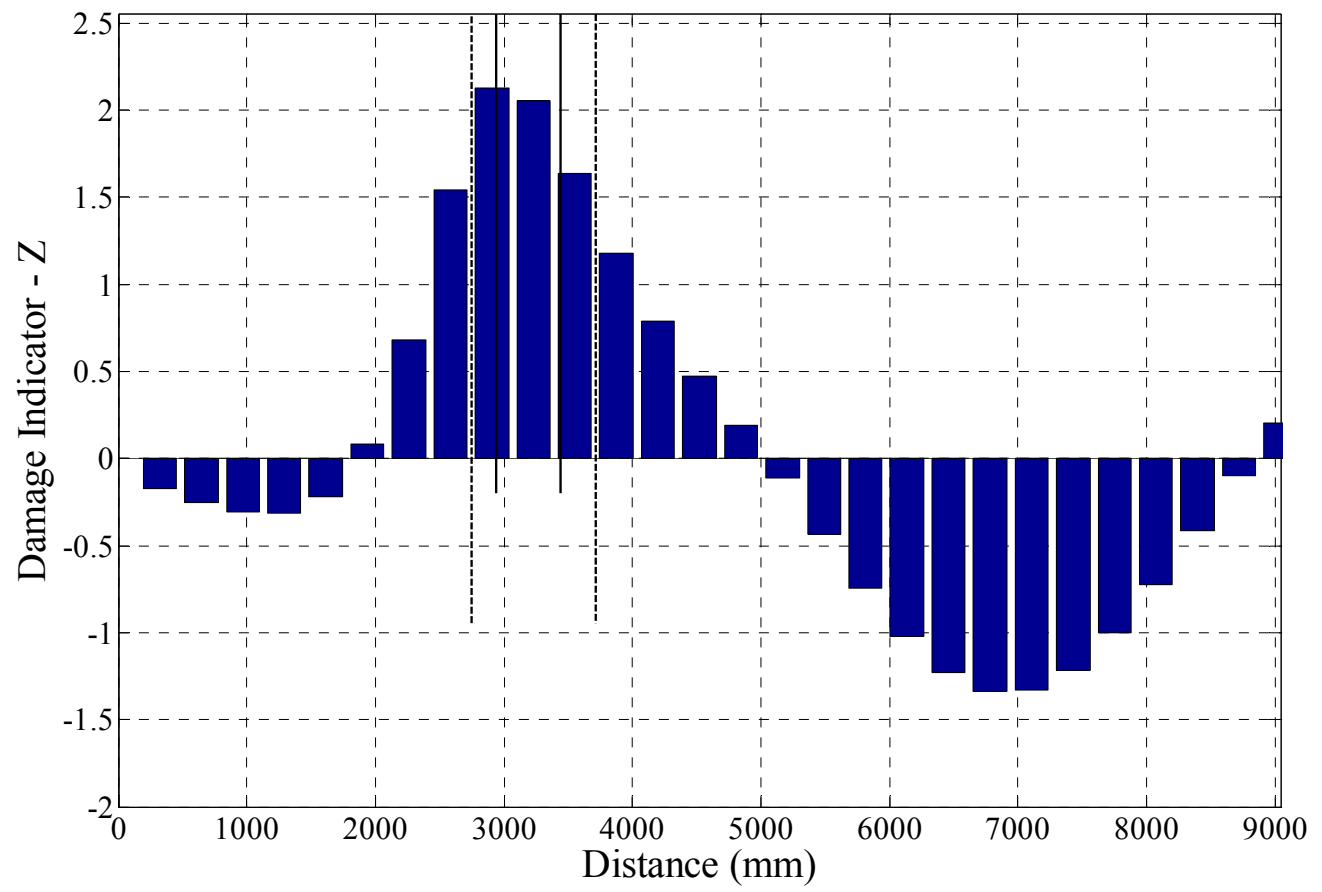

(b)

Figure 18. Damage prediction with 29 spline points in a pedestrian bridge using (a) the current DIM and (b) the proposed IDIM (solid lines indicate actual damage and dashed lines indicate predicted damage) 


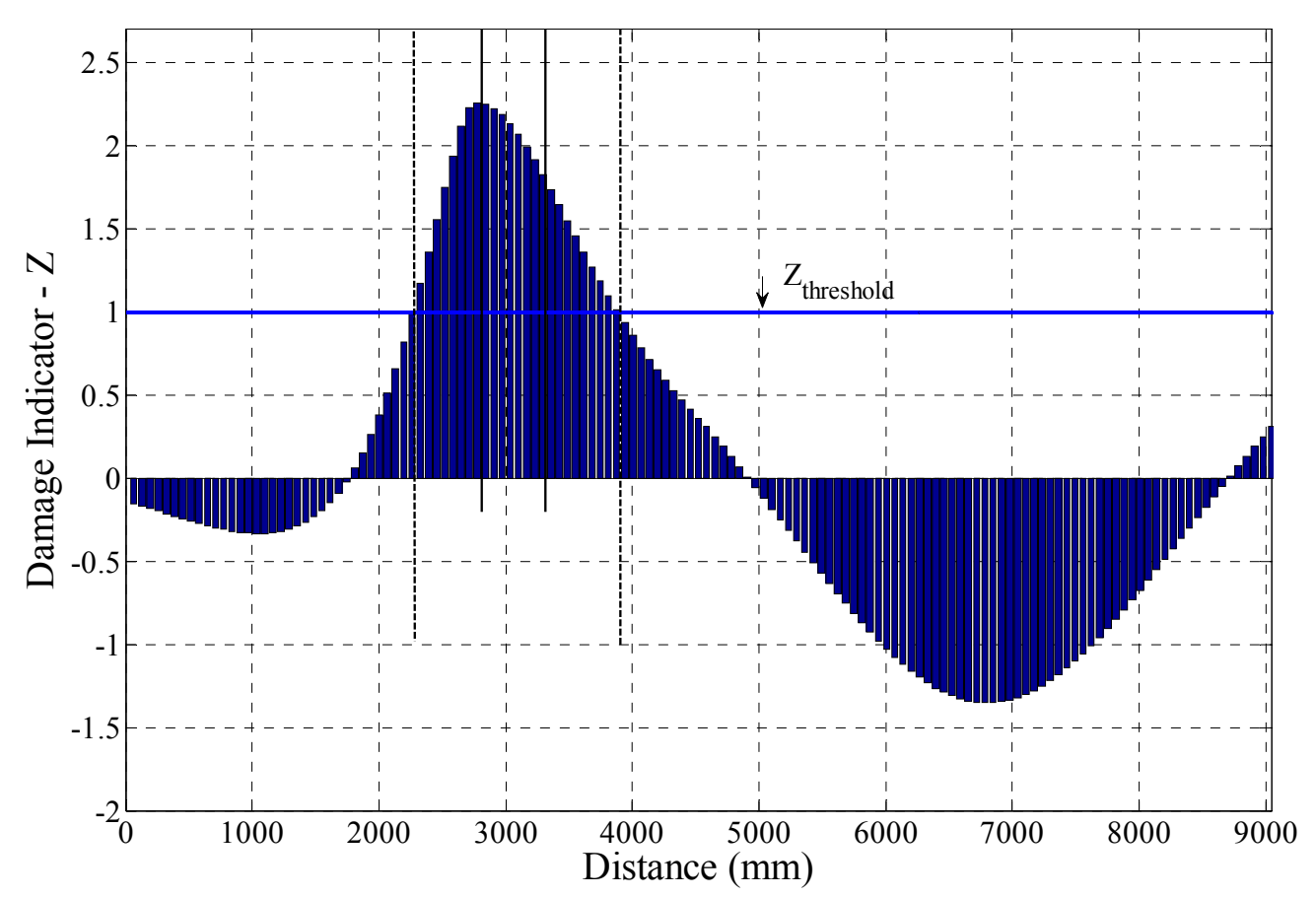

(a)

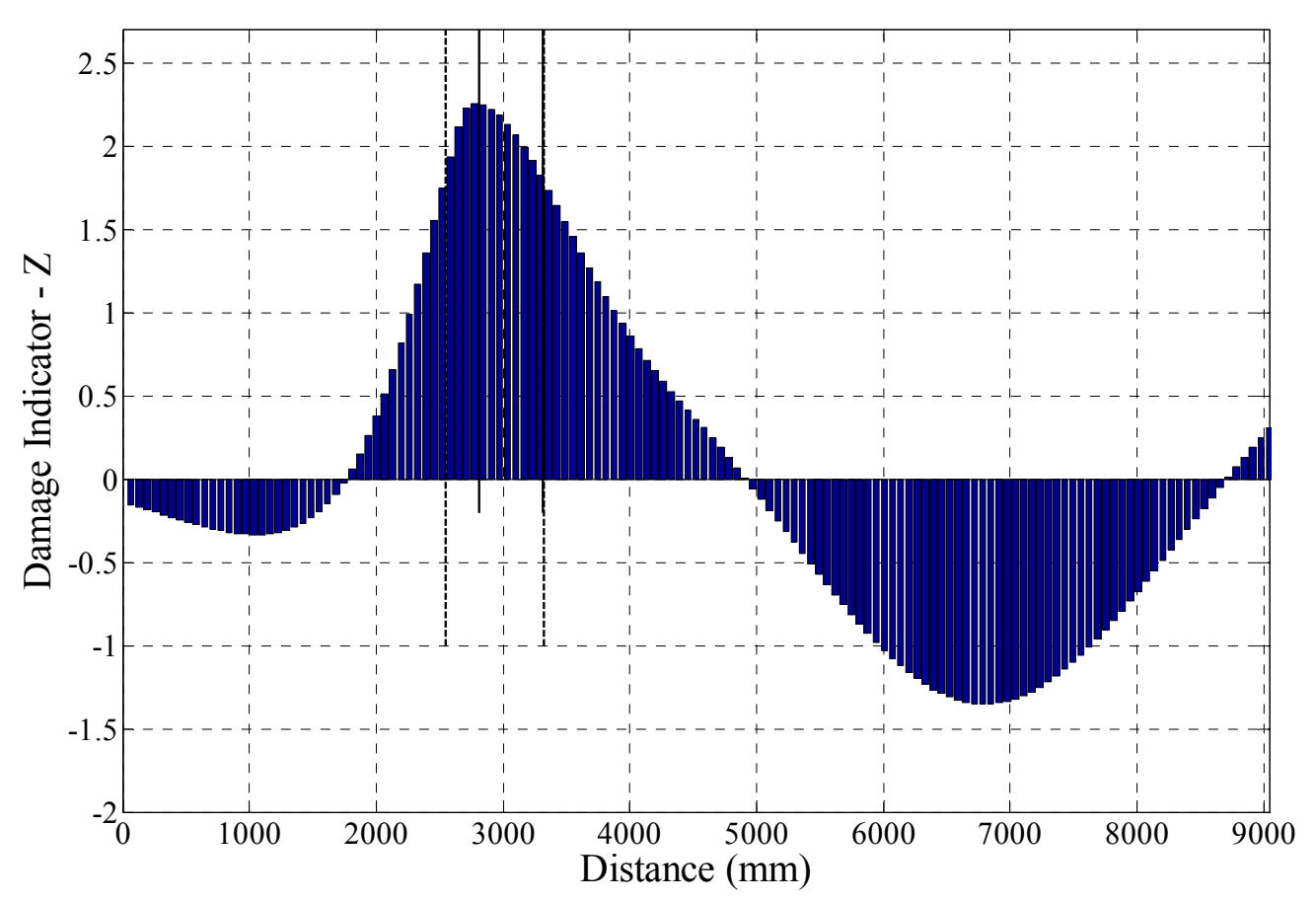

(b)

Figure 19. Damage prediction with 141 spline points in a pedestrian bridge using (a) the current DIM and (b) the proposed IDIM (solid lines indicate actual damage and dashed lines indicate predicted damage) 


\section{CONCLUSIONS}

The proposed Iterative Damage Index Method (IDIM) has both theoretical and performance advantages over the current DIM. It is a less arbitrary and more accurate vibration-based damage detection technique than the current DIM. Also, the proposed IDIM does not depend on a threshold, as required in the current DIM. Finally, the proposed IDIM is not affected by the number of spline points selected.

Simulation and experimental comparisons demonstrate the superior performance of IDIM. After correlations between modeshapes using the Curvature Assurance Criteria (CAC) and Total Curvature Assurance Criteria (TCAC) reveal the extent of damage prior to the damage detection process by the two methods, two parameters, e and $\Delta$, are used to quantify the accuracy of predicted damage. Two example cases are studied to compare the DIM and the proposed IDIM: a simply supported beam and a pedestrian bridge at the Texas A\&M golf course.

The CAC and TCAC between modeshapes from numerical models are enough to show the presence of damage and the modeshapes can be applied for the damage detection process by the two methods. From simulation results with numerical models, five major findings emerge. First, the proposed IDIM is more economical than the DIM. Second, the proposed method is more accurate across various damage cases. Third, the proposed method is more efficient in identifying low magnitude damage, which is rarely detected in practice. Fourth, the size of more severe damage is detected more correctly while the location of damage does not influence the accuracy of damage detection. Finally, the IDIM is more accurate than the DIM in estimating the multiple locations of damage.

The modeshapes extracted from the two real structures by the TDD are utilized to calculate the two kinds of criteria: CAC and TCAC. The similarity between numerical and 
experimental results proves that the modeshapes obtained from the experimental tests can be applied for the damage detection process by the two methods. Experimental tests with a simply supported beam and a pedestrian bridge show that the proposed IDIM is more accurate than the current DIM and that the proposed method can be applied successfully for Structural Health Monitoring.

For the future work, the proposed method should be further evaluated on complicated structures such as long-span bridges, offshore structures, and high-rise buildings. Moreover, it can be necessary to conduct experimental tests with an adequate number of measuring instruments for the verification of the findings of improved accuracy of damage prediction by the proposed method. 


\section{REFERENCES}

ABAQUS (2004), Version 6.5 User Manual. Hibbit, Karlsson \& Sorensen, Inc., Providence, RI.

Allemang, R. (2003), “The modal assurance criterion - twenty years of use and abuse." $J$. Sound and Vibration, 37, 14-21.

Alvandi, A. and Cremona, C. (2006). “Assessment of vibration-based damage identification techniques." J. Sound and Vibration, 292, 179-202.

Arici, Y. and Mosalam, K. (2000). "System identification and modeling of bridge system for assessing current design procedures.” Proc. SMIP2000 Seminar on Utilization of StrongMotion Data, Sacramento, CA, Sep. 14, 77 - 96.

Arici, Y., and Mosalam, K. (2005). "Modal identification of bridge systems using state-space methods." Struct. Control Health Monit., 12, 381-404.

Arici, Y. and Mosalam, K. (2007). "Towards health monitoring of bridge system using strong motion data." Proc. The $10^{\text {th }}$ International Conference on Application of Statistics and Probability in Civil Engineering, Tokyo, Japan.

Brinker, R., Anderson, P., and Cantieni, R. (2001). "Identification and level 1 damage detection of the Z24 Highway Bridge by frequency domain decomposition." Experimental Techniques, 25 (6), 51-57.

Brinker, R., Frandsen, J., and Anderson, P. (2000a). “Ambient response analysis of the Great Belt Bridge." Proc. The $18^{\text {th }}$ International Modal Analysis Conference, San Antonio, TX, USA, Feb. 7-10.

Brinker, R., Zhang, L., and Anderson, P. (2000b). "Modal identification from ambient responses using frequency domain decomposition." Proc. The $18^{\text {th }}$ International Modal Analysis Conference, San Antonio, TX, USA, Feb. 7-10. 
Brownjohn, J., Moyo, P., Menzetter, P., and Chakraborty, S. (2005). "Lessons from monitoring the performance of highway bridges." Struct. Control Health Monit., 12, $227-244$.

Bureau of Transportation Statistics (2008). "National transportation statistics (2008)." U.S. Department of Transportation, $<$ http://www.bts.gov/publications/national_transportation_statistics/index.html > (Feb. 20, 2008).

Casciati, F., Faravelli, L., and Borghtti, F. (2003). "Wireless links between sensor-device control stations in long span bridges." Proc. Smart Structures and Materials, 5057, 1-7.

Choi, F., Li, J., Samali, B., and Crews, K. (2008). “Application of the modified damage index method to timber beams." Engineering Structures, 30, 1124-1145.

Clayton, E. H., Koh, B., Xing, G., Fok, C., Dyke, S. J., and Lu, C. (2005). "Damage detection and correlation-based localization using wireless mote sensors." Proc. The $13^{\text {th }}$ Mediterranean Conference on Control and Automation, Limassol, Cyprus, June 27-29, 304-309.

Ewins, D. J. (1985). Modal testing: Theory and practice. John Wiley, New York.

Farrar, C. R. (2001). "Historical overview of structural health monitoring." Lecture Notes on Structural Health Monitoring Using Statistical Pattern Recognition. Los Alamos Dynamics, Los Alamos, NM.

Humar, J., Bagchi, A., and Xu, H. (2006). "Performance of vibration-based techniques for the identification of structural damage." Struct. Health Monit., 5 (3), 215-241.

Hurlebaus, S. and Gaul, L. (2006). "Smart structure dynamics." Mechanical Systems and Signal Processing, 20 (2), February, 255-281.

Kim, B., Stubbs, N., and Park, T. (2005). “A new method to extract modal parameters using output-only responses.” J. Sound and Vibration, 282, 215-230. 
Kim, C. and Kawatani, M. (2007). "Application of total squares algorithm for damage identification of bridges under a moving vehicle." Proc. The $10^{\text {th }}$ International Conference on Application of Statistics and Probability in Civil Engineering, Tokyo, Japan.

Kim, J., Park, J., and Lee, B. (2007a). "Vibration-based damage monitoring in model plategirder bridges under uncertain temperature conditions." Engineering Structures, 29, 1354-1365.

Kim, J., Ryu, Y., Cho, H., and Stubbs, N. (2003). "Damage identification in beam-type structures: Frequency-based method vs mode-shape-based method." Engineering Structures, 25, 57-67.

Kim, J. and Stubbs, N. (2002). "Improved damage identification method based on modal information.” J. Sound and Vibration, 252 (2), 223-238.

Kim, J., and Stubbs, N. (2003). "Nondestructive crack detection algorithm for full-scale bridges.” J. Structural Engineering, 129 (10), 1358-1366.

Kim, S., Pakzad, S., Culler, D., Demmel, J., Fenves, G., Glaser, S., and Turon, M. (2007b). "Health monitoring of civil infrastructures using wireless sensor networks." Proc. The $6^{\text {th }}$ International Conference on Information Processing in Sensor Networks, Cambridge, MA, USA, Apr. 25-27.

Kurata, N., Spencer, B. F. Jr., and Ruiz-Sandoval, M. (2005). "Risk monitoring of buildings with wireless sensor networks.” Struct. Control Health Monit., 12(3-4), 315-327.

Lenzen, A. (2005). "Monitoring and damage assessment of mechanical systems by vibration analysis." Proc. The $9^{\text {th }}$ International Conference on Structural Safety and Reliability, Rome, Italy, Jun. 20-23.

Lynch, J. P., Law, K. H., Kiremidjian, A. S., Kenny, T. W., Carryer, E., and Partridge, A. (2001). "The design of a wireless sensing unit for structural health monitoring." Proc. 
The $3^{\text {rd }}$ International Workshop on Structural Health Monitoring, Stanford, CA, 11771184.

Lynch, J. P. (2002). "Decentralization of wireless monitoring and control technologies for smart civil structures." $\mathrm{PhD}$ thesis, Stanford University, Palo Alto, CA.

Lynch, J. P. and Loh, K. K. (2006). "A summary review of wireless sensors and sensor networks for structural health monitoring.” The Shock and Vibration Digest, 38 (2), 91128.

Lynch, J. P., Loh, K. J., Hou, T. C., Wang, Y., Yi, J., Yum, C. B., Lu, K. C., and Loh, C. H. (2006a). "Validation on case studies of wireless monitoring systems in civil structures." Struct. Health Monit. and Intelligent Infrastructure, 1, 597-604.

Lynch, J. P., Wang, Y., Lu, K. C., Hou, T. C., and Loh, C. H. (2006b). "Post-seismic damage assessment of steel structures instrumented with self-interrogating wireless sensors." Proc. The $8^{\text {th }}$ National Conference on Earthquake Engineering, San Francisco, CA, April 18-21.

McHargue, P. and Richardson, M. (1993). "Operational deflection shapes from times versus frequency domain measurements." Proc. The $11^{\text {th }}$ International Modal Analysis Conference, Kissimmee, FL, USA.

Mizuno, Y., Monroig, E., and Fujino, Y. (2008). "Wavelet decomposition-based approach for fast damage detection of civil structures.” J. Infrastructure Systems, 14 (1), 27-32.

Omenzetter, P. and Brownjohn, J. (2006). "Application of time series analysis for bridge monitoring.” Smart Mater. Struct., Vol. 15, 129-138.

Paek, J., Kothari, N., Chintalapudi, K., Rangwala, S., Xu, N., Caffrey, J., Govindan, R., Masri, S., Wallace, J., and Whang, D. (2004). “The performance of a wireless sensor network for structural health monitoring." Proc. The $2^{\text {nd }}$ European Workshop on Wireless Sensor Networks, Istanbul, Turkey, Jan. 31 - Feb. 2, 1660. 
Pandey, A. K., Biswas, M, and Samman, M. M. (1991). "Damage detection from changes in curvature mode shapes." J. Sound and Vibration, 145 (2), 321-332.

Pandey, A. K. and Biswas, M. (1994). "Damage detection in structures using changes in flexibility.” J. Sound and Vibration, 169 (1), 3-17.

Park, S., Stubbs, N., Bolton, R., Choi, S., and Sikorsky, C. (2001). "Field verification of the damage index method in a concrete box-girder bridge via visual inspection." ComputerAided Civil and Infrastructure Engineering, 16, 58-70.

Pei, Q., Guo, X., Li, C. H., and Zhao, C. Y. (2006). "Design and laboratory performance verification of a wireless transmitting system for structural health monitoring." Struct. Health Monit. and Intelligent Infrastructure, 1, 611-618.

Reyer, M. (2007). "Design of a wireless sensor network for structural health monitoring of bridges.” Master thesis, Stuttgart University, Stuttgart, Germany.

Rodrigues, J., Brinker, R., and Anderson, P. (2004). "Improvement of frequency domain output-only modal identification from the application of the random decrement technique." Proc. The $22^{\text {nd }}$ International Modal Analysis Conference, Dearborn, MI, USA.

Rosenker, M. K. (2008). "Safety recommendation." Letter to Federal Highway Administration H-08-1, National Transportation Safety Board, Washington, DC, Jan. 15.

Shi, Z., Law, S., and Zhang, L. (2000). "Optimum sensor placement for structural damage detection. ” J. Engineering Mechanics, 126 (11), 1173-1179.

Shinozuka, M. (2003). "Homeland security and safety." Proc. Struct. Health Monit. and Intelligent Infrastructure, Tokyo, Japan, 22, 1139-1145.

Siringoringo, D. and Fujino, Y. (2007). "System identification applied to long-span cablesupported bridges using seismic records.” Earthquake Engineering Struct. Dyn., 37 (3), 361-386. 
Sohn, H. and Farrar, C. (2001). "Damage diagnosis using time series analysis of vibration signals.” Smart Mater. Struct., Vol. 10, 446-451.

Straser, E. G. and Kiremidjian, A. S. (1998). "A modular, wireless damage monitoring system for structures." Technical Report No. 128, John A. Blume Earthquake Engineering Center, Stanford University, Stanford, CA.

Stubbs, N., and Kim, J. (1996). "Damage localization in structures without baseline modal parameters." AIAA Journal, 34 (8), 1644-1649.

Stubbs, N. and Park, S. (1996). “Optimal sensor placement for mode shapes via Shannon's sampling theorem.” Microcomputers in Civil Engineering, 11, 411-419.

Wang, Y., Lynch, J. P., and Law, K. H. (2005). “A wireless structural health monitoring system with multithreaded sensing devices: Design and validation." Structure and Infrastructure Engineering, 3 (2), 103-120.

Wardhana, K. and Hadipriono, F. C. (2003). "Analysis of recent bridge failures in the United States.” J. Perform. Constr. Facil., 17(3), 144-150.

Whelan, M. J., Gangone, M. V., and Janoyan, K. D. (2007). "Integrated smart wireless sensors for bridge structural health and homeland security monitoring." Proc. The $3^{\text {rd }}$ International Conference on Structural Health Monitoring of Intelligent Infrastructure, Vancouver, British Columbia, Canada, Nov. 13-16, 2007.

Xu, N., Rangwala, S., Chintalapudi, K., Ganesan, D., Broad, A., Golvindan, R., and Estrin, D. (2004). "A wireless sensor network for structural monitoring." Proc. The $2^{\text {nd }}$ International Conference on Embedded Networked Sensor Systems, Baltimore, MD, USA, Nov. 3-5.

Zhang, Z. and Aktan, A. E. (1995). “The damage indices for constructed facilities.” Proc. The $13^{\text {th }}$ International Modal Analysis Conference, 1520-1529. 


\section{APPENDIX A}

To determine $C$ is very significant in the Iterative Damage Index Method. Table A.1 shows the calculated $C$ for different lengths of simply supported beams and various sizes of damage. From the table, it is found that the most of $C$ are the same as the lengths of simply supported beams. The simply supported beam with the length of $3.56 \mathrm{~m}(140 \mathrm{in})$ is used here. To calculate the damage detection percentage $(\gamma)$, two kinds of $C$ are used: the average of three $C$ for three different sizes of damage $(L / 14, L / 10$, and $L / 7), 153$ and the length of the simply supported beam, 140. Those percentages $(\gamma)$ for Cases 1, 2, 5, and 9 used in Section 4.1 are shown in Tables A.2 to A.5. From those tables, it is concluded that the length $(L)$ can be used as $C$ in the Iterative Damage Index Method.

Table A.1. $C$ for different lengths of simply supported beams and various sizes of damage

\begin{tabular}{ccccccc}
\hline \multirow{2}{*}{ Length $(L)$} & $L / 56$ & $L / 40$ & $L / 28$ & $L / 14$ & $L / 10$ & $\mathrm{~L} / 7$ \\
\cline { 2 - 7 } & 129.83 & 144.59 & 147.25 & 144.60 & 149.80 & 172.40 \\
\hline $3.56 \mathrm{~m}(140 \mathrm{in})$ & 294.85 & 288.26 & 289.60 & 289.40 & 310.80 & 344.80 \\
$7.11 \mathrm{~m}(280 \mathrm{in})$ & 65.06 & 69.60 & 72.28 & 72.25 & 77.84 & 86.30 \\
$1.78 \mathrm{~m}(70 \mathrm{in})$ & 6
\end{tabular}

Table A. 2. Damage detection percentage Case 1 with (a) $C=154$ and (b) $C=L=140$ (unit is \%)

(a)

\begin{tabular}{ccccccccccccc}
\hline \multirow{2}{*}{$\Delta$} & & \multicolumn{10}{c}{$\mathrm{e}$} \\
\cline { 3 - 12 } & & 0 & 0.1 & 0.2 & 0.3 & 0.4 & 0.5 & 1.0 & 1.5 & 2.0 & 2.5 & 3.0 \\
\hline \multirow{2}{*}{0} & DIM & 0.8 & 15.3 & 51.6 & 69.1 & 77.5 & 80.4 & 86.5 & 92.0 & 94.4 & 94.6 & 96.4 \\
& IDIM & 6.5 & 63.7 & 75.2 & 78.2 & 82.0 & 83.2 & 91.7 & 91.8 & 93.8 & 96.4 & 97.8 \\
\hline
\end{tabular}

(b)

\begin{tabular}{ccccccccccccc}
\hline \multirow{2}{*}{$\Delta$} & & \multicolumn{10}{c}{$\mathrm{e}$} \\
\cline { 3 - 12 } & & 0 & 0.1 & 0.2 & 0.3 & 0.4 & 0.5 & 1.0 & 1.5 & 2.0 & 2.5 & 3.0 \\
\hline \multirow{2}{*}{0} & DIM & 0.8 & 15.3 & 51.6 & 69.1 & 77.5 & 80.4 & 86.5 & 92.0 & 94.4 & 94.6 & 96.4 \\
& IDIM & 5.3 & 67.5 & 79.4 & 82.9 & 84.6 & 86.7 & 95.5 & 95.6 & 95.7 & 96.4 & 99.6 \\
\hline
\end{tabular}

Table A. 3. Damage detection percentage Case 2 with (a) $C=154$ and (b) $C=L=140$ (unit is \%) 
(a)

\begin{tabular}{ccccccccccccc}
\hline \multirow{2}{*}{$\Delta$} & & \multicolumn{10}{c}{$\mathrm{e}$} \\
\cline { 3 - 12 } & 0 & 0.1 & 0.2 & 0.3 & 0.4 & 0.5 & 1.0 & 1.5 & 2.0 & 2.5 & 3.0 \\
\hline \multirow{2}{*}{0} & DIM & 11.1 & 81.5 & 92.1 & 93.6 & 95.6 & 95.7 & 97.8 & 97.9 & 97.9 & 98.0 & 98.1 \\
& IDIM & 5.0 & 76.5 & 85.8 & 87.3 & 89.9 & 92.9 & 97.8 & 98.0 & 99.9 & 100.0 & 100.0 \\
\hline
\end{tabular}

(b)

\begin{tabular}{ccccccccccccc}
\hline \multirow{2}{*}{$\Delta$} & & \multicolumn{10}{c}{$\mathrm{e}$} \\
\cline { 3 - 12 } & & 0 & 0.1 & 0.2 & 0.3 & 0.4 & 0.5 & 1.0 & 1.5 & 2.0 & 2.5 & 3.0 \\
\hline \multirow{2}{*}{0} & DIM & 11.1 & 81.5 & 92.1 & 93.6 & 95.6 & 95.7 & 97.8 & 97.9 & 97.9 & 98.0 & 98.1 \\
& IDIM & 5.4 & 80.5 & 85.9 & 87.3 & 89.4 & 91.1 & 99.6 & 99.9 & 99.9 & 100.0 & 100.0 \\
\hline
\end{tabular}

Table A. 4. Damage detection percentage Case 5 with (a) $C=154$ and (b) $C=L=140$ (unit is \%)

(a)

\begin{tabular}{|c|c|c|c|c|c|c|c|c|c|c|c|c|}
\hline \multirow{2}{*}{$\Delta$} & & \multicolumn{11}{|c|}{$\mathrm{e}$} \\
\hline & & 0 & 0.1 & 0.2 & 0.3 & 0.4 & 0.5 & 1.0 & 1.5 & 2.0 & 2.5 & 3.0 \\
\hline \multirow{2}{*}{0} & DIM & 0.2 & 12.1 & 48.2 & 65.3 & 74.3 & 77.7 & 83.7 & 89.4 & 91.7 & 92.0 & 93.8 \\
\hline & IDIM & 1.6 & 25.5 & 68.7 & 80.1 & 82.3 & 84.1 & 91.7 & 91.8 & 93.8 & 96.3 & 97.8 \\
\hline \multicolumn{13}{|c|}{ (b) } \\
\hline \multirow{2}{*}{$\Delta$} & & \multicolumn{11}{|c|}{$\mathrm{e}$} \\
\hline & & 0 & 0.1 & 0.2 & 0.3 & 0.4 & 0.5 & 1.0 & 1.5 & 2.0 & 2.5 & 3.0 \\
\hline \multirow{2}{*}{0} & DIM & 0.2 & 12.1 & 48.2 & 65.3 & 74.3 & 77.7 & 83.7 & 89.4 & 91.7 & 92.0 & 93.8 \\
\hline & IDIM & 1.5 & 25.7 & 72.4 & 83.3 & 85.3 & 87.9 & 95.5 & 95.6 & 95.8 & 96.3 & 99.6 \\
\hline
\end{tabular}

Table A. 5 Damage detection percentage Case 9 with (a) $\mathrm{C}=154$ and (b) $\mathrm{C}=\mathrm{L}=140$ (unit is \%)

(a)

\begin{tabular}{ccccccccccccc}
\hline \multirow{2}{*}{$\Delta$} & & \multicolumn{10}{c}{$\mathrm{e}$} \\
\cline { 3 - 12 } & & 0 & 0.1 & 0.2 & 0.3 & 0.4 & 0.5 & 1.0 & 1.5 & 2.0 & 2.5 & 3.0 \\
\hline \multirow{2}{*}{0} & DIM & 0.0 & 21.2 & 60.0 & 73.2 & 80.2 & 82.7 & 87.2 & 88.9 & 92.6 & 92.9 & 94.9 \\
& IDIM & 3.7 & 55.2 & 72.3 & 78.5 & 82.7 & 84.2 & 92.9 & 93.8 & 95.8 & 96.1 & 96.3 \\
\hline
\end{tabular}

(b)

\begin{tabular}{ccccccccccccc}
\hline \multirow{2}{*}{$\Delta$} & & \multicolumn{10}{c}{$\mathrm{e}$} \\
\cline { 3 - 12 } & & 0 & 0.1 & 0.2 & 0.3 & 0.4 & 0.5 & 1.0 & 1.5 & 2.0 & 2.5 & 3.0 \\
\hline \multirow{2}{*}{0} & DIM & 0.0 & 21.2 & 60.0 & 73.2 & 80.2 & 82.7 & 87.2 & 88.9 & 92.6 & 92.9 & 94.9 \\
& IDIM & 3.1 & 53.2 & 75.9 & 82.5 & 83.9 & 84.4 & 91.1 & 91.9 & 93.8 & 93.9 & 95.8 \\
\hline
\end{tabular}




\section{APPENDIX B}

Selection of $C$ is very significant in the Iterative Damage Index Method. In Appendix A, it is found that the length of a simply supported beam can be used as $C$ in the Iterative Damage Index Method. Three beams with the length of $3.56 \mathrm{~m}$ (140 in) and different boundary conditions are used here (see Figure B.1). Table B.1 shows the calculated $C$ for different boundary conditions and various sizes of damage. To calculate the damage detection percentage $(\gamma)$, two kinds of $\mathrm{C}$ are used: each $C$ for a specific size of damage $(L / 28)$ and the effective length $\left(L_{\text {eff. }}\right)$ of each beam. Those percentages $(\gamma)$ for Cases 1, 2, 5, and 9 used in Section 4.1 are shown in Tables B.2 to B.13. From those tables, it is concluded that the effective length $\left(L_{\text {eff. }}\right)$ can be used as $C$ in the Iterative Damage Index Method. Note that the effective length $\left(L_{\text {eff. }}\right)$ of a simply supported beam is equal to the length $(L)$ of the beam.

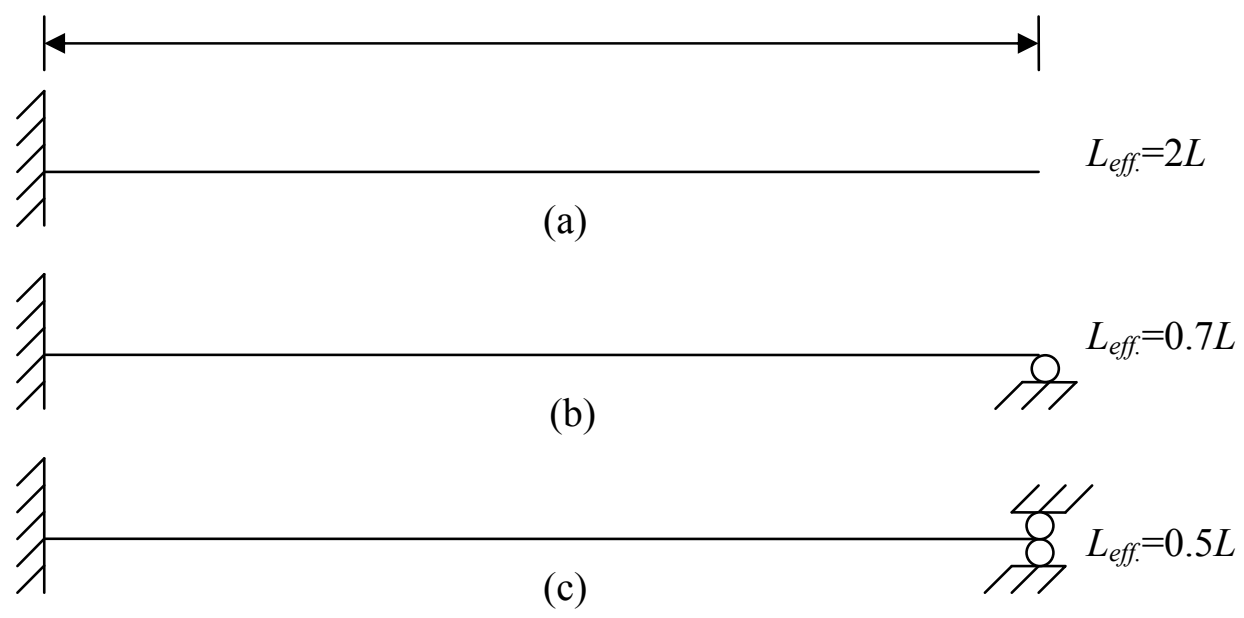

Figure B.1. Three boundary conditions and $L_{\text {eff: }}$ : (a) Fixed-free, (b) Fixed-pinned, and (c) Fixed-fixed

Table B.1. $C$ for different lengths of simply supported beams and various sizes of damage 


\begin{tabular}{cccc}
\cline { 2 - 4 } & $L / 28$ & $L / 14$ & $L / 10$ \\
\hline Fixed-free & 334.05 & 301.10 & 185.50 \\
Fixed-pinned & 159.60 & 160.70 & 136.92 \\
Fixed-fixed & 177.25 & 182.10 & 174.16 \\
\hline
\end{tabular}

Table B. 2. Damage detection percentage with damage size of $L / 40$ and fixed-free boundary condition, and three different $C$ : (a) $C=L_{\text {eff. }}=280$, (b) $\mathrm{C}=334$, and (c) $C=L=140$ (unit is \%)

(a)

\begin{tabular}{ccccccccccccc}
\hline \multirow{2}{*}{$\Delta$} & & \multicolumn{10}{c}{$\mathrm{e}$} \\
\cline { 3 - 13 } & & 0 & 0.1 & 0.2 & 0.3 & 0.4 & 0.5 & 1.0 & 1.5 & 2.0 & 2.5 & 3.0 \\
\hline \multirow{2}{*}{0} & DIM & 0.6 & 5.8 & 9.3 & 15.1 & 22.5 & 28.8 & 42.8 & 61.7 & 64.3 & 65.6 & 67.6 \\
& IDIM & 1.4 & 13.8 & 27.2 & 37.9 & 47.8 & 56.3 & 88.9 & 94.0 & 94.4 & 95.0 & 96.5 \\
\hline
\end{tabular}

(b)

\begin{tabular}{|c|c|c|c|c|c|c|c|c|c|c|c|c|}
\hline \multirow{2}{*}{$\Delta$} & & \multicolumn{11}{|c|}{$\mathrm{e}$} \\
\hline & & 0 & 0.1 & 0.2 & 0.3 & 0.4 & 0.5 & 1.0 & 1.5 & 2.0 & 2.5 & 3.0 \\
\hline \multirow{2}{*}{0} & DIM & 0.6 & 5.8 & 9.3 & 15.1 & 22.5 & 28.8 & 42.8 & 61.7 & 64.3 & 65.6 & 67.6 \\
\hline & IDIM & 1.1 & 11.9 & 25.8 & 37.0 & 47.1 & 53.3 & 77.3 & 82.1 & 85.2 & 89.1 & 92.6 \\
\hline
\end{tabular}

(c)

\begin{tabular}{ccccccccccccc}
\hline \multirow{2}{*}{$\Delta$} & & \multicolumn{10}{c}{$\mathrm{e}$} \\
\cline { 3 - 12 } & & 0 & 0.1 & 0.2 & 0.3 & 0.4 & 0.5 & 1.0 & 1.5 & 2.0 & 2.5 & 3.0 \\
\hline \multirow{2}{*}{0} & DIM & 0.6 & 5.8 & 9.3 & 15.1 & 22.5 & 28.8 & 42.8 & 61.7 & 64.3 & 65.6 & 67.6 \\
& IDIM & 1.1 & 12.1 & 25.3 & 36.2 & 46.0 & 52.6 & 77.1 & 82.1 & 85.2 & 89.1 & 92.6 \\
\hline
\end{tabular}


Table B. 3. Damage detection percentage with damage size of $L / 28$ and fixed-free boundary condition, and three different $C$ : (a) $C=L_{\text {eff. }}=280$, (b) $\mathrm{C}=334$, and (c) $C=L=140$ (unit is \%)

(a)

\begin{tabular}{|c|c|c|c|c|c|c|c|c|c|c|c|c|}
\hline \multirow{2}{*}{$\Delta$} & & \multicolumn{11}{|c|}{$\mathrm{e}$} \\
\hline & & 0 & 0.1 & 0.2 & 0.3 & 0.4 & 0.5 & 1.0 & 1.5 & 2.0 & 2.5 & 3.0 \\
\hline \multirow{2}{*}{0} & DIM & 3.1 & 22.9 & 34.2 & 40.3 & 44.1 & 45.3 & 50.5 & 57.5 & 59.9 & 60.1 & 61.8 \\
\hline & IDIM & 0.9 & 7.7 & 26.0 & 57.5 & 72.2 & 75.1 & 95.5 & 95.6 & 95.7 & 97.7 & 99.4 \\
\hline \multicolumn{13}{|c|}{ (b) } \\
\hline \multirow{2}{*}{$\Delta$} & & \multicolumn{11}{|c|}{$\mathrm{e}$} \\
\hline & & 0 & 0.1 & 0.2 & 0.3 & 0.4 & 0.5 & 1.0 & 1.5 & 2.0 & 2.5 & 3.0 \\
\hline \multirow{2}{*}{0} & DIM & 3.1 & 22.9 & 34.2 & 40.3 & 44.1 & 45.3 & 50.5 & 57.5 & 59.9 & 60.1 & 61.8 \\
\hline & IDIM & 0.1 & 1.7 & 16.6 & 38.6 & 46.9 & 51.7 & 83.4 & 87.6 & 89.9 & 93.9 & 95.7 \\
\hline \multicolumn{13}{|c|}{ (c) } \\
\hline \multirow{2}{*}{$\Delta$} & & \multicolumn{11}{|c|}{$\mathrm{e}$} \\
\hline & & 0 & 0.1 & 0.2 & 0.3 & 0.4 & 0.5 & 1.0 & 1.5 & 2.0 & 2.5 & 3.0 \\
\hline \multirow{2}{*}{0} & DIM & 3.1 & 22.9 & 34.2 & 40.3 & 44.1 & 45.3 & 50.5 & 57.5 & 59.9 & 60.1 & 61.8 \\
\hline & IDIM & 0.2 & 1.2 & 15.4 & 43.7 & 53.1 & 55.3 & 83.4 & 87.6 & 89.9 & 93.9 & 95.7 \\
\hline
\end{tabular}

Table B. 4. Damage detection percentage with damage size of $L / 14$ and fixed-free boundary condition, and three different $C$ : (a) $C=L_{\text {eff. }}=280$, (b) $\mathrm{C}=334$, and (c) $C=L=140$ (unit is \%)

(a)

\begin{tabular}{|c|c|c|c|c|c|c|c|c|c|c|c|c|}
\hline \multirow{2}{*}{$\Delta$} & & \multicolumn{11}{|c|}{$\mathrm{e}$} \\
\hline & & 0 & 0.1 & 0.2 & 0.3 & 0.4 & 0.5 & 1.0 & 1.5 & 2.0 & 2.5 & 3.0 \\
\hline \multirow{2}{*}{0} & DIM & 3.1 & 22.9 & 30.9 & 33.7 & 36.1 & 36.3 & 44.9 & 45.2 & 47.0 & 47.3 & 47.3 \\
\hline & IDIM & 1.5 & 28.6 & 35.8 & 38.0 & 38.6 & 40.4 & 98.7 & 98.9 & 99.6 & 99.9 & 99.9 \\
\hline \multicolumn{13}{|c|}{ (b) } \\
\hline \multirow{2}{*}{$\Delta$} & & \multicolumn{11}{|c|}{$\mathrm{e}$} \\
\hline & & 0 & 0.1 & 0.2 & 0.3 & 0.4 & 0.5 & 1.0 & 1.5 & 2.0 & 2.5 & 3.0 \\
\hline \multirow{2}{*}{0} & DIM & 3.1 & 22.9 & 30.9 & 33.7 & 36.1 & 36.3 & 44.9 & 45.2 & 47.0 & 47.3 & 47.3 \\
\hline & IDIM & 0.9 & 15.5 & 21.7 & 24.3 & 26.2 & 32.8 & 95.7 & 95.9 & 97.6 & 97.9 & 97.9 \\
\hline \multicolumn{13}{|c|}{ (c) } \\
\hline \multirow{2}{*}{$\Delta$} & & \multicolumn{11}{|c|}{$\mathrm{e}$} \\
\hline & & 0 & 0.1 & 0.2 & 0.3 & 0.4 & 0.5 & 1.0 & 1.5 & 2.0 & 2.5 & 3.0 \\
\hline \multirow{2}{*}{0} & DIM & 3.1 & 22.9 & 30.9 & 33.7 & 36.1 & 36.3 & 44.9 & 45.2 & 47.0 & 47.3 & 47.3 \\
\hline & IDIM & 1.1 & 18.0 & 25.4 & 27.2 & 30.5 & 34.0 & 95.7 & 95.9 & 97.6 & 97.9 & 97.9 \\
\hline
\end{tabular}


Table B. 5. Damage detection percentage with damage size of $L / 10$ and fixed-free boundary condition, and three different $C$ : (a) $C=L_{\text {eff: }}=280$, (b) $\mathrm{C}=334$, and (c) $C=L=140$ (unit is \%)

(a)

\begin{tabular}{|c|c|c|c|c|c|c|c|c|c|c|c|c|}
\hline \multirow{2}{*}{$\Delta$} & & \multicolumn{11}{|c|}{$\mathrm{e}$} \\
\hline & & 0 & 0.1 & 0.2 & 0.3 & 0.4 & 0.5 & 1.0 & 1.5 & 2.0 & 2.5 & 3.0 \\
\hline \multirow{2}{*}{0} & DIM & 12.6 & 74.8 & 75.0 & 75.2 & 75.5 & 79.0 & 79.2 & 81.2 & 81.2 & 81.2 & 81.2 \\
\hline & IDIM & 7.2 & 76.4 & 79.2 & 82.5 & 82.9 & 84.4 & 98.9 & 99.1 & 100.0 & 100.0 & 100.0 \\
\hline \multicolumn{13}{|c|}{ (b) } \\
\hline \multirow{2}{*}{$\Delta$} & & \multicolumn{11}{|c|}{$\mathrm{e}$} \\
\hline & & 0 & 0.1 & 0.2 & 0.3 & 0.4 & 0.5 & 1.0 & 1.5 & 2.0 & 2.5 & 3.0 \\
\hline \multirow{2}{*}{0} & DIM & 12.6 & 74.8 & 75.0 & 75.2 & 75.5 & 79.0 & 79.2 & 81.2 & 81.2 & 81.2 & 81.2 \\
\hline & IDIM & 3.3 & 58.9 & 63.1 & 67.9 & 70.6 & 75.5 & 95.7 & 97.9 & 99.9 & 100.0 & 100.0 \\
\hline \multicolumn{13}{|c|}{ (c) } \\
\hline \multirow{2}{*}{$\Delta$} & & \multicolumn{11}{|c|}{$\mathrm{e}$} \\
\hline & & 0 & 0.1 & 0.2 & 0.3 & 0.4 & 0.5 & 1.0 & 1.5 & 2.0 & 2.5 & 3.0 \\
\hline \multirow{2}{*}{0} & DIM & 12.6 & 74.8 & 75.0 & 75.2 & 75.5 & 79.0 & 79.2 & 81.2 & 81.2 & 81.2 & 81.2 \\
\hline & IDIM & 4.6 & 62.0 & 67.2 & 70.7 & 71.9 & 75.7 & 95.7 & 97.9 & 99.9 & 100.0 & 100.0 \\
\hline
\end{tabular}

Table B. 6. Damage detection percentage with damage size of $L / 40$ and fixed-pinned boundary condition, and three different $C$ : (a) $C=L_{\text {eff. }}=98$, (b) $\mathrm{C}=160$, and (c) $C=L=140$ (unit is \%)

(a)

\begin{tabular}{|c|c|c|c|c|c|c|c|c|c|c|c|c|}
\hline \multirow{2}{*}{$\Delta$} & & \multicolumn{11}{|c|}{$\mathrm{e}$} \\
\hline & & 0 & 0.1 & 0.2 & 0.3 & 0.4 & 0.5 & 1.0 & 1.5 & 2.0 & 2.5 & 3.0 \\
\hline \multirow{2}{*}{0} & DIM & 0.0 & 0.0 & 21.5 & 48.3 & 63.1 & 69.8 & 80.0 & 88.7 & 92.4 & 93.9 & 95.8 \\
\hline & IDIM & 0.9 & 14.5 & 31.9 & 62.9 & 77.5 & 83.3 & 89.4 & 89.7 & 91.6 & 93.7 & 95.7 \\
\hline \multicolumn{13}{|c|}{ (b) } \\
\hline \multirow{2}{*}{$\Delta$} & & \multicolumn{11}{|c|}{$\mathrm{e}$} \\
\hline & & 0 & 0.1 & 0.2 & 0.3 & 0.4 & 0.5 & 1.0 & 1.5 & 2.0 & 2.5 & 3.0 \\
\hline \multirow{2}{*}{0} & DIM & 0.0 & 0.0 & 21.5 & 48.3 & 63.1 & 69.8 & 80.0 & 88.7 & 92.4 & 93.9 & 95.8 \\
\hline & IDIM & 1.0 & 19.0 & 37.5 & 64.7 & 75.4 & 78.4 & 89.7 & 89.9 & 90.1 & 93.7 & 95.6 \\
\hline \multicolumn{13}{|c|}{ (c) } \\
\hline \multirow{2}{*}{$\Delta$} & & \multicolumn{11}{|c|}{$\mathrm{e}$} \\
\hline & & 0 & 0.1 & 0.2 & 0.3 & 0.4 & 0.5 & 1.0 & 1.5 & 2.0 & 2.5 & 3.0 \\
\hline \multirow{2}{*}{0} & DIM & 0.0 & 0.0 & 21.5 & 48.3 & 63.1 & 69.8 & 80.0 & 88.7 & 92.4 & 93.9 & 95.8 \\
\hline & IDIM & 0.2 & 4.3 & 16.1 & 51.1 & 72.8 & 79.1 & 92.7 & 95.2 & 95.5 & 95.6 & 95.7 \\
\hline
\end{tabular}


Table B. 7. Damage detection percentage with damage size of $L / 28$ and fixed-pinned boundary condition, and three different $C$ : (a) $C=L_{\text {eff. }}=98$, (b) $\mathrm{C}=160$, and (c) $C=L=140$ (unit is \%)

(a)

\begin{tabular}{|c|c|c|c|c|c|c|c|c|c|c|c|c|}
\hline \multirow{2}{*}{$\Delta$} & & \multicolumn{11}{|c|}{$\mathrm{e}$} \\
\hline & & 0 & 0.1 & 0.2 & 0.3 & 0.4 & 0.5 & 1.0 & 1.5 & 2.0 & 2.5 & 3.0 \\
\hline \multirow{2}{*}{0} & DIM & 3.7 & 30.8 & 59.3 & 73.8 & 79.4 & 81.2 & 87.3 & 93.6 & 95.8 & 95.9 & 95.9 \\
\hline & IDIM & 1.3 & 18.1 & 68.4 & 80.4 & 84.1 & 87.2 & 95.2 & 95.3 & 97.3 & 99.4 & 99.4 \\
\hline \multicolumn{13}{|c|}{ (b) } \\
\hline \multirow{2}{*}{$\Delta$} & & \multicolumn{11}{|c|}{$\mathrm{e}$} \\
\hline & & 0 & 0.1 & 0.2 & 0.3 & 0.4 & 0.5 & 1.0 & 1.5 & 2.0 & 2.5 & 3.0 \\
\hline \multirow{2}{*}{0} & DIM & 3.7 & 30.8 & 59.3 & 73.8 & 79.4 & 81.2 & 87.3 & 93.6 & 95.8 & 95.9 & 95.9 \\
\hline & IDIM & 1.7 & 21.8 & 67.4 & 76.0 & 80.0 & 82.8 & 93.6 & 93.7 & 95.6 & 97.8 & 97.8 \\
\hline \multicolumn{13}{|c|}{ (c) } \\
\hline \multirow{2}{*}{$\Delta$} & & \multicolumn{11}{|c|}{$\mathrm{e}$} \\
\hline & & 0 & 0.1 & 0.2 & 0.3 & 0.4 & 0.5 & 1.0 & 1.5 & 2.0 & 2.5 & 3.0 \\
\hline \multirow{2}{*}{0} & DIM & 3.7 & 30.8 & 59.3 & 73.8 & 79.4 & 81.2 & 87.3 & 93.6 & 95.8 & 95.9 & 95.9 \\
\hline & IDIM & 0.4 & 6.2 & 58.4 & 78.2 & 84.1 & 87.1 & 94.9 & 95.5 & 95.7 & 96.1 & 99.3 \\
\hline
\end{tabular}

Table B. 8. Damage detection percentage with damage size of $L / 14$ and fixed-pinned boundary condition, and three different $C$ : (a) $C=L_{\text {eff. }}=98$, (b) $\mathrm{C}=160$, and (c) $C=L=140$ (unit is \%)

(a)

\begin{tabular}{ccccccccccccc}
\hline \multirow{2}{*}{$\Delta$} & & \multicolumn{10}{c}{$\mathrm{e}$} \\
\cline { 3 - 12 } & & 0 & 0.1 & 0.2 & 0.3 & 0.4 & 0.5 & 1.0 & 1.5 & 2.0 & 2.5 & 3.0 \\
\hline \multirow{2}{*}{0} & DIM & 12.3 & 86.9 & 93.0 & 95.2 & 95.7 & 95.8 & 95.9 & 96.0 & 97.9 & 98.0 & 98.0 \\
& IDIM & 9.5 & 80.9 & 86.2 & 89.2 & 92.8 & 93.3 & 97.9 & 97.9 & 97.9 & 98.0 & 98.0 \\
\hline
\end{tabular}

(b)

\begin{tabular}{ccccccccccccc}
\hline \multirow{2}{*}{$\Delta$} & & \multicolumn{10}{c}{$\mathrm{e}$} \\
\cline { 3 - 12 } & & 0 & 0.1 & 0.2 & 0.3 & 0.4 & 0.5 & 1.0 & 1.5 & 2.0 & 2.5 & 3.0 \\
\hline \multirow{2}{*}{0} & DIM & 12.3 & 86.9 & 93.0 & 95.2 & 95.7 & 95.8 & 95.9 & 96.0 & 97.9 & 98.0 & 98.0 \\
& IDIM & 9.5 & 74.5 & 86.9 & 89.4 & 92.7 & 93.1 & 97.8 & 97.9 & 97.9 & 97.9 & 97.9 \\
\hline
\end{tabular}

(c)

\begin{tabular}{ccccccccccccc}
\hline \multirow{2}{*}{$\Delta$} & & \multicolumn{10}{c}{$\mathrm{e}$} \\
\cline { 3 - 12 } & & 0 & 0.1 & 0.2 & 0.3 & 0.4 & 0.5 & 1.0 & 1.5 & 2.0 & 2.5 & 3.0 \\
\hline \multirow{2}{*}{0} & DIM & 12.3 & 86.9 & 93.0 & 95.2 & 95.7 & 95.8 & 95.9 & 96.0 & 97.9 & 98.0 & 98.0 \\
& IDIM & 9.7 & 77.6 & 86.2 & 88.1 & 90.1 & 92.6 & 99.8 & 99.9 & 99.9 & 99.9 & 99.9 \\
\hline
\end{tabular}


Table B. 9. Damage detection percentage with damage size of $L / 10$ and fixed-pinned boundary condition, and three different $C$ : (a) $C=L_{\text {eff. }}=98$, (b) $\mathrm{C}=160$, and (c) $C=L=140$ (unit is \%)

(a)

\begin{tabular}{ccccccccccccc}
\hline \multirow{2}{*}{$\Delta$} & & \multicolumn{10}{c}{$\mathrm{e}$} \\
\cline { 3 - 12 } & & 0 & 0.1 & 0.2 & 0.3 & 0.4 & 0.5 & 1.0 & 1.5 & 2.0 & 2.5 & 3.0 \\
\hline \multirow{2}{*}{0} & DIM & 17.0 & 93.6 & 93.8 & 94.0 & 96.1 & 97.8 & 97.9 & 100.0 & 100.0 & 100.0 & 100.0 \\
& IDIM & 1.7 & 85.8 & 88.6 & 92.3 & 94.1 & 95.1 & 99.9 & 99.9 & 99.9 & 100.0 & 100.0 \\
\hline
\end{tabular}

(b)

\begin{tabular}{ccccccccccccc}
\hline \multirow{2}{*}{$\Delta$} & & \multicolumn{10}{c}{$\mathrm{e}$} \\
\cline { 3 - 12 } & & 0 & 0.1 & 0.2 & 0.3 & 0.4 & 0.5 & 1.0 & 1.5 & 2.0 & 2.5 & 3.0 \\
\hline \multirow{2}{*}{0} & DIM & 17.0 & 93.6 & 93.8 & 94.0 & 96.1 & 97.8 & 97.9 & 100.0 & 100.0 & 100.0 & 100.0 \\
& IDIM & 1.4 & 80.4 & 86.2 & 86.7 & 90.2 & 91.5 & 97.9 & 97.9 & 97.9 & 99.9 & 100.0 \\
\hline
\end{tabular}

(c)

\begin{tabular}{ccccccccccccc}
\hline \multirow{2}{*}{$\Delta$} & & \multicolumn{10}{c}{$\mathrm{e}$} \\
\cline { 3 - 12 } & & 0 & 0.1 & 0.2 & 0.3 & 0.4 & 0.5 & 1.0 & 1.5 & 2.0 & 2.5 & 3.0 \\
\hline \multirow{2}{*}{0} & DIM & 17.0 & 93.6 & 93.8 & 94.0 & 96.1 & 97.8 & 97.9 & 100.0 & 100.0 & 100.0 & 100.0 \\
& IDIM & 2.4 & 90.9 & 91.9 & 93.2 & 93.9 & 95.1 & 99.8 & 100.0 & 100.0 & 100.0 & 100.0 \\
\hline
\end{tabular}

Table B. 10. Damage detection percentage with damage size of $L / 40$ and fixed-fixed boundary condition, and three different $C$ : (a) $C=L_{\text {eff. }}=70$, (b) $\mathrm{C}=177$, and (c) $C=L=140$ (unit is \%)

(a)

\begin{tabular}{|c|c|c|c|c|c|c|c|c|c|c|c|c|}
\hline \multirow{2}{*}{$\Delta$} & & \multicolumn{11}{|c|}{$\mathrm{e}$} \\
\hline & & 0 & 0.1 & 0.2 & 0.3 & 0.4 & 0.5 & 1.0 & 1.5 & 2.0 & 2.5 & 3.0 \\
\hline \multirow{2}{*}{0} & DIM & 0.0 & 0.0 & 21.7 & 48.9 & 63.7 & 70.2 & 80.1 & 89.2 & 92.9 & 94.2 & 95.8 \\
\hline & IDIM & 0.4 & 8.0 & 21.7 & 52.8 & 74.8 & 82.7 & 89.3 & 89.7 & 91.1 & 93.8 & 95.8 \\
\hline \multicolumn{13}{|c|}{ (b) } \\
\hline \multirow{2}{*}{$\Delta$} & & \multicolumn{11}{|c|}{$\mathrm{e}$} \\
\hline & & 0 & 0.1 & 0.2 & 0.3 & 0.4 & 0.5 & 1.0 & 1.5 & 2.0 & 2.5 & 3.0 \\
\hline \multirow{2}{*}{0} & DIM & 0.0 & 0.0 & 21.7 & 48.9 & 63.7 & 70.2 & 80.1 & 89.2 & 92.9 & 94.2 & 95.8 \\
\hline & IDIM & 0.6 & 12.3 & 28.4 & 51.9 & 65.3 & 70.7 & 88.9 & 89.8 & 91.6 & 95.8 & 97.8 \\
\hline \multicolumn{13}{|c|}{ (c) } \\
\hline \multirow{2}{*}{$\Delta$} & & \multicolumn{11}{|c|}{$\mathrm{e}$} \\
\hline & & 0 & 0.1 & 0.2 & 0.3 & 0.4 & 0.5 & 1.0 & 1.5 & 2.0 & 2.5 & 3.0 \\
\hline \multirow{2}{*}{0} & DIM & 0.0 & 0.0 & 21.7 & 48.9 & 63.7 & 70.2 & 80.1 & 89.2 & 92.9 & 94.2 & 95.8 \\
\hline & IDIM & 0.0 & 0.0 & 5.2 & 27.6 & 45.6 & 57.2 & 77.9 & 84.8 & 94.5 & 95.4 & 95.7 \\
\hline
\end{tabular}


Table B. 11. Damage detection percentage with damage size of $L / 28$ and fixed-fixed boundary condition, and three different $C$ : (a) $C=L_{\text {eff. }}=70$, (b) $\mathrm{C}=177$, and (c) $C=L=140$ (unit is \%)

(a)

\begin{tabular}{|c|c|c|c|c|c|c|c|c|c|c|c|c|}
\hline \multirow{2}{*}{$\Delta$} & & \multicolumn{11}{|c|}{$\mathrm{e}$} \\
\hline & & 0 & 0.1 & 0.2 & 0.3 & 0.4 & 0.5 & 1.0 & 1.5 & 2.0 & 2.5 & 3.0 \\
\hline \multirow{2}{*}{0} & DIM & 4.3 & 33.1 & 61.5 & 74.8 & 80.0 & 81.5 & 87.5 & 94.2 & 95.8 & 95.9 & 95.9 \\
\hline & IDIM & 0.7 & 10.0 & 52.5 & 76.4 & 83.6 & 88.1 & 92.0 & 93.9 & 95.8 & 97.8 & 97.8 \\
\hline \multicolumn{13}{|c|}{ (b) } \\
\hline \multirow{2}{*}{$\Delta$} & & \multicolumn{11}{|c|}{$\mathrm{e}$} \\
\hline & & 0 & 0.1 & 0.2 & 0.3 & 0.4 & 0.5 & 1.0 & 1.5 & 2.0 & 2.5 & 3.0 \\
\hline \multirow{2}{*}{0} & DIM & 4.3 & 33.1 & 61.5 & 74.8 & 80.0 & 81.5 & 87.5 & 94.2 & 95.8 & 95.9 & 95.9 \\
\hline & IDIM & 1.1 & 12.2 & 56.3 & 74.9 & 78.8 & 80.6 & 93.7 & 93.9 & 97.7 & 99.8 & 99.9 \\
\hline \multicolumn{13}{|c|}{ (c) } \\
\hline \multirow{2}{*}{$\Delta$} & & \multicolumn{11}{|c|}{$\mathrm{e}$} \\
\hline & & 0 & 0.1 & 0.2 & 0.3 & 0.4 & 0.5 & 1.0 & 1.5 & 2.0 & 2.5 & 3.0 \\
\hline \multirow{2}{*}{0} & DIM & 4.3 & 33.1 & 61.5 & 74.8 & 80.0 & 81.5 & 87.5 & 94.2 & 95.8 & 95.9 & 95.9 \\
\hline & IDIM & 0.0 & 0.6 & 33.9 & 55.0 & 67.6 & 75.2 & 85.4 & 92.8 & 95.6 & 96.5 & 97.8 \\
\hline
\end{tabular}

Table B. 12. Damage detection percentage with damage size of $L / 14$ and fixed-fixed boundary condition, and three different $C$ : (a) $C=L_{\text {eff. }}=70$, (b) $\mathrm{C}=177$, and (c) $C=L=140$ (unit is \%)

(a)

\begin{tabular}{ccccccccccccc}
\hline \multirow{2}{*}{$\Delta$} & & \multicolumn{10}{c}{$\mathrm{e}$} \\
\cline { 3 - 12 } & & 0 & 0.1 & 0.2 & 0.3 & 0.4 & 0.5 & 1.0 & 1.5 & 2.0 & 2.5 & 3.0 \\
\hline \multirow{2}{*}{0} & DIM & 12.4 & 87.6 & 93.3 & 95.3 & 95.7 & 95.7 & 95.9 & 95.9 & 95.9 & 96.0 & 98.0 \\
& IDIM & 6.9 & 74.1 & 86.7 & 88.6 & 92.0 & 92.1 & 97.9 & 97.9 & 99.9 & 100.0 & 100.0 \\
\hline
\end{tabular}

(b)

\begin{tabular}{ccccccccccccc}
\hline \multirow{2}{*}{$\Delta$} & & \multicolumn{10}{c}{$\mathrm{e}$} \\
\cline { 3 - 11 } & & 0 & 0.1 & 0.2 & 0.3 & 0.4 & 0.5 & 1.0 & 1.5 & 2.0 & 2.5 & 3.0 \\
\hline \multirow{2}{*}{0} & DIM & 12.4 & 87.6 & 93.3 & 95.3 & 95.7 & 95.7 & 95.9 & 95.9 & 95.9 & 96.0 & 98.0 \\
& IDIM & 6.2 & 70.3 & 88.1 & 91.8 & 94.0 & 95.8 & 99.9 & 100.0 & 100.0 & 100.0 & 100.0 \\
\hline
\end{tabular}

(c)

\begin{tabular}{ccccccccccccc}
\hline \multirow{2}{*}{$\Delta$} & & \multicolumn{10}{c}{$\mathrm{e}$} \\
\cline { 3 - 12 } & & 0 & 0.1 & 0.2 & 0.3 & 0.4 & 0.5 & 1.0 & 1.5 & 2.0 & 2.5 & 3.0 \\
\hline \multirow{2}{*}{0} & DIM & 12.4 & 87.6 & 93.3 & 95.3 & 95.7 & 95.7 & 95.9 & 95.9 & 95.9 & 96.0 & 98.0 \\
& IDIM & 6.4 & 74.0 & 88.7 & 94.2 & 97.3 & 97.5 & 97.9 & 97.9 & 97.9 & 97.9 & 97.9 \\
\hline
\end{tabular}


Table B. 13. Damage detection percentage with damage size of $L / 10$ and fixed-fixed boundary condition, and three different $C$ : (a) $C=L_{\text {eff. }}=70$, (b) $\mathrm{C}=177$, and (c) $C=L=140$ (unit is \%)

(a)

\begin{tabular}{ccccccccccccc}
\hline \multirow{2}{*}{$\Delta$} & & \multicolumn{10}{c}{$\mathrm{e}$} \\
\cline { 3 - 12 } & & 0 & 0.1 & 0.2 & 0.3 & 0.4 & 0.5 & 1.0 & 1.5 & 2.0 & 2.5 & 3.0 \\
\hline \multirow{2}{*}{0} & DIM & 16.0 & 93.6 & 93.8 & 93.9 & 93.9 & 93.9 & 93.9 & 94.3 & 100.0 & 100.0 & 100.0 \\
& IDIM & 10.6 & 86.1 & 87.5 & 91.5 & 92.1 & 96.2 & 99.9 & 99.9 & 99.9 & 100.0 & 100.0 \\
\hline
\end{tabular}

(b)

\begin{tabular}{|c|c|c|c|c|c|c|c|c|c|c|c|c|}
\hline \multirow{2}{*}{$\Delta$} & & \multicolumn{11}{|c|}{$\mathrm{e}$} \\
\hline & & 0 & 0.1 & 0.2 & 0.3 & 0.4 & 0.5 & 1.0 & 1.5 & 2.0 & 2.5 & 3.0 \\
\hline \multirow{2}{*}{0} & DIM & 16.0 & 93.6 & 93.8 & 93.9 & 93.9 & 93.9 & 93.9 & 94.3 & 100.0 & 100.0 & 100.0 \\
\hline & IDIM & 9.3 & 81.7 & 88.0 & 88.7 & 93.2 & 95.9 & 99.9 & 99.9 & 99.9 & 99.9 & 100.0 \\
\hline \multicolumn{13}{|c|}{ (c) } \\
\hline \multirow{2}{*}{$\Delta$} & & \multicolumn{11}{|c|}{$\mathrm{e}$} \\
\hline & & 0 & 0.1 & 0.2 & 0.3 & 0.4 & 0.5 & 1.0 & 1.5 & 2.0 & 2.5 & 3.0 \\
\hline \multirow{2}{*}{0} & DIM & 16.0 & 93.6 & 93.8 & 93.9 & 93.9 & 93.9 & 93.9 & 94.3 & 100.0 & 100.0 & 100.0 \\
\hline & IDIM & 10.7 & 90.7 & 93.5 & 93.8 & 93.8 & 93.9 & 97.0 & 97.1 & 99.8 & 100.0 & 100.0 \\
\hline
\end{tabular}




\begin{abstract}
APPENDIX C
As mentioned in Section 4.1, the Iterative Damage Index Method is more accurate than the Damage Index Method in identifying the multiple locations of damage. Cases 12 and 14 used in Section 4.1 have two locations of damage, where the left location of damage is called 'left damage' and the right location of damage is referred as 'right damage' here. The Case 12 has different severities of damage while the severities of damage are same in the Case 14. Tables C. 1 to 2 show the damage detection percentages $(\gamma)$ for the two damage cases. From those tables, it is certain that the damage detection percentage to detect the multiple damage is calculated by combining the damage detection percentage to estimate the left damage and the damage detection percentage to identify the right damage. Note that the damage detection percentage to detect either the left damage or the right damage detection is higher than the damage detection percentage to identify the multiple damage.
\end{abstract}


Table C. 1. Damage detection percentage Case 12 to detect (a) multiple damage, (b) left damage, and (c) right damage (unit is \%)

(a)

\begin{tabular}{ccccccccccccc}
\hline \multirow{2}{*}{$\Delta$} & & \multicolumn{10}{c}{$\mathrm{e}$} \\
\cline { 3 - 12 } & 0 & 0.1 & 0.2 & 0.3 & 0.4 & 0.5 & 1.0 & 1.5 & 2.0 & 2.5 & 3.0 \\
\hline \multirow{2}{*}{0} & DIM & 0.0 & 0.0 & 0.0 & 1.4 & 12.3 & 22.3 & 67.0 & 67.0 & 67.0 & 67.0 & 67.0 \\
& IDIM & 8.4 & 61.4 & 71.2 & 75.9 & 78.5 & 81.6 & 89.6 & 90.2 & 93.7 & 95.7 & 95.8 \\
\hline
\end{tabular}

(b)

\begin{tabular}{ccccccccccccc}
\hline \multirow{2}{*}{$\Delta$} & & \multicolumn{10}{c}{$\mathrm{e}$} \\
\cline { 3 - 13 } & 0 & 0.1 & 0.2 & 0.3 & 0.4 & 0.5 & 1.0 & 1.5 & 2.0 & 2.5 & 3.0 \\
\hline \multirow{2}{*}{0} & DIM & 0.0 & 0.0 & 0.0 & 1.4 & 12.3 & 22.3 & 67.0 & 67.0 & 67.0 & 67.0 & 67.0 \\
& IDIM & 9.2 & 64.6 & 72.3 & 76.5 & 78.9 & 82.0 & 89.8 & 90.5 & 95.8 & 95.9 & 95.9 \\
\hline
\end{tabular}

(c)

\begin{tabular}{ccccccccccccc}
\hline \multirow{2}{*}{$\Delta$} & & \multicolumn{10}{c}{$\mathrm{e}$} \\
\cline { 2 - 12 } & & 0 & 0.1 & 0.2 & 0.3 & 0.4 & 0.5 & 1.0 & 1.5 & 2.0 & 2.5 & 3.0 \\
\hline \multirow{2}{*}{0} & DIM & 3.7 & 33.0 & 62.5 & 75.2 & 80.0 & 81.1 & 87.3 & 92.0 & 93.0 & 93.1 & 93.1 \\
& IDIM & 9.6 & 65.8 & 76.3 & 79.4 & 81.3 & 83.8 & 91.8 & 92.6 & 95.8 & 97.7 & 97.8 \\
\hline
\end{tabular}

Table C. 2. Damage detection percentage Case 14 to detect (a) multiple damage, (b) left damage, and (c) right damage (unit is \%)

(a)

\begin{tabular}{ccccccccccccc}
\hline \multirow{2}{*}{$\Delta$} & & \multicolumn{10}{c}{$\mathrm{e}$} \\
\cline { 3 - 12 } & & 0 & 0.1 & 0.2 & 0.3 & 0.4 & 0.5 & 1.0 & 1.5 & 2.0 & 2.5 & 3.0 \\
\hline \multirow{2}{*}{0} & DIM & 9.0 & 63.8 & 78.3 & 81.3 & 82.4 & 83.7 & 92.5 & 95.6 & 95.8 & 95.9 & 95.9 \\
& IDIM & 9.6 & 64.9 & 74.8 & 78.8 & 81.8 & 84.5 & 93.6 & 93.8 & 95.4 & 97.8 & 97.9 \\
\hline
\end{tabular}

(b)

\begin{tabular}{ccccccccccccc}
\hline \multirow{2}{*}{$\Delta$} & & \multicolumn{1}{c}{$\mathrm{c}$} \\
\cline { 3 - 12 } & & 0 & 0.1 & 0.2 & 0.3 & 0.4 & 0.5 & 1.0 & 1.5 & 2.0 & 2.5 & 3.0 \\
\hline \multirow{2}{*}{0} & DIM & 9.0 & 63.8 & 78.3 & 81.4 & 82.5 & 83.7 & 92.7 & 95.6 & 95.8 & 95.9 & 95.9 \\
& IDIM & 9.8 & 65.3 & 75.3 & 80.1 & 83.6 & 85.1 & 94.2 & 95.9 & 97.5 & 99.9 & 99.9 \\
\hline
\end{tabular}

(c)

\begin{tabular}{ccccccccccccc}
\hline \multirow{2}{*}{$\Delta$} & & \multicolumn{10}{c}{$\mathrm{e}$} \\
\cline { 3 - 12 } & 0 & 0.1 & 0.2 & 0.3 & 0.4 & 0.5 & 1.0 & 1.5 & 2.0 & 2.5 & 3.0 \\
\hline \multirow{2}{*}{0} & DIM & 9.3 & 66.3 & 79.0 & 81.5 & 82.6 & 83.8 & 92.8 & 95.7 & 97.7 & 97.9 & 97.9 \\
& IDIM & 9.8 & 65.3 & 74.9 & 78.9 & 81.9 & 84.6 & 93.7 & 93.8 & 95.5 & 97.9 & 97.9 \\
\hline
\end{tabular}




\title{
VITA
}

\author{
Name Taesun You \\ Address Zachry Department of Civil Engineering \\ Texas A\&M University \\ College Station, Texas 77843-3136 \\ Email:you0727@tamu.edu
}

Education B.S. 2003 Hanyang University, Seoul, South Korea

M.S. 2009 Texas A\&M University, College Station, Texas, USA 